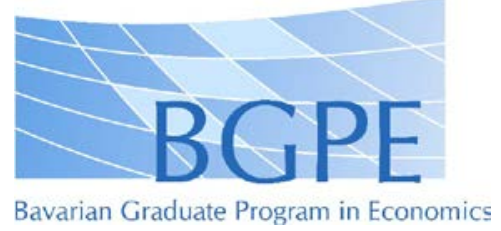

BGPE Discussion Paper

No. 160

\title{
Moving to an earnings-related parental leave system - do heterogeneous effects on parents make some children worse off?
}

\section{Katrin Huber}

\section{August 2015}




\title{
Moving to an earnings-related parental leave system - do heterogeneous effects on parents make some children worse off?*
}

\author{
Katrin Huber **
}

11 August, 2015

\begin{abstract}
Can moving to an earnings-related parental leave system influence children's wellbeing and are heterogeneous effects on parents carried over to the entire family, making special groups of children worse off than others? To answer this question, this study exploits a large and unanticipated parental leave reform in Germany as a natural experiment. By replacing a means-tested by an earnings-related system the reform affected different groups of families to a variable extent. I detect significant negative effects on the personality of newborns whose families are subject to a nonpositive change in the overall benefit amount compared to the pre-reform situation. 2-3-year-old children belonging to the reform's winners, however, improve their basic life skills and language skills.
\end{abstract}

Keywords: Children's Well-Being, Parental Leave, Heterogeneous Effects

JEL Classification: J13, J18, J22

*I gratefully acknowledge helpful comments by Stefan Bauernschuster, Ramona Molitor, Susanna Grundmann, Erwin Winkler and Anna Raute, as well as by participants of the Economics Research Seminar and the BGPEWorkshop in Passau, of the Annual Congresses of the SSES in Basel and the ESPE in Izmir. Helen Zeidler provided excellent research assistance.

** University of Passau, Innstr. 27, 94032 Passau, Germany 


\section{Introduction}

Cunha and Heckman (2007) point out that investments into early childhood skill formation are extremely important for a child's future development because toddlers' and youngsters' skills underlie a self-reinforcing mechanism and are complementary to later skill formation. Since the 1980s, psychological research (e.g. Erikson, 1980) also has been coming to the conclusion that a child's attachment to one parent or key caregiver especially in the first year of life serves as a cornerstone for a sound personality and thus shapes a child's future behavior and development. Family and labor market policies, particularly parental leave regulations, can influence the time and resources parents devote to their child and hence contribute to shaping early child development in the light of these findings.

While there is already some evidence on parental leave and children's long-run outcomes (e.g. Dustmann and Schönberg, 2011; Carneiro et al., 2015), studies evaluating short-run effects on child development remain scarce. To the best of my knowledge there are only two papers (Baker and Milligan, 2010; Baker and Milligan, 2015) which investigate the effects of parental leave on children aged younger than five.

To complete this narrow strand of literature, this study exploits the parental leave reform in Germany in 2007 as a natural experiment and determines the causal effect of parental leave on development of toddlers and young children in a very special institutional setting. The reform, on the one hand, reduced benefit duration for already eligible families but, on the other hand, changed eligibility criteria and thus largely increased the group of eligible parents. Moreover, benefit amounts are no longer fixed and means-tested but relate to parents' pre-birth earnings. Consequently, this reform created both winner - and loser - families. The German SocioEconomic-Panel (GSOEP) provides me with a battery of proxies for children's development, cognitive and non-cognitive skills. This data can be matched with wide-ranging and accurate information on households and on parents' characteristics which is used to determine the expected gain or loss in benefits induced by the reform. The empirical strategy combines a Difference-in-Differences and a Regression Discontinuity Design and additionally takes into account that the effects might differ for children whose parents belong to the winners and for children from loser - families.

The average effects estimates suggest significant negative effects on newborns' personality, while older children seem to improve their basic life skills and language skills. The heterogeneous effects framework detects that the adverse effect on personality is driven by children of 
families who were subject to a non-positive change in the overall benefit amount compared to the pre-reform situation. Moreover, there is some evidence that a higher amount of Elterngeld can attenuate this negative effect on newborns' personality. The positive effects on 2-3-yearolds' skills originate from families belonging to the reform's winners. The results thus show that the direction of change in benefits, which is heterogeneous across families, significantly influences the reform's effect on children's well-being and might make some children worse off than others. The detrimental impact on the personality of newborns could be due to a qualitatively lower attachment of the child to its mother, resulting from a lower life satisfaction of mothers whose benefits are likely to be reduced compared to the pre-reform situation (see Maeder, 2014). For the 2-3-year-old children, several channels could be at work.

To rule out a violation of the common trend assumption and selection effects, I run several robustness checks to validate my findings. First, I exclude December 2006 and January 2007 births to test whether women with due dates very close to the cutoff might have selected into or out of the treatment. Second, I reduce the time frame around the date of implementation in order to avoid long-run selection through planned births. I further check sensitivity by changing the control cohorts, introducing a placebo-outcome and estimating a Placebo-Diff-in-Diff in the pre-treatment years. To avoid measurement error when determining winners and losers I, furthermore, exclude parents who are just on the edge of being a winner or a loser. The robustness checks largely corroborate the validity of my identification strategy.

The structure of the paper is as follows: Section 2 summarizes the potential channels through which parental leave can affect children's development and provides an overview of the related literature. Section 3 briefly describes the institutional setting. Section 4 introduces the identification strategy, Section 5 describes the data. Section 6 shows the main results and provides robustness checks. Section 7 discusses the results and Section 8 concludes.

\section{Background and related literature}

According to both Psychologists and Economists, the time, the resources and the quality of care parents devote to their children in the very first years of life are pivotal for short-run as well as long-run child development: Erikson (1980) points out that it is essential for a child's well-being to have a reference person in its first year of life, since the child's sense of basic trust (Ur-Vertrauen) is established in this period. If a child fails to build this basic trust, long-lasting mental problems can arise. Moreover, parental investments into early skill formation are well- 
known to be extremely important for the child because these skills can have multiplier-effects and are complementary to later skill development (see Cunha and Heckman, 2007). According to Brooks-Gunn and Duncan (1997), household income is also a main contributer to early child development because a low income can have detrimental effects on children's health and mental advancement. Family and labor market policies, especially when targeting parental leave or the provision of public childcare, seem to be effective means to influence parents' time with the child, their available resources and the quality of childcare through various channels. These channels are discussed in the following.

\subsection{Why parental leave might matter for child outcomes}

First, parental leave could influence children's well-being through an impact on maternal employment because maternal labor market participation is likely to affect both the time and the resources a mother can devote to her child ${ }^{1}$. A different strand of literature on maternal employment and child outcomes (e.g. Neidell, 2000; Baum, 2003; Brooks-Gunn et al., 2002; Ruhm, 2004; Hill et al., 2005) all in all finds negative effects on children's cognitive and behavioral outcomes up to age 7 if their mothers are employed in the first year after birth, especially if they are employed full-time. Since (full-time) employment means higher income on the one hand but less time to care for the child on the other hand, the mother's presence in the first year of life seems to be more important than additional income. After the first year, the effects reverse and the mother's return to the labor market is rather beneficial for the child's development, hinting at, for example, positive effects through increased interaction of toddlers with peers in childcare institutions or a more advantageous development due to the additional earnings ${ }^{2}$. Parental leave enables mothers to take care of the child without being exposed to the risk of losing their job and thus effectively results in a reduction of maternal labor supply and in an increase in maternal care in the period of parental leave coverage (see e.g. Schönberg and Ludsteck, 2014; Kluve and Tamm, 2013).

Second, parental leave might have an impact on child outcomes via maternal life satisfaction. According to Berger and Spiess (2011), maternal life satisfaction can influence a child's attachment to the mother and thus is related to the quality of care the mother provides to her child.

\footnotetext{
${ }^{1}$ Moreover, parental leave regulations do not only have an impact on maternal employment decisions but likewise on fathers' leave-taking and employment behavior (see e.g. Geisler and Kreyenfeld, 2012). A couple of studies (e.g Crockett et al., 1993; Carlson, 2006; Harris et al., 1998) show that paternal involvement in childcare and fathers' presence during both young ages and adolescence could also have an influence on child outcomes.

${ }^{2}$ According to Ruhm (2004), additional income effects might even overcompensate possible negative effects of early maternal employment especially for low-income families.
} 
Indeed, some research suggests a significant relationship between parental leave and maternal life satisfaction (e.g. Maeder, 2014).

Finally, parental leave could determine child development if it has an impact on parents' fertility decisions. The famous proposition of a possible interaction between children's ,quantity and ,quality ' by Becker and Lewis (1973) suggests that parental fertility decisions might also be crucial for children's well-being, because the resources, the quality of care and the time devoted to a child might be related to the interval between births and to the number of siblings the child has. As a different strand of literature shows, there actually is empirical evidence that parental leave systems partly determine parents' fertility decisions (e.g. Raute, 2014; CyganRehm, 2015; Lalive and Zweimüller, 2009), especially the number of children a family has and the spacing between births.

Taken together, previous research provides plausible channels through which parental leave could determine children's well-being and development. Thus, as a next step, it is necessary to piece together this puzzle and to investigate whether we actually find a causal effect of parental leave on child outcomes. The studies described in the following provide such evidence, particularly concerning long-run outcomes, for different countries and for varying institutional settings.

\subsection{Evidence for parental leave and children's long-run outcomes}

Liu and Skans (2010) exploit an extension of parental leave payments from 12 to 15 months in Sweden to detect an enhancement of grade point averages (GPAs) for daughters of higheducated mothers. Instead of focusing on an extension of the benefit period, Carneiro et al. (2015) work out the effect of an introduction of paid parental leave in a country without any prior parental leave entitlements. They apply a combination of a Difference-in-Differences technique and a Regression Discontinuity Design to show that the introduction of 4 months of paid parental leave in Norway resulted in positive effects on children's decisions to go to college, on the high-school dropout rate and on later labor market earnings. Dunifon et al. (2013) evaluate the effects of early maternal employment instead of parental leave regulations and extend the observation period to the first 15 years of a child's life. They compare Ordinary Least Squares regressions with maternal fixed effects estimates and the results of an instrumental variable approach to uncover the causal impact of average maternal employment in the first 3 to 15 years of a child's life on the child's academic performance in Denmark. The authors find an im- 
provement of GPAs, if the average maternal employment is high. Thus, this study provides the important insight that it could be beneficial for a child's long-run development to induce mothers to return to the job market after the first phase of the child's life. Danzer and Lavy (2013) additionally show that parental leave might have different impacts on children depending both on gender and on the socio-demographic background. The authors exploit an Austrian parental leave reform extending parental leave benefits from 12 to 24 months to apply a Difference-inDifferences strategy as well as a triple differences approach. They uncover positive effects on PISA test scores for sons of high-educated mothers, negative effects on sons of low-educated mothers and no effects on girls. Dustmann and Schönberg (2011) add to this literature by considering both the extension of paid and of unpaid parental leave coverage. They concentrate on the stepwise expansion of German parental leave coverage from 1979 to 1992 and detect that expanding benefits up to 18 months had no effects, while extending the job protection period (without granting further benefits) from 18 to 36 months after birth reduced the share of children choosing the higher education track. Taken together, quasi-experimental literature on parental leave and children's long-run outcomes in adolescence or in adulthood suggests that it is beneficial for the child if parental leave regulations incentivize mothers to stay at home in the early phase after birth but induce them to return to the labor market thereafter.

\subsection{Evidence for parental leave and children's short-run outcomes}

As mentioned before, empirical papers reliably uncovering causal effects of parental leave on children's short-run outcomes are scarce. However, as both economic and psychological research highlights that a child's first phase of life is the most pivotal one, the effects of parental leave should not only come to light at older ages but should already be relevant during infancy. Discovering parental leave regulations' impact on toddlers could hence contribute to understanding the origin of long-run effects on adolescents. The findings of Cunha and Heckman (2007) moreover suggest that policy interventions targeting very young children are likely to be much more effective than interventions at school age. This urgently requires that potential adverse effects on special groups of children are detected as soon as possible in order to take counteracting steps at a point in time that is not yet too late.

Gathmann and Sass (2012) therefore analyze a reform in the East German state of Thuringia that increased prices for public daycare to identify deteriorations of motor ability and social skills of girls aged 1 to 2 years. However, these results rather reveal the effect of taxing child- 
care than providing evidence on short-run effects of parental leave. To focus more on the true impact of parental leave, Baker and Milligan (2010) exploit a parental leave extension from 6 to 12 months in Canada significantly increasing the amount of first-year maternal care. They aim to uncover a causal effect of parental leave on 0-3-year-olds' cognitive and behavioral development. The authors do not find any notable average effects. Baker and Milligan (2015) expand their analysis on children aged 4 to 5 and come to a similar conclusion - if anything, they suggest a very modest negative effect on some cognitive indexes.

Existing empirical literature on short-run effects of parental leave thus suggests zero to modest effects of slightly expanding parental leave coverage in the first year after birth. These two studies, however, rely on a reform with homogeneous effects ${ }^{3}$ on all families and are hence incapable of detecting whether heterogeneous effects - creating both winners and losers - on parents are transmitted to their children. Consequently, the study at hand could provide important new insights by potentially uncovering heterogeneous short-run effects on child development depending on the direction and the extent to which the reform of interest influenced different groups of families.

\section{Institutional setting}

\subsection{Core changes in parental leave regulations}

Before January 1st, 2007 parents received the so called Erziehungsgeld which was means-tested and granted parents either 300 EUR for 24 months or 450 EUR for 12 months ${ }^{4}$. In order to be eligible for Erziehungsgeld, net yearly pre-birth income must not exceed 30,000 EUR for partners and 23,000 EUR for singles. Consequently, about $24 \%$ of parents were not eligible for any subsidy at all (see Kluve and Tamm, 2013). After 6 months, parents had to pass a second means-test and subsidies potentially expired or were reduced. Thus, Erziehungsgeld was essentially targeted at lower-income families.

With the introduction of the new Elterngeld (literally ,parent money“ ) on January 1st, 2007, the thresholds have been increased to a maximum of a gross yearly pre-birth income of 500,000

\footnotetext{
${ }^{3}$ Homogeneous effects means that the reform had the same intensity, for example, in terms of the change in the benefit amount for all families. Although a reform with homogeneous effects can result in heterogeneous reactions across different types of families, one cannot distinguish between varying intensities of one and the same reform.

${ }^{4}$ Parents could - dependent on income - choose between these two options. As only about $10 \%$ of all parents chose the second option (called ,Budget '), I will concentrate on the first one.
} 
EUR for partners and 250,000 EUR for singles, which made nearly $100 \%$ of parents eligible to receive the new Elterngeld ${ }^{5}$. Moreover, Elterngeld is no fixed amount but replaces $67 \%$ of pre-birth income. The monthly subsidy lies between 300 and 1,800 EUR (see BMFSFJ, 2013). The new regulation is thus more generous in terms of the maximum amount of benefits and does no longer only address low-income families. Benefit duration however, was reduced from 24 to 12 months. If parents share parental leave, they can take two additional, daddy months ${ }^{\text {‘6 }}$. The German Federal Ministry for Family Affairs, Senior Citizens, Women and Youth explicitly named three major goals of the reform: income security for families in the first year after birth, economic independence for both partners and an enlarged involvement of fathers in childcare. Moreover, it should provide fertility incentives for working mothers and help to keep these women closer to the labor market.

Strikingly, summary statistics for the amounts of overall benefits under each regulation show that the average amount of benefits is much higher under the new regulation, especially for those being pre-birth employed. While on average the post-reform benefits exceed the prereform benefits, there are also some parents who would lose up to 3,768 EUR in comparison with Erziehungsgeld ${ }^{7}$ (see table A1 Appendix). Table 1 shows that the reform would induce negative changes in the overall benefit amount after the entire transfer duration for about $39 \%$ of all families, while $61 \%$ should gain compared to the pre-reform situation.

\section{[Table 1 about here]}

These heterogeneous reform effects on parents, resulting in winner - and loser - families, are likely to be also transmitted to the youngest members of these families.

\subsection{Heterogeneous effects on parents}

Kluve and Tamm (2013) provide a detailed description of possible effects on different subgroups. To sum up: Parents who would also have been eligible for Erziehungsgeld and have quite a low pre-birth income definitely lose 10-12 months of transfer duration. Depending on pre-birth income, the amount of the monthly benefit remains the same (300 EUR) or slightly increases compared to the old system. Thus, after 12 months these families don't end up worse

\footnotetext{
${ }^{5}$ In the new system like in the old one, parents are only eligible if they are main care-takers of the child and do not work more than 30 hours per week.

${ }^{6}$ Moreover, parents are free to receive half of the benefit for at most 24 months. As this option is only chosen by about $7.5 \%$ of all parents (see RWI, 2008), I will not consider it in my further evaluation.

${ }^{7}$ For details on benefit calculation see Appendix A.1.
} 
than before. However, since Elterngeld benefits expire after 12 months while Erziehungsgeld supported low-income families for up to 24 months, the overall transfer is very likely to be reduced. In the following, I will refer to this group as the reform's losers even though these families would only lose in terms of overall benefits after the entire transfer duration ${ }^{8}$, not so after the first year. Parents who would not have been eligible for any subsidy under the old regulation because their yearly pre-birth income exceeded the threshold, experience an increase in transfer duration from 0 to 12 months on the one hand and an enormous increase in the amount of transfer on the other hand. High-income parents would now receive up to 21,600 EUR $(1,800 \times 12)$ more $^{9}$ compared to the pre-reform situation. I will refer to this group as the reform's winners. ${ }^{10}$

Figure 1, Panel A and B compare the overall benefit amounts under the old and the new regulation dependent on the gross (pre-birth) income the benefit calculation is based on ${ }^{11}$. Due to the fixed nature of the monthly benefit amounts under the old regulation the upper limits of Erziehungsgeld reached only 7,200 EUR ${ }^{12}$ altogether. Benefits from Elterngeld increase with pre-birth income and exceed the former fixed amounts by far as soon as a relevant income of about 13,500 EUR has been reached. Panel C and D depict transfer duration for different gross (pre-birth) incomes and indicate that the transfer duration decreased especially for lower-income families, while higher-earners benefit.

\section{[Figure 1 about here]}

Having a closer look at the composition of the different groups of parents, I am able to identify several characteristics increasing or decreasing the probability to be subject to a positive change in the overall benefit amount due to the reform. Table 2 summarizes the results of a linear probability model regressing a dummy variable for a positive change in benefit amount on different background characteristics. Moreover, table 2 comprises the results of OLS-regressions using the absolute difference between total benefit amounts under both regulations as dependent

\footnotetext{
${ }^{8}$ Transfer duration is 12 months for Elterngeld and varies between 0 months and 24 months for Erziehungsgeld. Low-income families were mostly eligible for the full period of 24 months.

${ }^{9}$ Even 23,760 EUR more, if there are several children and the sibling premium of $10 \%$ is considered, too.

${ }^{10}$ Transfer duration remained constant for those who would have been eligible for the Budget option. Their monthly benefit amount is either reduced from 450 to 300 EUR, remains approximately constant or increases. The overall effect on this negligibly small group of families is thus ambiguous.

${ }^{11}$ This is the applicant's income in the 12 months before birth for Elterngeld. For Erziehungsgeld the partner's income in the calendar year before birth/of birth plus the mother's income while receiving benefits is the relevant income.

${ }^{12}$ The sibling premium is not considered here.
} 
variable ${ }^{13}$.

First, families without a migration background have a higher probability to experience a positive change compared to families with direct or indirect migration backgrounds. Even though, on average, both migrants and non-migrants would benefit from the reform, the averaged positive change for parents without a migration background is about 2,000 EUR higher. Second, families living in East Germany have a lower probability to gain due to the Elterngeldreform than West German families; the latter would gain about 1,900 EUR more on average. Moreover, older mothers have a higher probability to experience a positive change than younger women. For example, mothers aged 30-35 years would nearly gain 4,500 EUR on average, while very young mothers would lose, on average, about 2,700 EUR. Additionally, mothers who have their first child have a higher probability for a positive income effect than mothers with two or more children. Single-households have a quite low probability to experience a positive change, the expected change is even negative on average . Moreover, the probability of a positive change is higher for spouses than for unmarried partners. Having a closer look at the mother's pre-birth employment status, a positive change gets more likely the more hours the mother worked before her child was born. Full-time employed mothers would get, on average, 6,500 EUR more than they would have received pre-reform. A similar pattern applies for the partner's pre-birth employment - the difference between full-time and part-time is not as high as for mothers however, which might be due to the lower number of part-time working men. As expected, the pre-birth education level also serves as a suitable determinant for the direction of change: While mothers and partners without any education would experience a negative effect on average, the probability for a positive change increases with education leve ${ }^{14}$ and high-educated mothers would receive about 6,000 EUR more than under the old regulation.

\section{[Table 2 about here]}

Naturally, all of these characteristics indicating a more positive reform effect are also likely to be positively correlated with a higher pre-birth income which is the main determinant of the amount of benefits. Whether these heterogeneities in the direction and the intensity of being affected also cause heterogeneous parental responses to the reform and especially whether this affects children's well-being to a variable extent will be discussed in the following.

\footnotetext{
${ }^{13}$ Since I want to investigate these relationships before any selection could possibly have taken place, I exclude families whose children were born after December 2007.

${ }^{14} \mathrm{~A}$ similar relationship applies for years of education.
} 


\section{Identification strategy}

\subsection{General Analysis}

Estimating the causal effects of parental leave on children's well-being by Ordinary Least Squares would be prone to Omitted Variable Bias and reverse causality problems: Mothers can self-select into parental leave dependent on observable and unobservable maternal characteristics, which could also be related to children's well-being. Furthermore, employment decisions could be endogenous to children's well-being as they might, for example, depend on the child's health. For that reason, I use the Elterngeldreform as a natural experiment, that quasi-randomly creates a treatment and a control group without giving rise to possible selection: families with children born before January 1st, 2007 are not treated (and receive the old Erziehungsgeld), while families with children born on or after January 1st, 2007 are subject to the new regulation and represent the treatment group.

To estimate the causal effects of the reform, I follow e.g. Dustmann and Schönberg (2011), Cygan-Rehm (2015) or Maeder (2014) and combine a Regression Discontinuity Design with a Difference-in-Differences approach. There are two reasons for which I add a second control group to the sharp RD which would directly compare outcomes of children born shortly before and after the reform: first, a sharp RD would optimally go very close to the cutoff in order to assure that parents and children in both groups have very similar characteristics. This is not possible because of the low number of observations around the date of implementation in my sample. Second, by enlarging the time frame surrounding the cutoff, I risk that children born in different months generally differ in terms of socio-demographic characteristics or health (see Buckles and Hungerman, 2013) and that this results in general differences in children's wellbeing (see Currie and Schwandt, 2013) even without any influence of the reform. To isolate these seasonal effects from the reform effects, I add children born in the same months, but in cohorts which are unaffected by the reform as a second control group and estimate the following linear regression:

$$
y_{i}=\alpha+\beta \text { reform }_{i}+\text { born }_{0607} \delta+\text { month }_{i}^{\prime} \gamma+X_{i}^{\prime} \zeta+\varepsilon_{i}
$$

$y_{i}$ denotes children's well-being, measured by different indexes depending on age ${ }^{15} \cdot \beta$ is the coefficient of main interest, as the variable reform $_{i}$ indicates whether the child was born after

\footnotetext{
${ }^{15}$ For precise information on index composition see Section 5.
} 
the reform, thus after January 1st, $2007^{16}$. $\beta$ measures the intention-to-treat (ITT) effect as I do not have precise information on actual benefit receipt. Due to the almost universal eligibility and a take-up rate of effectively 100\% (Destatis, 2008), all parents which are intended-to-betreated should actually be treated and the ITT should be quite close to the average treatment effect. born $_{0607}$ shows whether the child belongs to the treatment cohort $2006 / 2007^{17}, \delta$ thus estimates the pure effect of being born in 2006/2007 compared to the average of the control cohorts 2004/05, 2005/06 and 2007/08 ${ }^{18}$. mont $h_{i}$ indicates the month the child is born in and controls for seasonal effects. $X_{i}^{\prime}$ is a vector of further predetermined controls: the child's age at survey, the gender of the child, the child's number of older siblings (at birth), information on the migration background of parents, the mother's education and the region of residence ${ }^{19}$. This regression is estimated separately for two different age groups, namely 0-1-year-olds and 2-3-year-olds.

My estimation strategy is only valid if two crucial assumptions are met: First, seasonal differences between children born in different months of the year have to be constant over time such that they can be separated from the true reform effects. I assess the common trend assumption by graphical inspection and by several robustness checks in Section 6. Moreover, I choose control groups which are temporally close to the treatment group ${ }^{20}$ and I also estimate the regression using different control groups ${ }^{21}$. A related concern is that further policy changes in the months surrounding the reform also influenced the well-being of the treatment group and the control group children differently. My identification strategy would attribute the effects of all other interventions at the beginning of 2007 to the parental leave reform. I am, however, not aware of any policy changes in 2007 that might have had a similar impact on children as the

\footnotetext{
${ }^{16}$ Actually, reform $m_{i}$ is an interaction term between the indicator variable for the birth cohort 2006/2007, born 0607 , and a dummy after $_{i}$ which is 1 if the child is born in the first half/quarter of the year.

${ }^{17} \mathrm{~A}$ birth cohort is not equal to a calender year, but corresponds to births between July and June. As my control group consists of children born two years before and one year after the reform, I include the cohorts: 07/200406/2005, 07/2005-06/2006, 07/2006-06/2007 and 07/2007-06/2008.

${ }^{18} \mathrm{All}$ regressions were also estimated with cohort fixed effects, i.e. including dummies for each cohort. The results do not change and, moreover, one cannot reject the hypothesis that the effects of the control cohorts are equal to each other in most specifications and for most indexes. Thus, to gain statistical power, I only consider the effect of being born in 2006/07 compared to the average of the control cohorts.

${ }^{19}$ I would also like to control for marital status of the mother. However, this might give rise to a bad control problem as mentioned by Angrist and Pischke (2009): it is possible that women endogenously change their marital status foreseeing that this might influence the benefit amount. Further potentially relevant controls like maternal happiness or breastfeeding are omitted for the same reasons: Kottwitz et al. (2015), for example, find a significant effect of the German parental leave reform on the duration of breastfeeding.

${ }^{20}$ Children being born in 2002/03 are more likely to be different from the 2006/07 cohort than children born in 2005/06.

${ }^{21}$ The fewer cohorts are included, the lower the risk of diverging trends over time should be - the disadvantage of fewer control groups, however, is a lower number of usable observations.
} 


\section{Elterngeld.}

Second, as treatment- and control groups have to be quasi-random, the reform has to be largely unanticipated such that parents could not plan births according to expected changes. If high-educated mothers realized that they would benefit from the reform and thus postponed their births after January 1st, 2007, this would change the composition of the treatment group and my approach would not be an improvement compared to simple OLS-estimation. Kluve and Tamm (2013) point out that public discussion about the Elterngeldreform started in May 2006. Until the end of September 2006, however, when the grand coalition voted in favor of the Elterngeld, it was not clear at all at which time and in which form the reform would be introduced. Moreover, the law for the introduction of the Elterngeld belongs to the German laws requiring approval (Zustimmungsgesetz) by the Federal Council of Germany (Bundesrat). This approval was given on the 3rd of November, 2006, meaning that until this point, there was still no absolute security about the implementation of the Elterngeld. With the new law's proclamation in the Federal Law Gazette (Bundesgesetzblatt), making it accessible to all citizens, the entire process of legislation then ended only three weeks before Elterngeld would become law (see Verlag C.H.BECK, 2015). The Google Search Volume Index, which was used by Kluve and Tamm (2013) as well, also shows a small peak in searches for Elterngeld in May 2006. Thereafter, searches for Erziehungsgeld and Elterngeld are largely comparable until the end of August 2006, where the new regulation finally became more famous.

\section{[Figure 2 about here]}

Thus, it is nearly impossible that children born until or even during April 2007 (and thus conceived by August 2006) were deliveries induced by the reform. If I consider all births between July 2006 and June 2007, however, there might be a small chance that some children were directly conceived after the reform was affirmed by the grand coalition and the Elterngeld hence gained increasing public awareness. Some births in May or June 2007 might thus be planned with regard to the reform - since mothers cannot perfectly plan their births, however, I do not consider this as a large problem. Nevertheless, I will also provide all estimates restricting the time frame to three months before and after the reform. Still, one threat to validity remains if births with due dates very close to the cutoff were artificially shifted either into the old or into the new regulation. Tamm (2013) showed that the Elterngeldreform actually caused such birth-shifting behavior: births per week decreased in December 2006 and increased in January 2007 compared to previous years. Moreover, he finds that these shifting especially took place 
in families who would benefit most from the reform. Neugart and Ohlsson (2013) support these results but point out that there were some women with due date in early December, that tried to postpone the birth, but didn't succeed. As I have information on the pregnancy week in which each child was born and on cesarean sections in the sample of 0-1-year-olds, I can at least check some descriptive statistics and compare the number of late deliveries (later than 41st week of pregnancy) in January 2007 and in January of the other cohorts, to detect whether some mothers might have selected into the new regulation by delaying their due date. Only two children born in January 2007 were born after the 41st week, this number varies between 0 and 2 for the other years. Moreover, I investigate whether there were more premature births $(<36$ th week) or cesarean sections in December 2006 than usual in order too see whether some parents selected into the old regulation. Only three children born in December 2006 were born too early, this number varies between 0 and 7 for the other years. I also do not find any evidence for an increase in cesarean sections. ${ }^{22}$ Nevertheless, I exclude children born in December 2006 and January $2007^{23}$ in my sensitivity analysis.

\subsection{Subgroup analysis}

Besides estimating an average impact of the parental leave reform, I choose a pooled-model with interaction terms to test whether the reform had heterogeneous effects on children's wellbeing depending on whether their parents belong to the reform's winners or losers. I estimate the following two regressions:

$$
\begin{aligned}
y_{i}= & \alpha+\beta_{1} \text { reform }_{i}+\beta_{2}\left(\text { reform }_{i} \times \text { gain }_{i}\right)+\beta_{3} \text { gain }_{i} \\
& +\beta_{4}\left(\text { born }_{0607} \times \text { gain }_{i}\right)+\beta_{5}\left(\text { after }_{i} \times \text { gain }_{i}\right)+\text { born }_{0607} \delta+\text { month }_{i}^{\prime} \gamma+X_{i}^{\prime} \zeta+\varepsilon_{i} \\
y_{i}= & \alpha+\beta_{1} \text { reform }_{i}+\beta_{2}\left(\text { reform }_{i} \times \text { change }_{i}\right)+\beta_{3} \text { change }_{i} \\
& +\beta_{4}\left(\text { born }_{0607} \times \text { change }_{i}\right)+\beta_{5}\left(\text { after }_{i} \times \text { change }_{i}\right)+\text { born }_{0607} \delta+\text { month }_{i}^{\prime} \gamma+X_{i}^{\prime} \zeta+\varepsilon_{i}
\end{aligned}
$$

\footnotetext{
${ }^{22}$ Running t-tests on the probability of being born late in January, premature in December or being born by cesarean section in December, comparing only 2006 and 2007, I do not get any significant differences either.

${ }^{23}$ Optimally, I would exclude only children born in the last week of December 2006 and in the first week of January 2007, as it is unlikely that women can shift births for a longer period of time. Unfortunately, my data only contains month of birth, but not the exact birthday of each child.
} 
All variables are defined as in equation (1), and after $_{i}$ represents a dummy variable indicating whether the child was born in the months after the reform came into effect, thus between January and June in the widest specification. Compared to equation (1), equation (2) additionally contains an interaction with a dummy variable indicating a positive change in the overall benefit amount compared to the pre-reform situation. It is important to note again that these changes describe the overall changes after the entire transfer duration and not after the first year where there shouldn't be any loser - families. I replace the dummy by a continuous variable with the exact amount of expected change (in 1,000 EUR) in equation (3). While it is more interesting to investigate whether and in how far the exact amount of change in overall benefits drives the results, change $_{i}$ might suffer from measurement errors due to the quite complex procedure of calculating each family's relevant income and the respective amount of both Erziehungsgeld and Elterngeld (see Appendix A.1). To avoid attenuation bias, it thus makes sense to additionally consider the dummy variable gain $_{i}$ which is less prone to measurement errors.

The interaction terms $\left(\right.$ reform $_{i} \times$ gain $\left._{i}\right)$ and $\left(\right.$ reform $_{i} \times$ change $\left._{i}\right)$ actually represent a triple interaction of an indicator for the treatment cohort $\left(\right.$ born $\left._{0607}\right)$, an indicator for a birth month between January and June $\left(\right.$ after $\left._{i}\right)$ and the change induced by the reform (change $e_{i}$ or gain $\left._{i}\right) . \beta_{1}$ in equation (2) hence captures the reform effect on families, who would not benefit due to the reform. $\beta_{2}$ shows the additional effect of the reform for a child whose family would experience a positive change compared to a non-positive one. The coefficient $\beta_{1}$ in equation (3) reflects the pure reform effect for a family without any changes in the overall benefit amount; $\beta_{2}$ thus shows the additional reform effect per 1,000 EUR of change in the benefit amount. The interpretation of the other coefficients is similar for both specifications: $\beta_{3}$ estimates the pure effect of a gain (or the exact amount of change) on well-being for all children and hereby also accounts for the fact that some parents, like those with less children and thus higher income, are more likely to belong to the reform's winners than others. $\beta_{4}$ allows this effect to vary between the 2006/2007 cohort and the control cohorts. $\beta_{5}$ enables a different effect of a gain (or the exact amount of change) for children born in the first half of a year compared to children born in the second half. $\delta$ is the pure effect of belonging to the 2006/2007 cohort compared to the average of the control cohorts, $\gamma$ captures seasonal effects and $\zeta$ includes the effects of socio-demographic characteristics.

One might be concerned with the possibility of parents adapting their pre-birth income before the reform in order to get higher benefits, thus making the expected direction of change endogenous (see Ruhm, 1998). However, the reform was approved only two months before it 
was implemented. Thus, income earned before November 2006 is very unlikely to be affected by such adaption behavior. Even though there might be some adjustments after the reform had been passed, I do not consider this a problem for my identification strategy. First, increases in salaries are very unlikely to happen within one or two months and are probably rather modest. Second, taking up a new job or a side job to increase pre-birth earnings also takes some time, especially for mothers who were previously out of the labor market or are already pregnant. Consequently, the identification should not be prone to any adjustments of pre-birth income, especially when using the small time frame of three months surrounding the reform.

Furthermore, the specifications above result in a kind of reduced form estimate: while only the reform's income effect is truly estimated, the channels through which this income effect influences children's well-being can be manifold. One should thus not interpret $\beta_{2}$ as a pure monetary effect but take into account that being a winner does not only result in higher benefit amounts but can, for example, also change maternal life satisfaction or labor market participation.

\section{Data}

For my analysis, I use data from the German Socio-Economic-Panel (GSOEP), a longitudinal and representative survey of approximately 11,000 private households in Germany, interviewed from 1984 to 2013 (East Germany from 1990-2013). Since the birth cohort 2002/03, the GSOEP includes mother-child-questionnaires, which contain age-specific questions on a battery of proxies for a child's development and well-being. Moreover, I can exactly identify a child's year and month of birth and the mother or main parent of the child.

Additionally, data from individual and household questionnaires can be matched with these data such that I get quite rich information on a child's family background, for example on parents' average monthly income which is important to decide about eligibility for former Erziehungsgeld or the expected direction of change in the overall benefit amount due to the reform. I am also able to reconstruct income information for years before the child's birth. This rich set of information overweights the disadvantage of the relatively small sample size in the GSOEP $^{24}$.

I end up with 1,926 observations in the sample of 0 -1-year-olds and 1,483 observations for

\footnotetext{
${ }^{24}$ In many other datasets containing more observations (e.g. Paifarm, which is used by Maeder (2014)), I do not have any income information and could thus only use proxies to decide about eligibility or the benefit amount.
} 
the 2-3-year-old children. Depending on the choice of control groups and the time frame surrounding the cutoff date, usable observations naturally decrease. The first sample covers birth cohorts 2002/03 - 2010/11, the second one birth cohorts 2002/03 - 2007/08.

About $99 \%$ of the children included in the mother-child-questionnaire for newborns (0-1year-olds) are between 0 and 16 months old. Very few children are aged up to 23 months. 99 $\%$ of the children covered by the questionnaire for 2-3-year-olds are aged between 26 and 42 months. Since age can influence my outcome variables, I control for the age of the child at the time of the survey in most of the regressions.

Both for newborn and older children, different indexes are constructed, based on several parent-answered questions. According to Schmiade et al. (2008) or Felfe and Lalive (2012) there might be some doubts about the reliability of such parent-answered questionnaires, because mothers tend to overestimate their children's abilities and sometimes give socially desirable answers, for example, in order to justify the respective childcare situation. However, I do not consider this as a serious bias to my data: First, there are some studies (see Sparrow and Cicchetti, 1985) that confirm the reliability of such questionnaires, reporting high correlations between parents' answers and teachers' or nurseries' answers. Second, some indexes described below contain both subjective and more objective variables thus mitigating the concern that my effects might be driven by misreporting ${ }^{25}$. Third, Schmiade et al. (2008) show for the group of 2-3-year old children that the questions on language skills, basic life skills, motor ability and social skills, representing the SOEP-version of the Vineland Adaptive Behaviour Scale, are at least as a whole suitable to measure a child's state of development and satisfy the criterion of objectivity and reliability. Nevertheless, it is important to bear in mind that a change in maternal behavior (e.g. concerning labor market participation) could also have an impact on a mother's perception vis-à-vis her child: a mother who stays at home and takes care of the child herself might be more likely to realize potential problems in her child's development or health than a mother whose child attends public childcare during the day. This will be discussed in more detail in section 7 .

As a first step, I recode all variables such that higher values stand for a more positive development of the child. Afterwards, I standardize them to a mean of 0 and a standard deviation of 1 according to Kling et al. (2007) and combine several variables to get the following indexes (with also a mean of 0 and a SD of 1) for the 0-1-year-olds: The health \& development index

\footnotetext{
${ }^{25}$ Moreover, this would only threaten my identification strategy if treatment group mothers misreported systematically differently from control group mothers.
} 
includes dummies for disorders in sensory skills, in motor ability, in speech and in regulation ${ }^{26}$ as well as a variable indicating whether the mother, in general, is worried about the child's health. For the personality index, I investigate whether a mother describes her child as happy and content or rather the opposite, whether she indicates that her child is easily irritable and cries a lot, whether the child is hard to console and whether it is curious and active. Moreover, I construct one placebo index containing variables which should not be influenced by the reform because they are either innate or measured directly after birth (e.g. number of doctor or hospital visits in the first two months, weight-for-age at birth, height-for-age at birth, BMI at birth, handicaps). It is used to check the robustness of my results. The distribution of the indexes for 0-1-year-olds are depicted in figure 3, showing that all indexes are skewed to the left. Thus, better values occur more frequently than bad ones.

\section{[Figure 3 about here]}

I repeat this procedure for the data of 2-3-year-olds. Due to more extensive information in this questionnaire, 7 different indexes are constructed: The health index includes dummy variables for different illnesses (bronchitis, middle-ear inflammation, croup syndrome, nutritional disorders) that could possibly be influenced by the respective childcare situation ${ }^{27}$. Additionally, I include a variable indicating whether the mother is in general worried about the child's health, a variable informing about the number of doctor and hospital visits in the last 3 or 12 months, and indicators for regular height-for-age, weight-for-age and BMI ${ }^{28}$. The personality index is similar to the index for newborn children, but additionally includes two variables showing whether the child is communicative and whether it is able to show empathy vis-à-vis others. The behavior index is composed of the following questions: is the child shy or outgoing? Is is concentrated or not focused? Is it obedient or defiant? Does the child learn very quickly or does it need some more time? Moreover, I choose to follow Gathmann and Sass (2012) ${ }^{29}$ and construct a language index, a basic life skills index, a motor ability index and a social skills index by analyzing parents' assessments of what their child is already able to accomplish in these different categories. Exemplary questions are whether the child understands easy instruc-

\footnotetext{
${ }^{26}$ E.g. child is crying a lot, disorders in sleeping or eating behavior.

${ }^{27}$ Dummies for asthma, hayfever, neurodermitis and hearing disorders were not included, as literature on children's health classifies these illnesses as mainly determined genetically and thus innate.

${ }^{28}$ Height-for-age, weight-for-age and BMI were constructed as Z-scores with children of the same gender and agegroup in the sample serving as reference population. A z-score is considered as regular, if it lies in between -2 and +2 standard deviations of the mean.

${ }^{29}$ Gathmann and Sass (2012) use exactly the same dataset, but they didn't use standardized indexes. Instead, they constructed the four indexes by summing up scores of the respective questions.
} 
tions like „Go get your shoes“, whether it can listen to a story longer than 5 minutes, whether the child already uses toilets and brushes its teeth, whether it can cut paper or paint, whether it participates in games with other children, says mommy and daddy and several more.

To increase statistical power to detect effects that point in the same direction, I also aggregate the individual skill variables into a composite skills index and aggregate questions on personality, health and behavior into a general well-being index. The distribution of all indexes is shown in figure 4. Some indexes are skewed to the left (e.g. language skills index, social skills index), some indexes are centered around the mean of 0 and exhibit both positive and negative deviations for about the same percentage of children (e.g. personality index, behavior index). Nevertheless, it is evident that positive deviations from the mean are never larger than 2 to 3 standard deviations, while negative deviations reach up to 10 to 12 standard deviations.

\section{[Figure 4 about here]}

Besides the information on the child's birth and the proxies for well-being, I especially need information on parents' pre-birth income for my subgroup analysis. After merging data on children and their parents, I can identify average gross monthly income and the number of months parents worked in each year. I approximate average gross yearly income for each family with these data and determine whether parents would have been eligible for the old Erziehungsgeld, how much they would get under each benefit system ${ }^{30}$, whether the reform would altogether lead to a gain or a loss in benefits and how large this change in the overall benefit amount would exactly be. ${ }^{31}$

Figure 5 shows the means of the overall amounts of benefits of Elterngeld and Erziehungsgeld for different brackets of net yearly pre-birth income of the household. Strikingly, lower-income households seem to be better off with the old regulation on average, while higher-earners clearly benefit from the reform. This positive gap between Elterngeld and Erziehungsgeld widens the higher pre-birth earnings are. Again, it comes to light that the introduction of the Elterngeld created both winners and losers in terms of the overall benefit amount.

\section{[Figure 5 about here]}

\footnotetext{
${ }^{30}$ For details on benefit and eligibility calculation see Appendix A.1.

${ }^{31}$ I am not aware of any other study using such detailed and accurate information on the direction and the extent to which the German parental leave reform affected different groups of families to identify heterogeneous effects on children. Raute (2014) also computes pre- and post-reform benefits to assess the reform's impact on fertility. However, she uses midpoints of the benefit intervals and does not consider the women's own earnings, but only their spouses' income.
} 
Moreover, my data provide me with many different background- and socio-demographic variables for both parents which I partly include in my regressions as control variables. Strictly speaking, I control for the child's age at survey, the gender of the child, the child's number of older siblings (at birth), for whether the mother is born in Germany, for the mother's education level and for the family's region of residence. For summary statistics of the control variables refer to table 3 .

\section{[Table 3 about here]}

\section{Results}

\subsection{Descriptive results}

After controlling for seasonal trends, the treatment and the control group seem to be largely comparable in terms of background characteristics (see table A2 in the Appendix). By construction, children in the first quarter of a year are, on average, somewhat older when the data is collected than children born before the cut-off. This is due to the varying survey months in which the interviews were conducted ${ }^{32}$ and also explains the significant differences in weight. Given that the large majority of the various background variables does not show any significant differences between the treatment and control group, the few differences for migration background of the mother, for maternal education, for the child's number of older siblings and for premature births ${ }^{33}$ do not give rise to serious problems. First, nearly all of these differences disappear when only considering children born between October and March of each cohort (see table A3 in the Appendix). Second, my regressions partly contain pre-birth socio-demographic controls which should account for these very few observable differences. To make sure that my results are not driven by selection effects, I will nevertheless provide all results both for the large time frame of six months before and after the reform and for the smaller time frame of three months. Due to the unexpectedness of the reform, the small time frame should not be prone to any selection.

Table 4 shows the simple comparison of means of the dependent variables and indicates significant negative effects of the reform on the personality index of newborn children. Taking

\footnotetext{
${ }^{32}$ e.g.: Most of the 2-3-year-old children born at the end of 2006, were surveyed at the beginning of 2009 and are thus on average 30 months old; those being born at the beginning of 2007 however, were surveyed in the first months of 2010 and are thus 6 months older on average.

${ }^{33}$ Most of these differences also stay significant when only using the birth cohort 2005/2006 as control group. Results are forwarded by the author upon request.
} 
into account possible seasonal effects, the negative effect on personality remains significant and even increases.

\section{[Table 4 about here]}

For the older children, the simple RD-estimator in column (3) shows significant positive effects on language skills, motor ability, basic life skills and social skills, as well as on the composite skills index. After taking seasonal effects into account, however, only the positive effect on language skills, on basic life skills and on the composite skills index remains significant.

As mentioned before, an important requirement for my Difference-in-Differences strategy is the common trend assumption. To get a valid counterfactual, it has to be the case that, without the treatment, all indexes would have followed parallel trends in all treatment and control years. Residuals' means after having controlled for background characteristics of parents and children (e.g. age of child, migration background, mother's education) for all four cohorts do not deviate a lot from each other in terms of standard deviations and they are also very close to a mean of 0 . Moreover, even though one can observe some minor differences between the second and the first half of a year, these differences are rather modest and much smaller than the effects estimated in the following (see figures A1 and A2 in the Appendix). Further robustness checks are provided in the next two subsections.

\subsection{Results for 0-1-year-old children}

Table 5 reports regression results of equation (1) for the sample of 0-1-year-old children. Columns (1) and (2) show estimates for the large time frame (births between July and June) both without and with additional socio-demographic controls. Columns (5) and (6) restrict the sample to births between October and March. Regressions in columns (3) and (4) exclude observations born in December 2006 or January 2007 to account for potential short-run selection into or out of Elterngeld. I choose the cohorts 2004/05, 2005/06 and 2007/08 as control groups ${ }^{34}$, results with different control cohorts are reported below. Standard errors are clustered at the mother's level $^{35}$.

\footnotetext{
${ }^{34}$ I did not choose cohorts before 2004 because there was a change in eligibility and benefit calculation for Erziehungsgeld on January 1st, 2004. I did not choose years after 2008, because there were many other reforms potentially influencing children's development, e.g. the expansion of public childcare provision. Moreover, I tried to be as close to the treatment cohort as possible to avoid diverging trends.

${ }^{35} \mathrm{My}$ results are largely robust to only allowing for heteroscedasticity but not for serial correlation, i.e. to using robust instead of clustered standard errors. However, as there are several siblings with the same mother in both samples, clustering standard errors on the mother's level seems to be the most suitable specification.
} 
The regression results confirm the first impression and suggest a large negative effect of -0.388 to -0.549 standard deviations on personality, while there are no significant effects on the placebo index and on development $\&$ health. Despite the quite large standard errors for some estimates, I can reject with a 95\% (90\%) confidence that the reform reduces the personality index by less than $1.4 \%(7.5 \%)$ of a standard deviation and by more than $77 \%(70.9 \%)$ of a standard deviation $^{36}$ for my preferred specification in column (2). For the small time frame (column (6)), one can thus reject with 95\% (90\%) confidence that the reform increases the personality index by more than 3\% (reduces it by less than 5.7\%) of a standard deviation.

Decomposing the personality index into its components ${ }^{37}$ detects that the overall negative impact is driven by detrimental reform effects on happiness and emotions (e.g. children seem to cry more often and are hard to console).

\section{[Table 5 about here]}

All in all, the baseline Difference-in-Differences regressions show evidence for, on average, considerable negative reform effects on the personality of newborn children. Next, I estimate equation (2) to check whether these effects are driven by a special group of children. Since the reform created both winners and losers in terms of overall transfers, parents might also react differently concerning, for example, labor market participation, fertility decisions or life satisfaction (see Section 2). Consequently, these heterogeneous effects on parents are also very likely to be passed on to their children and well-being of a winner's child might be different from well-being of a loser's child. Moreover, only concentrating on equation (1) could hide potentially offsetting effects for these two groups.

Table 6 shows the results for equation (2). The reform effect $\left(\beta_{1}\right)$ is significantly negative for the personality index, i.e. there is an adverse effect on the personality of children whose families would not expect a gain in the benefit amount. For the specification in column (2), one can reject at a 95\% (90\%) confidence that the reform increased losers' children's personality index by more than $5.8 \%$ (decreased it by less than $4.9 \%$ ) of a standard deviation.

\section{[Table 6 about here]}

$\beta_{2}$ is positive, but not significant and smaller than $\beta_{1}$ for all specifications. Considering the sufficiently large standard errors of the estimates for $\beta_{2}$, however, the overall reform effect on

\footnotetext{
36 95\%-confidence interval: $[-0.392-1.96 \times 0.193 ;-0.392+1.96 \times 0.193]$ for $\beta$ in column $(2)$.

${ }^{37}$ Results are forwarded by the author upon request.
} 
the group of winners $\left(\beta_{1}+\beta_{2}\right)$ never gets significant. One can thus conclude that the negative average effect on personality is driven by the children of losers and is likely to be less pronounced for children of winners ${ }^{38}$. Coefficients of the placebo index and the health $\&$ development index are not significant for any type of family.

Estimating equation (3), i.e. interacting the reform-variable with the exact amount of positive or negative change in the overall benefit amount again shows that the reform led to negative effects on children's personality if their parents experienced negative changes due to the reform $^{39}$. Table 7 shows the development of the personality index for different possible amounts of change in the overall benefit. The results suggest again that higher amounts of positive changes help to offset the negative impact on the child's personality. Since the coefficient of the interaction $\left(\right.$ reform $_{i} \times$ change $\left._{i}\right)$ is not significant, however, the precision of the estimates remains insecure and the focus of the interpretation lies on the significant main effect of the reform $\left(\beta_{1}\right)$.

\section{[Table 7 about here]}

To rule out that my results are driven by anything other than the change in the parental leave regulation in 2007, I carefully check their sensitivity in different robustness tests. First, I could not determine any significant effect on the placebo index for newborn children in any regressions. Since this index contains only variables that should not be influenced by the reform, this result is in favor of my identification strategy and confirms that the negative effect on personality is, in fact, induced by the change in parental leave. Second, the sign and significance of the effects does mostly not depend on the in- or exclusion of socio-demographic controls. Third, reducing the observation period from six months before and after the cutoff date to three months before and after does not considerably influence the estimated effects. To control for potential self-selection of mothers with due dates very close to January 1st, 2007, I drop observations born in December 2006 and January 2007 in column (3) and (4) of the previous regressions (tables 5, 6, A4). None of the significant effects detected in these estimates disappeared when excluding births very close to the cutoff, in most cases coefficients get even larger and more significant. A further sensitivity check is to estimate the same regressions using a different control group. As the 2007/08 cohort could have been affected by the expansion of public childcare

\footnotetext{
${ }^{38}$ As a robustness check, I also estimated equation (1) separately for potential winners and losers in terms of the overall benefit amount. These regressions also suggest, that the negative effect on personality for the full sample seems to be driven by those who would experience a non-positive change due to the reform. Results are forwarded by the author upon request.

${ }^{39}$ For presentational reasons, regression results can be found in table A4 in the Appendix.
} 
provision in Germany, I repeat all regressions only using the cohorts 2004/05 and 2005/06 as control group ${ }^{40}$. The findings are qualitatively robust to changing the control group.

Regarding the quite complex procedure of household income and benefit calculation, one concern might be that some winner-families are spuriously classified as losers and the other way round. To make sure that the results are not driven by such measurement errors, I exclude all families who are just on the edge of being a loser or a winner as a further robustness check. Estimates excluding families who experienced a change of between -500 EUR to +500 EUR due to the Elterngeldreform and who are thus close to the winner-to-loser-switching-point confirm my main estimates and do not detect a bias in classifying winner - and loser - families ${ }^{41}$.

As a last robustness test, I use a pseudo-reform to check whether my identification strategy also detects effects on children's well-being even without a true reform. I thus estimate equation (1), (2) and (3) pretending that the Elterngeldreform had actually taken place in January 2006, i.e. reform $_{i}=1$ if the child is born in January to June 2006. If my common trend assumption was perfectly valid, I should not find any effects of this fake-reform. Table 8 shows that the pseudo-reform did, indeed, not cause any significant effects on 0-1-year-old children.

\section{[Table 8 about here]}

All in all, the results for the 0-1-year-olds pass all robustness checks and corroborate the validity of my identification strategy and thus the existence of a quite large negative reform effect on newborn children's personality originating from the reform's losers.

Due to my quite low overall sample size, testing for further heterogeneities by splitting the sample into different subgroups is a doubtful task to undertake. Nevertheless, the two most relevant results of the heterogeneity analysis will be presented in the following ${ }^{42}$. They should not be over-interpreted though. First, there was a higher share of eligible women under the old system in East Germany compared to West Germany (Fendrich et al., 2003). Table 2 moreover showed that the average expected change in the benefit amount is much lower for East German families, thus creating on average less winners or at least lower gains among East Germans. While one might thus expect a less pronounced negative effect on newborns' personality when dropping East German families from the sample ${ }^{43}$, regression results show that the coefficients

\footnotetext{
${ }^{40}$ Results are forwarded by the author upon request.

${ }^{41}$ Results are forwarded by the author upon request.

${ }^{42}$ Due to the limited number of observations, a heterogeneity analysis is only feasible for specification (1).

${ }^{43}$ Another reason to drop East German families might be due to the lasting cultural differences between East and West Germany: resulting from the former socialist past, East German women are traditionally more attached to the labor market. Moreover, making use of (in)formal childcare was never seen as socially undesirable in the eastern part of Germany.
} 
of all specifications remain qualitatively and quantitatively unchanged ${ }^{44}$.

Second, psychological research (e.g. Jacobs and Moss, 1976) points out that mother-child interactions differ between firstborn children and those born thereafter. The results could thus depend on whether the newborn child is the mother's firstborn or a child from a higher birthorder. Estimating all specifications separately for firstborn and non-firstborn children, I detect that the effects in the full sample are entirely driven by children from a higher birth-order ${ }^{45}$.

\subsection{Results for 2-3-year-old children}

Table 9 reports regression results from equation (1) for 2-3-year-old children, for both time frames, without and with socio-demographic controls. For the large time frame, I find that the reform had significantly positive effects of 0.348 to 0.482 standard deviations on language skills, of 0.253 to 0.328 standard deviations on basic life skills and of 0.380 to 0.476 standard deviations on the composite skills index. Despite the imprecision of some estimates, I can reject with $95 \%$ (90\%) confidence that the reform decreased children's language skills by more than $4.8 \%$ (increased it by less than 1.6\%) of a standard deviation. Moreover, I can reject with 95\% (90\%) confidence that the reform decreased the basic life skills index by more than $7.9 \%$ $(2.6 \%)$ of a standard deviation and that the composite skills index is reduced by more than $9 \%$ $(2.5 \%)$ of a standard deviation. Furthermore, the same positive pattern can be found for all other indexes, too, and I can never identify a significant negative effect on any dimension of child development.

\section{[Table 9 about here]}

Decomposing the indexes ${ }^{46}$ shows that the positive effect on language skills is especially driven by children's improved understanding of instructions and messages. The drivers of the positive impact on basic life skills are not so clear, one can however identify a tendency towards better usage of bathroom-items (like toilet and toothbrush). Reducing the time frame, the coefficients of language skills, basic life skills and the composite skills index are still quite large and positive but lose significance, which might be due to the reduction in sample size ${ }^{47}$.

\footnotetext{
${ }^{44}$ Results are forwarded by the author upon request.

${ }^{45}$ Regression results for equation (1) are shown in table A5 in the Appendix.

${ }^{46}$ Results are forwarded by the author upon request.

${ }^{47}$ I reestimate the regression for a randomly drawn $50 \%$ observation sample of the large time frame. All but one coefficients are found to be insignificant, too, as soon as the pre-determined socio-demographic controls are included. Results are forwarded by the author upon request. Thus, it seems to be justified to assume that the loss in significance results from the smaller sample size instead of emerging from selection effects in the large time frame.
} 
Table 10 depicts results of estimating equation (2) and does not show the clear significant positive effects on language, basic life skills and the composite skills index I detected in the average effects framework ${ }^{48}$. In some specifications, however, $\beta_{2}$ gets significantly positive and indicates quite large positive effects on language skills of children whose families would gain in terms of the overall benefit amounts. For specification (6) for example, I can reject with 95\% (90\%) confidence that winners' children's language index is decreased by more than $0.16 \%$ (is increased by less than $18.3 \%$ ) of a standard deviation compared to losers' children, suggesting that the overall positive effect on language skills originates from children of winners ${ }^{49}$. I cannot identify a significant effect on the group of children whose parents would not experience a positive change.

\section{[Table 10 about here]}

Moreover, all other indexes - except for the basic life skills index - show a similar pattern of quite large positive, though mostly insignificant, reform effects on winners' children, while the effect on losers' children is often close to zero or even negative. This again suggests that winners' children are better off than losers' children in several aspects.

Regression results for equation (3) (see table A6 in the Appendix) display significant positive coefficients for $\beta_{1}$ for some of the skills indexes. Again, $\beta_{2}$ mostly is quite small and estimated with relatively large standard errors. Table 11 shows calculations similar to table 7 for the language skills index and the basic life skills index: experiencing a larger positive change could have a small additional positive influence on language skills.

\section{[Table 11 about here]}

As for the younger children, several robustness checks were conducted to test the sensitivity of the results. First, the findings for the 2-3-year-olds are not significantly influenced by the in- or exclusion of socio-demographic controls. The reduction of the time frame from six to three months surrounding the reform, however, leads to a loss of significance for all indexes in specification (1), but increases significance of some indexes in specifications (2) and (3). Third, the exclusion of December 2006 and January 2007 births in columns (3) and (4) in the

\footnotetext{
${ }^{48}$ This might be due to the fact that I do not observe many children who are born after the reform and expect positive changes in the benefit amount. In the largest time frame I only have 53 observations for which reform $\times$ gain $=1$.

${ }^{49}$ Results from estimating equation (1) separately for winners and losers confirm this finding. Results are forwarded by the author upon request.
} 
previous tables did not make any of the significant effects disappear and thus shows that the results should not be contaminated by short-run selection into or out of the treatment. Fourth, the findings are qualitatively robust to changing the control cohort. Excluding families very close to the winner-to-loser-switching-point, i.e. those within an interval of -500 to +500 EUR of expected change in benefits leads to a loss in significance for some of the coefficients, the general pattern, however, is robust ${ }^{50}$.

As a last robustness check, a pseudo-reform is introduced again. Table 12 shows the results of this placebo-Diff-in-Diff estimation and detects some significant effects especially for the behavior index and the general well-being index which should in fact not appear for a fakereform ${ }^{51}$. Since I did not discover any robust and significant true reform effects for the health index, the personality index, the behavior index and the general well-being index for 2-3-yearolds, this finding should nonetheless not invalidate my previous results. The coefficients of the different skills indexes, which I found to be affected by the Elterngeldreform, remain insignificant for the pseudo-reform and thus provide further evidence for the validity of my estimates in this section.

\section{[Table 12 about here]}

In conclusion, the results for the 2-3-year-olds are not as robust as the results for the newborn children. However, all specifications and all robustness checks always present a similar and reliable pattern of positive reform effects on winners' children, especially in terms of skills, and small to negative effects on those whose families would not gain due to the reform.

As for the younger children, dropping East German families does not lead to different results. Concerning birth-order heterogeneities, the significant positive effects on skills only appear for firstborns, not for higher-order children (see tables A7 and A8 Appendix).

\section{Discussion of the results}

Results in Section 6 suggest a negative reform effect on newborns' well-being in terms of personality, especially on emotions. The effect seems to be mostly driven by those whose families would expect overall non-positive changes compared to the pre-reform situation. These are either families with very low income eligible for receiving the minimum amount of Elterngeld or

\footnotetext{
${ }^{50}$ Results are forwarded by the author upon request.

${ }^{51}$ One potential reason for this finding is that the pseudo-reform isn't really pseudo. However, I am not aware of any family policy introduced in January 2006 that could have affected children born before and after this reform differently.
} 
families with low income who receive between 300 and 600 EUR per month; both groups are likely to lose in terms of overall benefits because of the shortened transfer duration. Since the average age of the children in this sample is about six months, the negative personality effect cannot be explained by any labor market or income effects, which become relevant after the first year. As shown by several studies (e.g Kluve and Tamm, 2013; Bergemann and Riphahn, 2011a), the Elterngeldreform did neither have any labor market effects on low-earning mothers nor any large income effects during the first year after birth ${ }^{52}$. Changes in fertility decisions are also unlikely to play a role six months after delivery. Consequently, one of the other channels must be at work here: Maeder (2014) refers to the findings of the literature on the Easterlin Paradox $^{53}$ (e.g. Clark et al., 2008) ${ }^{54}$ and accordingly argues that mothers belonging to the reform's winners might experience a positive effect on well-being. This occurs when winner mothers compare themselves to a hypothetical situation before the reform, to themselves in the past or to families with comparable income but not eligible for the new benefit (i.e. with a child born shortly before the reform) and then realize their beneficial situation. Following the same argumentation, women belonging to the reform's losers should experience a negative effect on well-being and life satisfaction. Maeder (2014) actually finds that women who are newly eligible for paid parental leave and are thus likely to be part of the higher-earnings group experience positive effects on overall life satisfaction, are more satisfied with school, with their job and with their family 1.5 to 5.5 years after birth. In contrast, these effects are rather negative for those who were already eligible under the old regulation and might expect an overall decrease of the benefit amount. Even though this reduction in benefits has not yet come into effect after six months, the mere awareness of a shorter transfer duration could already influence a mother's life satisfaction in the first months after birth. Mothers might realize that their benefits will soon expire, that it will probably be necessary to return to work and that their free time to care for the child will be reduced. These factors are likely to provoke stress for mothers. This argumentation is well in line with the finding that shortly after the reform had been introduced, a large majority of parents were well aware of most features of the new parental leave regulation (RWI, 2008) and thus were also likely to have realized whether they were subject to a gain or a loss in benefit amounts compared to Erziehungsgeld.

\footnotetext{
${ }^{52}$ Labor market participation was found to be reduced in the first 12 months after birth, but this effect was driven by families with rather high income.

${ }^{53}$ The paradox results from growing real income in many countries without any increase in reported levels of happiness (see Easterlin, 1995).

${ }^{54}$ Clark et al. (2008) find that it is not absolute but relative income which matters for happiness, because individuals compare their income both to others (social comparison) and to themselves in the past (habituation).
} 
Berger and Spiess (2011) investigate the relationship between maternal life satisfaction and child outcomes using data from the GSOEP. They find that higher maternal life satisfaction leads to better socio-economic development at the age of 5 to 6 years. Arguing that this might be due to a better quality of a child's attachment to its mother, which is especially important in the first year of life, I see no reason why this relationship could not also be a driving factor for the emotional development of toddlers. Also, the results of the heterogeneities by birth-order point in the same direction: that the effects seem to be driven by non-firstborn children hints at the importance of the habituation effect mentioned before. Mothers only have a suitable reference point for higher-order births and might thus be more easily dissatisfied with a change in the parental leave situation than mothers who never experienced a similar situation before. Due to the low number of observations, testing this channel with my data is difficult. Nevertheless, I run my baseline Diff-in-Diff framework ${ }^{55}$ using the SOEP variables on mothers' satisfaction with different areas of daily life as dependent variables. Results do not detect a clear pattern for maternal life satisfaction in the first phase after birth: while both loser and winner mothers seem to be slightly more satisfied with personal income compared to the pre-reform situation, there is no effect on overall life satisfaction. However, losers' satisfaction with family life tends to be reduced, while the effect on winners has a positive $\operatorname{sign}^{56}$.

As mentioned in Section 5, one might attribute a part of the large negative effect on personality to an increased awareness of post-reform mothers who, on average, spend more time with their children than pre-reform mothers. However, labor market participation in the first 6 months after birth should not differ for the pre-reform and the post-reform period, making this point less pressing. Moreover, if the negative effect on personality was only due to a change in mothers' perceptions, we should observe an effect of similar size for both winners and losers what is obviously not the case here.

Results for the 2-3-year-olds suggest a significant positive effect on the composite skills index, especially on language and basic life skills, originating from children whose families would gain in terms of the overall benefit amount. These children are likely to be affected by the income and labor market effects after 12 months: A wide array of studies (e.g Bergemann and Riphahn, 2011a; Bergemann and Riphahn, 2011b; Geyer et al., 2012; Geyer et al., 2014; Kluve and Tamm, 2013) found that the German parental leave reform led to an overall reduction of maternal labor supply in the first year after childbirth, but that mothers plan to return to the

\footnotetext{
${ }^{55}$ Time frame of 6 months, with and without socio-demographic controls.

${ }^{56}$ Results are forwarded by the author upon request.
} 
labor market thereafter. The first effect is especially pronounced for women who were previously employed, benefit from the reform and thus see the opportunity cost of maternal childcare reduced. The second effect seems to be driven by lower-income or unemployed mothers whose transfer duration was shortened by about one year. In a recent paper, Kluve and Schmitz (2014) showed that not all mothers implemented their return-to-work-plans after the first year but they find significant positive effects of the Elterngeld on the probability to be employed after the second year. This increase in parental time investments of high-educated and thus high-earning parents in the very first phase of the child's life could have caused the positive impact on child development in light of the findings mentioned in Section 2. Del Bono et al. (2014) also investigate maternal time investment in terms of different mother-child-activities and find that early time investments are very productive for children's cognitive and non-cognitive outcomes, especially in the case of verbal skills. Jacobs and Moss (1976) point out that, in the first phase of the child's life, mothers spend more time in social, affectionate and caretaking activities with their first child than with their second child. Combining this insight with the finding that the reform's positive effects on skills are especially pronounced for firstborns hints at the importance of increasing time investments as a potential channel.

Second, the positive income effect related to higher benefits might have improved young children's mental development (see Brooks-Gunn and Duncan, 1997) as well. However, the Elterngeld underlies a progressivity effect (Progressionsvorbehalt) meaning that parental leave benefits increase the average tax rate on married couples' income, thus inflating their tax payment due ${ }^{57}$ and reducing the positive income effect because of higher benefits. Simple impact estimates on the change in net monthly household income experienced between the year before and the year after childbirth show that the change in household income is affected slightly positively for winners and slightly negatively for losers (see table A9 Appendix) ${ }^{58}$. The coefficients are not significant, however. Applying my baseline Diff-in-Diff to gross income of mothers of 2-3-year-olds does not detect any significant effects ${ }^{59}$. If anything, the reform resulted in slightly negative effects on all mothers which is in line with the results of Kluve and Schmitz (2014) who found that mothers predominately return to the labor market in the third year, not yet in the second one. Consequently, though the changes in the benefit amounts are likely to have had some impact on household income, I do not consider the income effect as the exclusive

\footnotetext{
${ }^{57}$ This results from a special feature of the German tax system, where households with identical income are taxed identically, no matter how spouses split their earnings.

${ }^{58}$ The results of Kluve and Tamm (2013) point in a similar direction.

${ }^{59}$ Results are forwarded by the author upon request.
} 
driver of the results.

Nevertheless, the gain in the benefit amounts could still be related to a higher maternal life satisfaction that is proposed by Maeder (2014). According to RWI (2008), most parents were not aware of the progressivity effect when receiving Elterngeld and thus even overestimated the gain in income. Berger and Spiess (2011) showed that the verbal skills of 2-3-year-olds improve the higher their mother's life satisfaction is. This can be explained by either qualitatively better attachment or better parenting behavior of happy mothers.

Furthermore, even though the overall benefit amount increases for high-earning mothers, many are likely to return to the labor market after the first or at least the second year (see Kluve and Schmitz, 2014). Consequently, mothers need to find a substitute for maternal care, which could be either formal childcare or care by family members or friends. Since the expansion of public childcare has been at the top of the political agenda for the past two decades in Germany, one might presume that enlarged provision of childcare slots in combination with the Elterngeldreform could have resulted in a higher usage rate of public childcare after 2007. As shown by Felfe and Lalive (2010), early formal childcare improves language skills, basic life skills, behavior and social skills, i.e. most of the skills I find enhanced after the change in the parental leave regulation. Moreover, Felfe and Lalive (2010) provide some evidence that the quality of mother-child-interactions improves when children spend more time in formal childcare. Lowquality time ${ }^{60}$ decreases, while activities stimulating cognitive skills increase. This in turn could also have positive effects on children's skills, especially on language skills. Again, investigating the childcare situation in my data does not provide any clear answers. Nevertheless, there is a small (insignificant) positive reform effect concerning the use of care by nannys for loser children and a small (insignificant) positive effect on care by daycare centers for winners. This points towards the mechanisms just mentioned. Moreover, care by fathers increases for winners, while it decreases for losers (see table A10 Appendix).

For the 2-3-year olds, however, I cannot completely rule out that the positive effects are at least to a minor extent determined by a change in maternal awareness for the child's well-being resulting from an increase in parental contact time with the child especially in the first year. As contact time in the second and third year tends to decrease due to the reform, this bias should if there actually is one - be rather modest.

Another issue to discuss is the insignificance of $\beta_{2}$ in all specifications of equation (3), which suggests that the exact amount of change in benefits induced by the reform does not have a di-

\footnotetext{
${ }^{60}$ E.g. going shopping with the child.
} 
rect effect on children's well-being. This result is not completely in line with the results of Dahl and Lochner (2012), who find that a $\$ 1.000$ increase in current family income has a modest positive impact on math and reading test scores of children aged 5 and older. There are two reasons, for which my results could differ: first, Dahl and Lochner (2012) investigate the effects of Earned Income Tax Credit (EITC) expansions which affected low and medium income families, but not higher-earners. Second, they detect that contemporary income has a much larger effect than past income. As Elterngeld is only paid in the first year of a child's life, the positive effect could already be diluted at the age of 2-3 years. Moreover, they argue that a permanent income shock might have much larger effects than temporary income shocks. Del Boca et al. (2014) develop a model of child development for different transfer programs. According to their definition, the Elterngeld would be an unrestricted transfer, which is granted to households with no restrictions on how it should be spent and thus increases non-labor income ${ }^{61}$. They argue that such unconditional transfers are partly spent on child investment goods and increase parental contact time with the child ${ }^{62}$, but the other part of the transfer is used for increasing parental consumption and leisure. The proportion of the transfer used for the child depends on parental preferences, but also on the household's pre-transfer resources and the productivity of the investments. These findings could also explain that I cannot detect a clear direct impact of a 1000 EUR change in the overall benefit amount on children's well-being, since this income effect could rather lead to changes in consumption and leisure behavior of parents instead of changing parental time spent with their children. Furthermore, the progressivity effect mentioned above could reduce the direct effect of higher benefits.

\section{Conclusion}

This paper studies the effect of a recent change in the German parental leave system on young children's well-being. The reform resulted in, on average, higher transfers for a shorter period of time and largely increased the group of eligible parents. Since the benefit amounts are no longer fixed but increase with parents' pre-birth earnings, the reform had very heterogeneous effects on parents which are suspected to translate into heterogeneous effects on children. The

\footnotetext{
${ }^{61}$ The other two transfer systems they mention are either restricted (i.e. a certain amount of the subsidy has to be spent on the child) or conditional cash transfers. The first case does clearly not apply for Elterngeld. One could argue that the Elterngeld is conditional on working no more than 30 hours per week, but according to Del Boca et al. (2014), such transfers are rather conditional on performance criteria which directly improve a child's level of development, e.g. conditional on taking the child to school or to a doctor.

${ }^{62}$ They assume that child quality is a normal good.
} 
unexpectedness of the reform allows the application of quasi-experimental methods to estimate the causal effects of parental leave on many aspects of children's well-being. My average effects results suggest that the parental leave reform in Germany led to remarkable and throughout negative effects on newborns' personality, which fortunately disappear after 2-3 years. At this age, the well-being of children affected by the reform improves, especially concerning skills. Exploiting the heterogeneous effects on parents' overall benefit amounts in my estimation strategy, I find that, in several aspects, children of families who experience a positive change in terms of the overall benefits compared to the pre-reform situation, are better off than children from families who belong to the group of losers: the adverse reform effect on newborns' personality mainly originates from loser - family children, whereas winners' children are responsible for the improvements in verbal skills and basic life skills.

What conclusions can be drawn from these results? First, it is important to investigate possibly heterogeneous effects, which could be hidden in average effects estimates. Although the main goals behind the introduction of the Elterngeld were not directly related to children's well-being, its implementation affected young family members via their parents. More to the point, heterogeneous effects on parents are at least partly mirrored in their children's well-being and development. Thus, policy makers should perhaps raise their consciousness of such effects and might give some thoughts on taking steps towards reducing possible detrimental effects on some types of families.

Second, it might be worthwhile for family policies to not only target children at school age but to focus also on very young children: reducing the negative effects on personality or increasing the positive effects on language skills and basic life skills could perhaps lead to even more positive effects of early maternal time investments in the long run. Third, investigating a wide variety of different aspects of well-being can help to determine the starting points for such interventions.

Although some possible channels through which the Elterngeld's heterogeneous effects on parents could have influenced children's well-being were suggested in Section 7, it remains an open question for future research to investigate the real causal channels of these effects. Especially the large negative effect on newborns' personality needs to be examined and explained in more detail. 


\section{References}

Angrist, J.D.; Pischke, J.-S. (2009). Mostly harmless Econometris - An empiricist's companion. Princeton, Oxford: Princeton University Press.

Baker, M.; Milligan, K. (2010). Evidence from maternity leave expansions of the impact of maternal care on early child development. Journal of Human Resources 45 (1), pp. 1-32.

- (2015). Maternity leave and children's cognitive and behavioral development. Journal of Population Economics 28 (2), pp. 373-391.

Baum, C.L. II (2003). Does early maternal employment harm child development? An analysis of the potential benefits of leave taking. Journal of Labor Economics 21 (2), pp. 409-448.

Becker, G.; Lewis, H. (1973). Economics of the Family: Marriage, Children, and Human Capital, UMI. Interaction between quantity and quality of children. Ed. by T.W. Schultz, pp. 8190.

Bergemann, A.; Riphahn, R.T. (2011a). Female labour supply and parental leave benefits the causal effect of paying higher transfers for a shorter period of time. Applied Economics Letters 18, pp. 17-20.

- (2011b). The Introduction of short-term earnings-related parental leave benefit system and differential effects on employment intentions. Schmollers Jahrbuch 131, pp. 315-325.

Berger, E.M.; Spiess, K. (2011). Maternal life satisfaction and child outcomes: Are they related? Journal of Economic Psychology 32 (1), pp. 142-158.

BMFSFJ (2005). Erziehungsgeld, Elternzeit. Das Bundeserziehungsgeldgesetz.

- (2013). Elterngeld und Elternzeit - das Bundeselterngeld- und Elternzeitgesetz. 13th ed. Berlin.

Brooks-Gunn, J.; Duncan, G. J. (1997). The effects of poverty on children. The Future of the Children - Children and Poverty 7 (2), pp. 55-71.

Brooks-Gunn, J.; Han, W.-J.; Waldfogel, J. (2002). Maternal employment and child cognitive outcomes in the first three years of life: The NICHD study of early child care. Child Development 73 (4), pp. 1052-1072.

Buckles, K.; Hungerman, D. M. (2013). Season of birth and later outcomes: old questions, new answers. The Review of Economics and Statistics 95 (3), pp. 711-724.

Carlson, M.J. (2006). Family structure, father involvement, and adolescent behavioral outcomes. Journal of Marriage and Family 68 (1), pp. 137-154. 
Carneiro, P.; Loken, K. V.; G., Salvanes K. (2015). A flying start? Maternity leave benefits and long run outcomes of children. Journal of Political Economy 123 (2), pp. 365-412.

Clark, A.E.; Frijters, P.; Shields, M.A. (2008). Relative income, happiness, and utility: An explanation for the Easterlin Paradox and other puzzles. Journal of Economic Literature 46 (1), pp. 95-144.

Crockett, L.J.; Eggebeen, D.J.; Hawkins, A.J. (1993). Father's presence and young children's behavioral and cognitive adjustment. Journal of Family Issues 14 (3), pp. 355-377.

Cunha, F.; Heckman, J. (2007). The technology of skill formation. American Economic Review 97 (2), pp. 31-47.

Currie, J.; Schwandt, H. (2013). Within-mother analysis of seasonal patterns in health at birth. PNAS 110 (32).

Cygan-Rehm, K. (2015). Parental leave benefit and differential fertility responses: Evidence from a German reform. Journal of Population Economics forthcoming.

Dahl, G.B.; Lochner, L. (2012). The Impact of family income on child achievement: Evidence from the Earned Income Tax Credit. American Economic Review 102 (5), pp. 1927-1956.

Danzer, N.; Lavy, V. (2013). Parental leave and children's schooling outcomes: Quasi-experimental evidence from a large parental leave reform. NBER Working Paper 19452.

Del Boca, D.; Flinn, C.; Wiswall, M. (2014). Transfers to households with children and child development. IZA Discussion Paper 8393.

Del Bono, E.; Francesconi, M.; Kelly, Y.; A., Sacker (2014). Early maternal time investments and early child outcomes. IZA Discussion Paper 8608.

Destatis (2008). Statistik zum Elterngeld - Anträge von Januar 2007 bis Juni 2008. Wiesbaden: Statistisches Bundesamt.

Dunifon, R.; Hansen, A. T.; Nicholson, S.; Palmhoj Nielsen, L. (2013). The effect of maternal employment on children's academic performance. NBER Working Paper 19364.

Dustmann, C.; Schönberg, U. (2011). Expansions in maternity leave coverage and children's long-term outcomes. American Economic Journal: Applied Economics 4 (3), pp. 190-224.

Easterlin, R.A. (1995). Will raising the incomes of all increase the happiness of all? Journal of Economic Behavior and Organization 27 (1), pp. 35-47.

Erikson, E.H. (1980). Identität und Lebenszyklus. 6th ed. Frankfurt am Main: Suhrkamp.

Felfe, C.; Lalive, R. (2010). "How does early child care affect child development? Learning from the children of German Unification”. In: Beiträge zur Jahrestagung des Vereins für 
Sozialpolitik 2010: Ökonomie der Familie - Session: Economics of Child Care and Child Development. B11-V2.

Felfe, C.; Lalive, R. (2012). Does early child care help or hurt children's development? IZA Discussion Paper 8484.

Fendrich, S.; Fischer, J.; Schilling, M. (2003). Erziehungsgeld und Elternzeit - Bericht des Jahres 2003. Dortmunder Arbeitsstelle Kinder- und Jugendhilfestatistik, Dortmund. Im Auftrag des Bundesministeriums für Familie, Senioren, Frauen und Jugend.

Gathmann, C.; Sass, B. (2012). Taxing childcare: Effects on family labor supply and children. CESifo Working Paper 3776.

Geisler, E.; Kreyenfeld, M. (2012). How policy matters: Germany's parental leave benefit reform and fathers' behavior 1999-2009. Max Planck Institute for Demographic Research: MPIDR Working Paper 2012-021.

Geyer, J.; Haan, P.; Wrohlich, K. (2012). Labor supply of mothers with young children: Validating a structural model using a natural experiment. IZA Conference Paper.

- (2014). The effects of family policy on mothers' labor supply. Combining evidence from a structural model and a natural experiment. DIW Discussion Papers 1366.

Google Trends (2015). URL: https : / www .google.de/trends/explore\#q=Elterngeld\% $2 \mathrm{C} \% 20$ Erziehungsgeld\&cmpt $=q \& t z=E t c \% 2 F G M T-2$.

Harris, K.M.; Furstenberg, F.F.; Marmer, Jr.; Marmer, J.K. (1998). Paternal involvement with adolescents in intact families: The influence of fathers over the life course. Demography 35 (2), pp. 201-216.

Hill, J. L.; Waldfogel, J.; Brooks-Gunn, J.; Han, W.-J. (2005). Maternal employment and child development: A fresh look using newer methods. Developmental Psychology 41 (6), pp. 833850.

Jacobs, B.S.; Moss, H.M. (1976). Birth order and sex of sibling as determinants of mother-infant interaction. Child Development 47 (2), pp. 315-322.

Kindergeld.info (2012). URL: http: / / ww . kindergeld . info/elterngeld/elterngeld2013.html.

Kling, J.R.; Liebman, J.B.; Katz, L.F. (2007). Experimental analysis of neighborhood effects. Econometrica 75 (1), pp. 83-119.

Kluve, J.; Schmitz, S. (2014). Parental benefits and mothers' labor market outcomes in the medium run, mimeo. 
Kluve, J.; Tamm, M. (2013). Parental leave regulations, mothers' labor force attachment and fathers' childcare involvement: evidence from a natural experiment. Journal of Population Economics 26 (3), pp. 983-1005.

Kottwitz, A.; Oppermann, A.; Spieß, K. (2015). Parental leave benefits and breastfeeding in Germany: Effects of the 2007 reform. Review of Economics of the Household forthcoming.

Lalive, R.; Zweimüller, J. (2009). How does parental leave affect fertility and return to work? Evidence from two natural experiments. The Quarterly Journal of Economics 124 (3), pp. 13631402.

Liu, Q.; Skans, O.S. (2010). The duration of paid parental leave and children's scholastic performance. The B.E. Journal of Economic Analysis and Policy 10 (1), pp. 1-35.

Maeder, M. (2014). Earnings-related parental leave benefits and subjective well-being of young mothers: evidence from a German parental leave reform. BGPE Discussion Paper 148.

Neidell, M.J. (2000). Early parental time investments in children's human capital development: Effects of time in the first year on cognitive and non-cognitive outcomes. UCLA Department of Economics Working Paper 806.

Neugart, M.; Ohlsson, H. (2013). Economic incentives and the timing of births: evidence from the German parental benefit reform of 2007. Journal of Population Economics 26 (1), pp. 87108.

Raute, A. (2014). Do financial incentives affect fertility - Evidence from a reform in maternity leave benefits. Job Market Paper.

Ruhm, C.J. (1998). The economic consequences of parental leave mandates: lessons from Europe. The Quarterly Journal of Economics 113 (1), pp. 285-317.

- (2004). Parental employment and child cognitive development. The Journal of Human Resources 39 (1), pp. 155-192.

RWI (2008). Evaluation des Gesetzes zum Elterngeld und zur Elternzeit, Endbericht.

Schmiade, N.; Spieß, K.; Tietze, W. (2008). Zur Erhebung des adaptiven Verhaltens von zwei - und dreijährigen Kindern im Sozio-oekonomischen Panel (SOEP). SOEPpapers on Multidisciplinary Panel Data Research 116.

Schönberg, U.; Ludsteck, J. (2014). Expansions in maternity leave coverage and mothers' labor market outcomes after childbirth. Journal of Labor Economics 32 (3), pp. 469-505.

Süddeutsche Zeitung (2012). URL: http : / / www . sueddeutsche . de / geld / elterngeld geaendert - wer - frueh - plant - bekommt - mehr - geld - fuer - den - nachwuchs - 1 . 1423695. 
Sparrow, S.S.; Cicchetti, D.V. (1985). Diagnostic uses of the Vineland Adaptive Behavior Scales. Journal of Pediatric Psychology 10 (2), pp. 215-225.

Tamm, M. (2013). The Impact of a large parental leave benefit reform on the timing of birth around the day of implementation. Oxford Bulletin of Economics and Statistics 75 (4), pp. 585601.

Verlag C.H.BECK, oHG, ed. (2015). beck-aktuell Gesetzgebung, Entwicklungsgeschichte Elterngeld. URL: http: //gesetzgebung. beck.de/node/185751.

\section{Figures and tables}

Table 1: Expected direction of change in the overall benefit amount

\begin{tabular}{lccc}
\hline & Freq. & Percent & Cum. \\
\hline no change & 8 & 0.4 & 0.4 \\
negative change & 781 & 38.88 & 39.27 \\
positive change & 1,220 & 60.73 & 100 \\
\hline total & 2,009 & 100 & \\
\hline
\end{tabular}

Notes: This table shows whether parents would be subject to no change, to a negative change or to a positive change in the overall benefit amount due to the reform. The overall benefit is defined as the sum of all monthly benefits during the entire transfer duration. Transfer duration is 12 months for Elterngeld and varies between 0 months and 24 months for Erziehungsgeld. 
Figure 1: Changes in overall benefit amount and transfer duration

Panel A

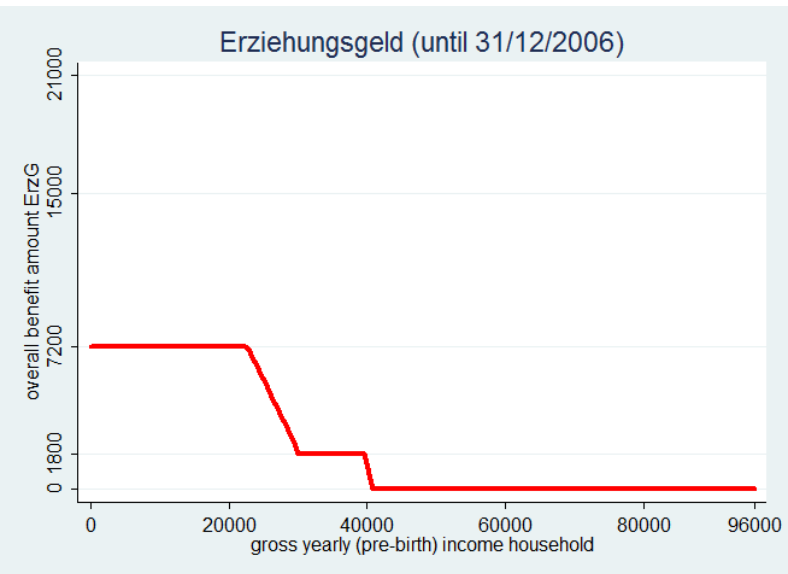

Panel C

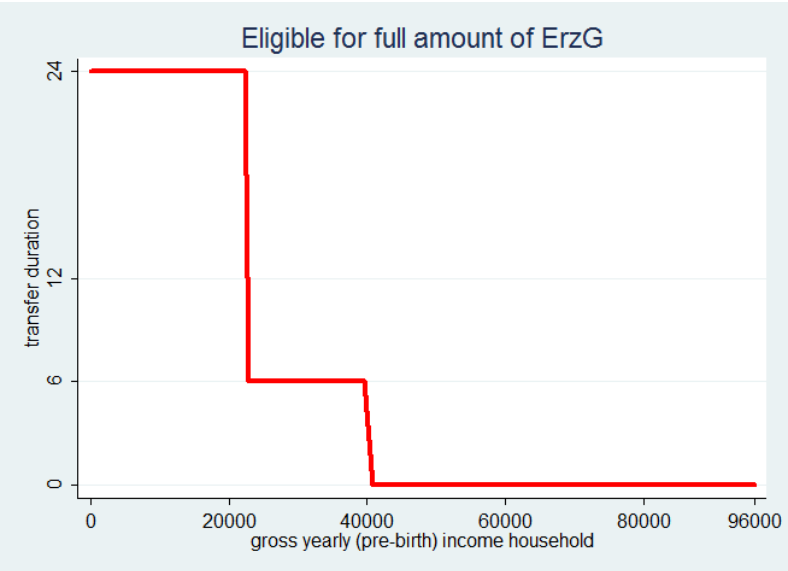

Panel B

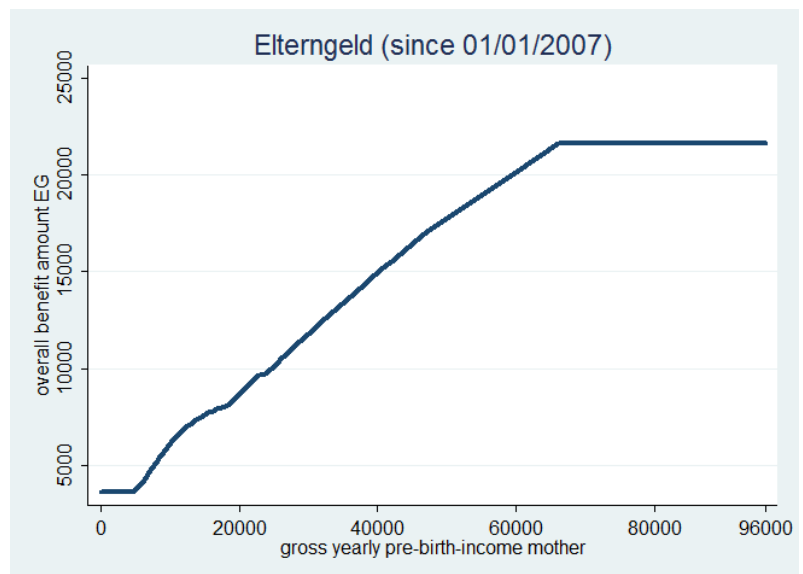

Panel D

Eligible for EG

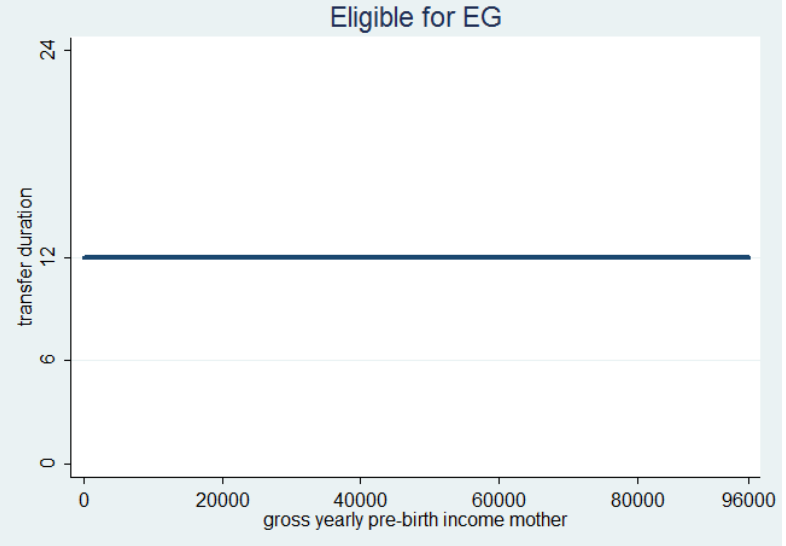

Notes: Panels A and B show the overall benefit amounts of Elterngeld and Erziehungsgeld for the gross yearly (pre-birth) income (in EUR) of both partners for ErzG or only of the mother for EG (see Appendix A.1 for further details). As net income is differently calculated under each regulation, I choose gross income to guarantee comparability. Moreover, parents are assumed to be partners, to have one child, compulsory health insurance and not to be self-employed.

Panels C and D compare the transfer duration (in months) for different income groups. Panel D neglects that some parents take two additional daddy months or make use of the Dehnungsoption. 
Table 2: Determinants of expected change in overall benefit amount

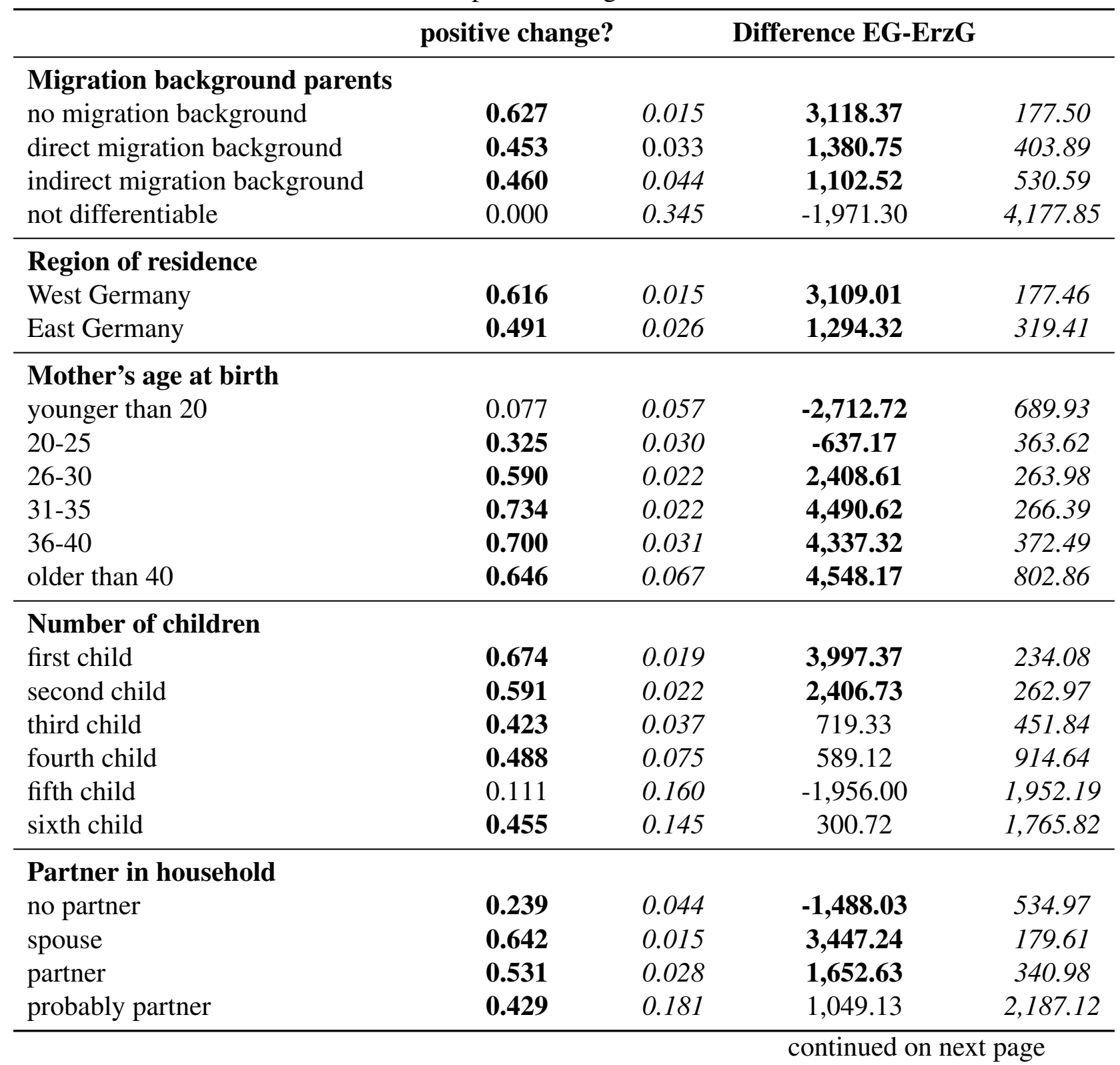


Table 2 continued from previous page

\begin{tabular}{|c|c|c|c|c|}
\hline & positive change? & & Difference EG-ErzG & \\
\hline \multicolumn{5}{|l|}{ Marital status mother } \\
\hline married & 0.642 & 0.015 & $3,431.93$ & 181.10 \\
\hline single & 0.434 & 0.028 & 542.33 & 343.45 \\
\hline separated/divorced/widowed & 0.407 & 0.063 & $1,078.55$ & 761.44 \\
\hline \multicolumn{5}{|c|}{ Pre-birth employment status mother } \\
\hline full time employment & 0.866 & 0.020 & $6,513.53$ & 230.92 \\
\hline regular part-time & 0.667 & 0.031 & $3,132.86$ & 347.81 \\
\hline vocational training & 0.185 & 0.059 & $-1,744.62$ & 671.04 \\
\hline marginal part-time & 0.420 & 0.052 & 86.55 & 593.64 \\
\hline not employed & 0.383 & 0.020 & -251.62 & 230.17 \\
\hline \multicolumn{5}{|c|}{ Pre-birth employment status partner } \\
\hline full time employment & 0.678 & 0.017 & $3,787.71$ & 207.62 \\
\hline regular part-time & 0.737 & 0.108 & $3,925.66$ & $1,344.71$ \\
\hline vocational training & 0.429 & 0.178 & -664.71 & $2,215.43$ \\
\hline marginal part-time & 0.364 & 0.142 & -502.37 & $1,767.30$ \\
\hline not employed & 0.380 & 0.049 & -46.11 & 611.10 \\
\hline \multicolumn{5}{|l|}{ Education level mother } \\
\hline no education & 0.036 & 0.087 & $-2,913.54$ & $1,016.68$ \\
\hline low education & 0.340 & 0.036 & -541.25 & 422.68 \\
\hline medium education & 0.583 & 0.018 & $2,158.23$ & 209.09 \\
\hline high education & 0.816 & 0.025 & $6,056.43$ & 288.80 \\
\hline \multicolumn{5}{|l|}{ Education level partner } \\
\hline no education & 0.231 & 0.125 & -188.69 & $1,557.35$ \\
\hline low education & 0.452 & 0.049 & 959.43 & 612.66 \\
\hline medium education & 0.541 & 0.021 & $1,848.08$ & 260.68 \\
\hline high education & 0.841 & 0.024 & $6,112.60$ & 301.44 \\
\hline
\end{tabular}

Notes: The first column shows coefficients from a linear probability model regressing a dummy for a positive change in benefit amount on the set of possible characteristics for each category. The constant is omitted in all regressions. For example, for the category education level mother :

$\operatorname{prob}($ positive change $)=\beta_{1}$ no education $+\beta_{2}$ low education $+\beta_{3}$ medium education + $\beta_{4}$ high education $+u$.

The third column shows coefficients of exactly the same regressions but taking the absolute difference in overall benefit amounts (Elterngeld - Erziehungsgeld) as dependent variable. Standard errors are provided in italics. Significance on at least $10 \%$-level is indicated by bold numbers. 
Figure 2: Google Search Volume Index

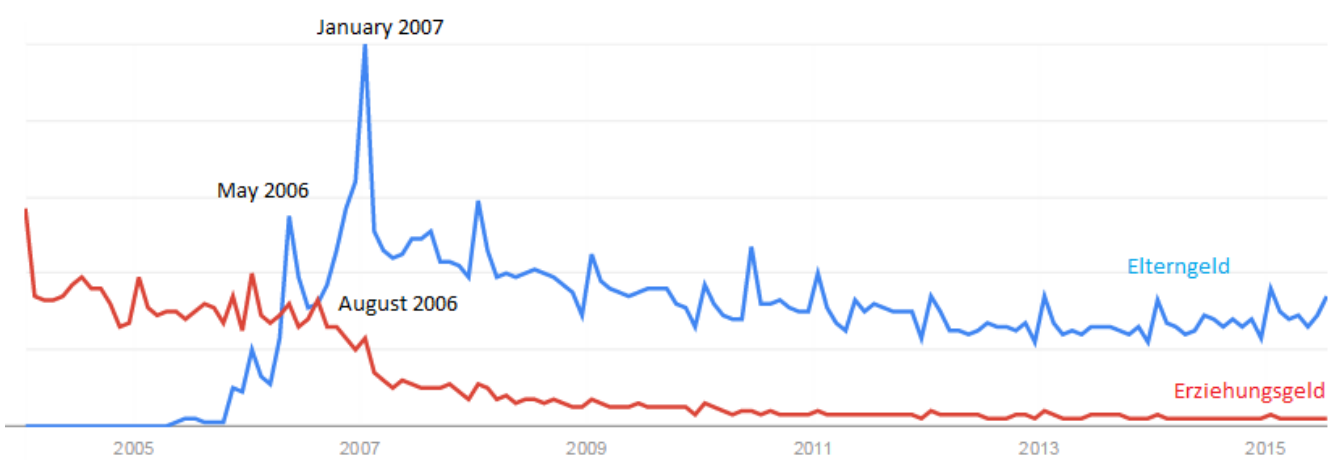

Notes: The trends do not show absolute search volume, but searches relative to the peak value in the graph. The red trend line shows searches for Erziehungsgeld, the blue line for Elterngeld.

Data Source: Google Trends (2015) 
Figure 3: Distribution of the indexes for 0-1-year-olds

Personality index

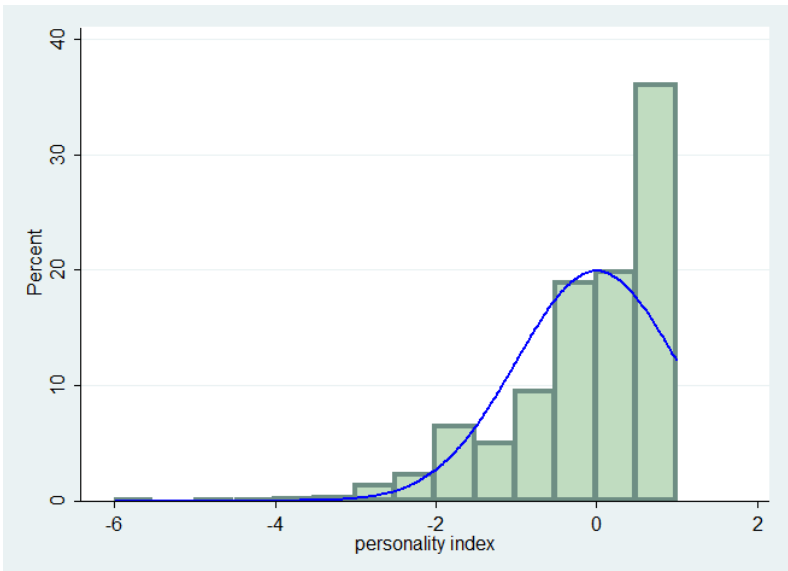

Placebo index

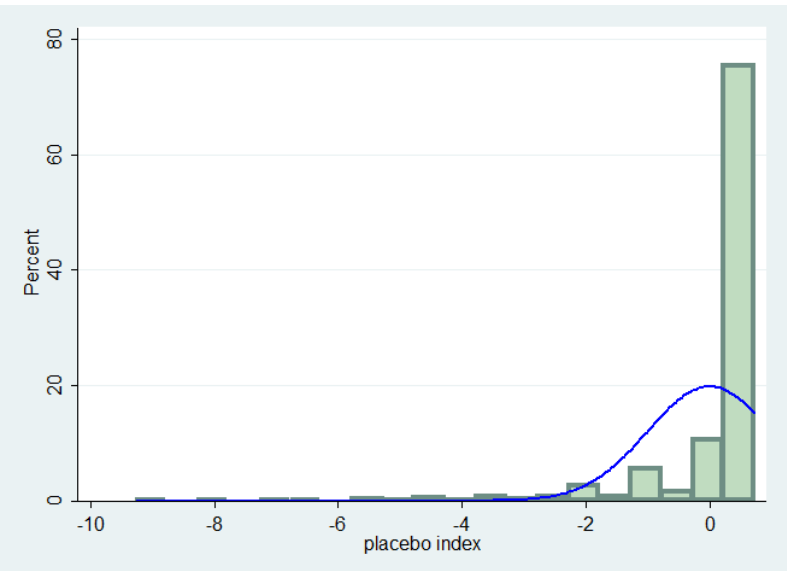

Development \& health index

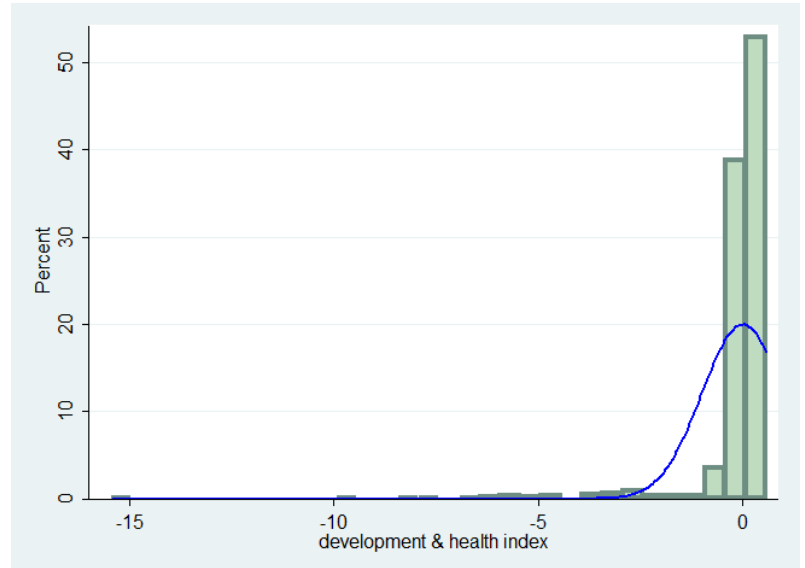

Notes: This figure shows the distribution of the $\mathrm{z}$-standardized indexes. The horizontal axis is scaled in standard deviations. Bin width is 0.5 standard deviations. 
Figure 4: Distribution of the indexes for 2-3-year-olds

Health index

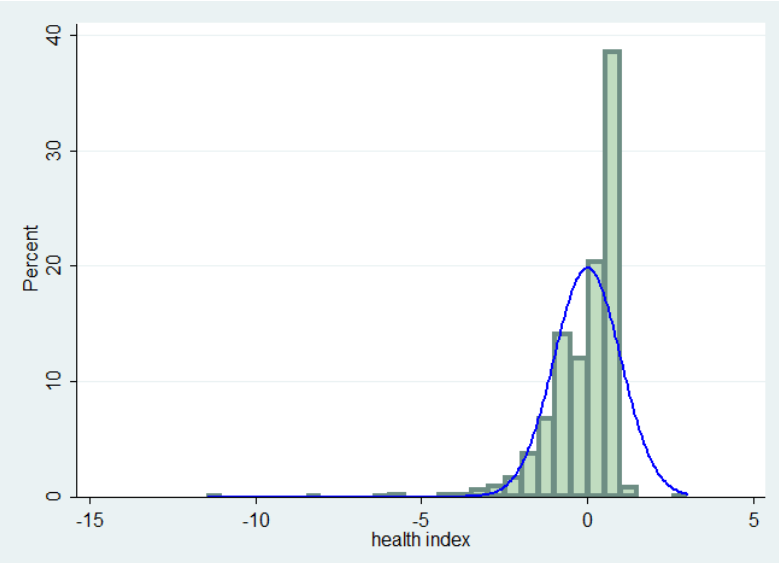

Personality index

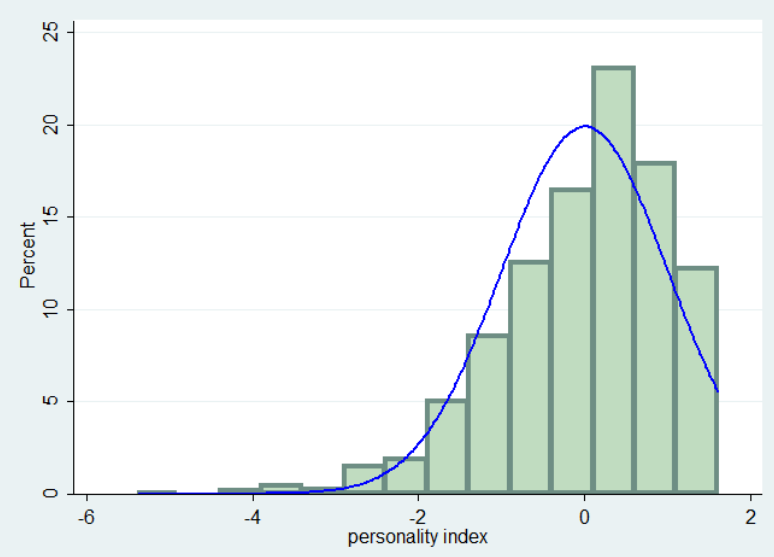

Motor ability index

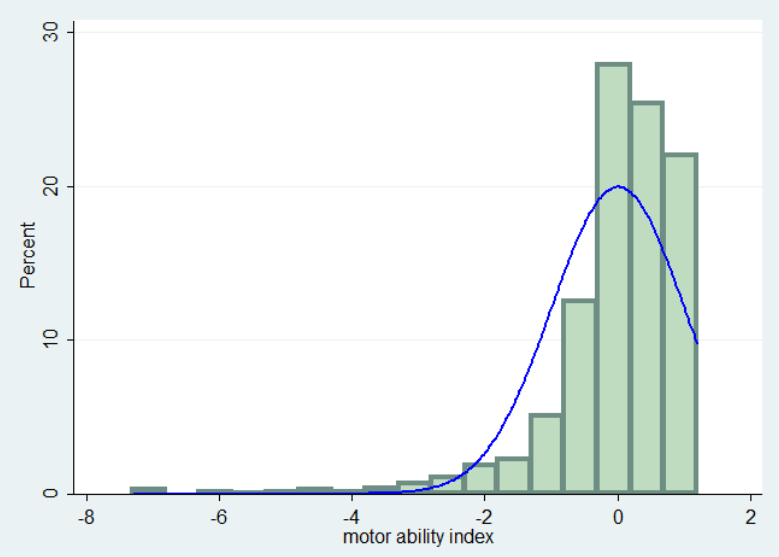

Behavior index

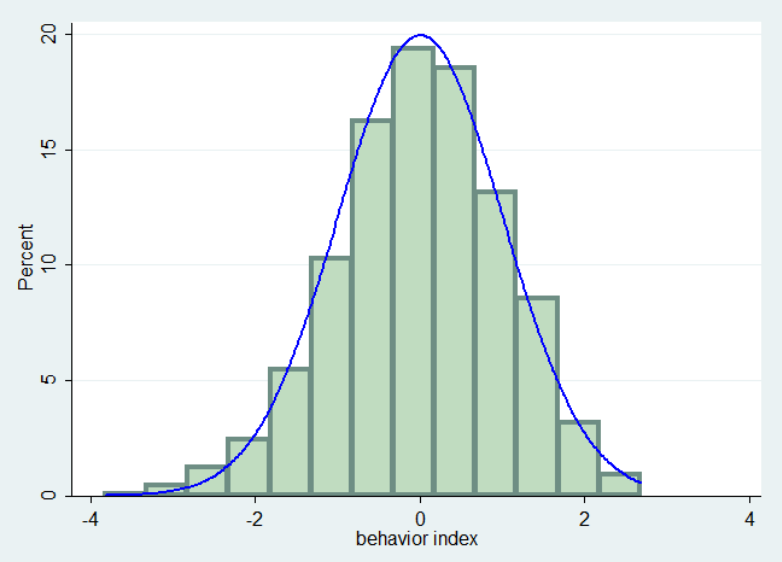

Language skills index

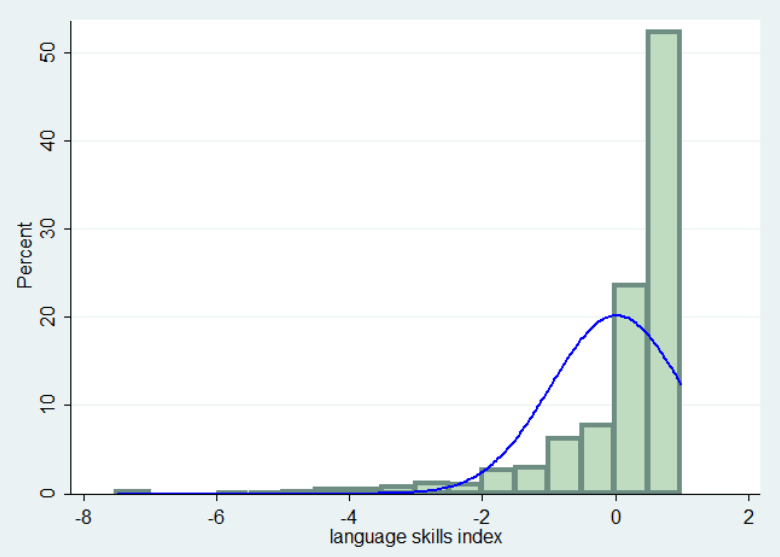

Basic life skills index

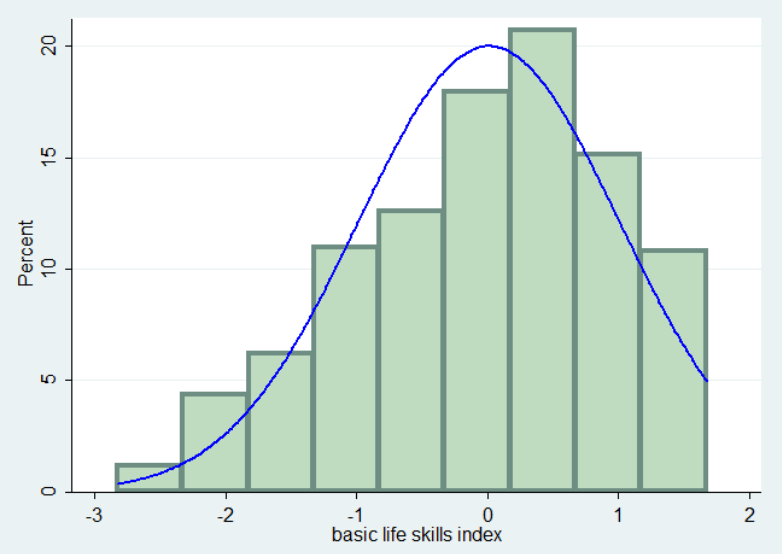

continued on next page 
Figure 4 continued from previous page

Social skills index

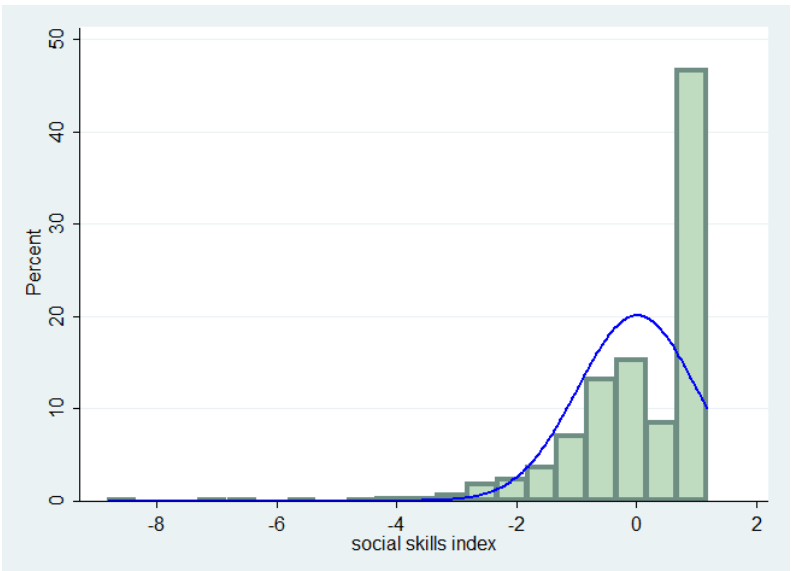

Skills index

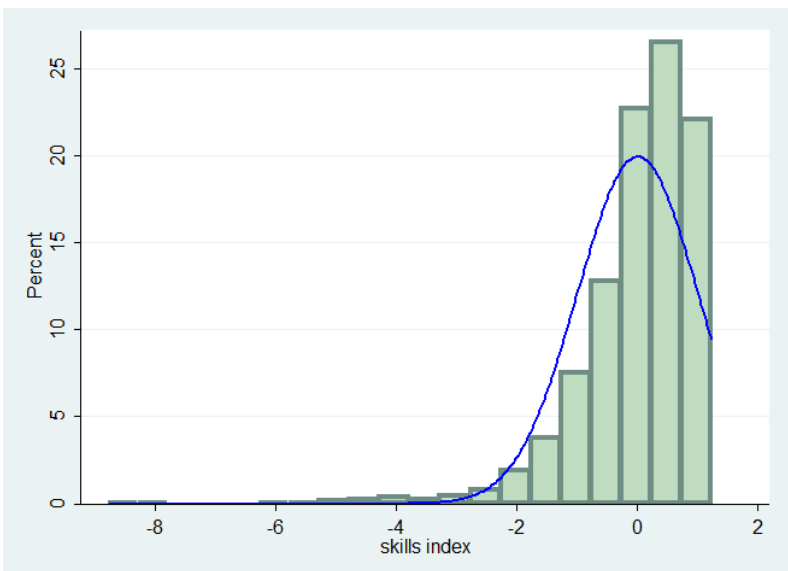

General well-being index

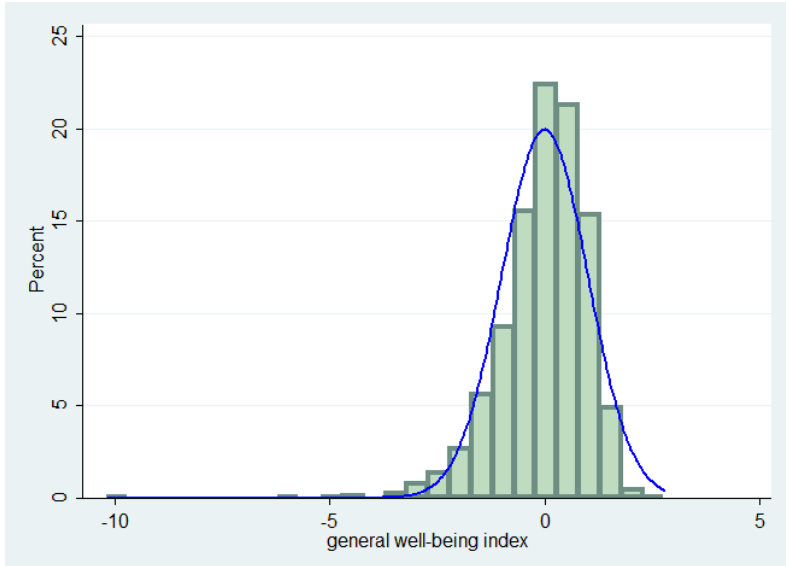

Notes: This figure shows the distribution of the $\mathrm{z}$-standardized indexes. The horizontal axis is scaled in standard deviations. Bin width is 0.5 standard deviations. 
Figure 5: Means of overall benefits by household income
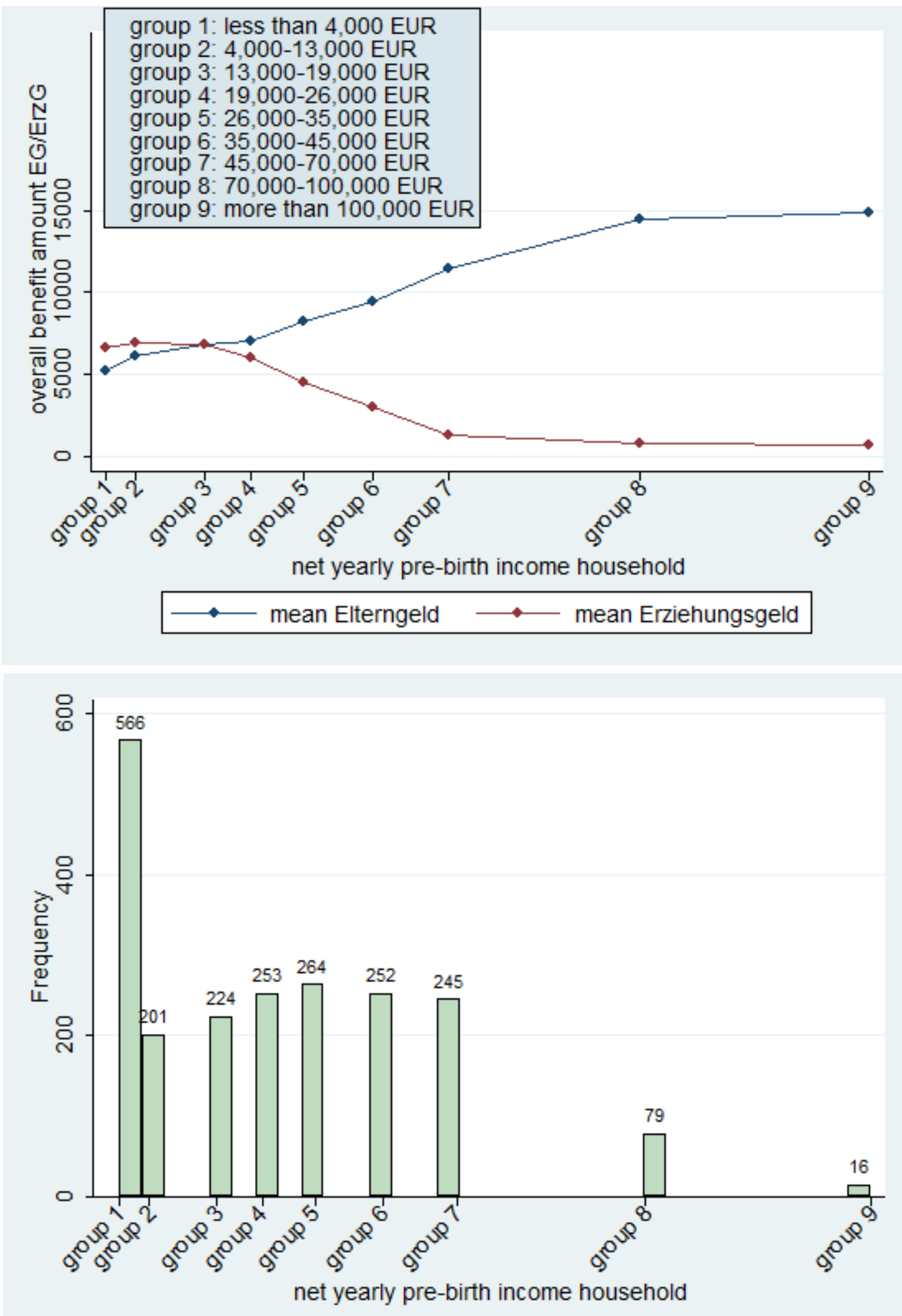

Notes: Depicted are the means of Elterngeld and Erziehungsgeld for different brackets of net yearly pre-birth income of the household. The lower panel shows the number of households in each income bracket. 
Table 3: Summary statistics control variables

\begin{tabular}{lccccc}
\hline & $\mathbf{N}$ & Mean & Std. Dev & Min & Max \\
\hline $\begin{array}{l}\text { Control variables 0-1-year-olds } \\
\text { child's age (in months) }\end{array}$ & 1923 & 6.937 & 3.835 & 0 & 23 \\
child's gender (male) & 1926 & 0.508 & 0.500 & 0 & 1 \\
n $^{\circ}$ older siblings at birth & 1921 & 0.831 & 1.047 & 0 & 11 \\
mother born in Germany & 1922 & 0.860 & 0.348 & 0 & 1 \\
mother no education & 1633 & 0.0227 & 0.149 & 0 & 1 \\
mother low education & 1633 & 0.119 & 0.324 & 0 & 1 \\
mother medium education & 1633 & 0.543 & 0.498 & 0 & 1 \\
mother high education & 1633 & 0.315 & 0.465 & 0 & 1 \\
familiy lives in East Germany & 1926 & 0.234 & 0.423 & 0 & 1 \\
& & & & & \\
\hline Control variables 2-3-year-olds & & & & & \\
child's age (in months) & 1481 & 33.303 & 3.910 & 26 & 45 \\
child's gender (male) & 1483 & 0.507 & 0.500 & 0 & 1 \\
$n^{\circ}$ older siblings at birth & 1400 & 0.765 & 1.026 & 0 & 11 \\
mother born in Germany & 1482 & 0.856 & 0.352 & 0 & 1 \\
mother no education & 1185 & 0.024 & 0.152 & 0 & 1 \\
mother low education & 1185 & 0.122 & 0.327 & 0 & 1 \\
mother medium education & 1185 & 0.549 & 0.498 & 0 & 1 \\
mother high education & 1185 & 0.306 & 0.461 & 0 & 1 \\
familiy lives in East Germany & 1483 & 0.229 & 0.420 & 0 & 1 \\
\hline
\end{tabular}

Notes: This table shows summary statistics on the control variables. The statistics are based on all available cohorts for each age group. The education levels are equivalent to the following ISCED categories: No education $=$ ISCED 0 or 1 , low education $=$ ISCED 2 , medium education $=$ ISCED 3 or 4, high education $=$ ISCED 5 or 6 . 
Table 4: Comparison of means dependent variables

\begin{tabular}{|c|c|c|c|c|c|c|c|}
\hline & \multicolumn{2}{|c|}{$2006 / 2007$} & \multicolumn{5}{|c|}{$2004 / 05,2005 / 06,2007 / 08$} \\
\hline & July-Dec. & Jan.-June & $\mathrm{RD}$ & July-Dec. & Jan.-June & seasonal effects & DiD \\
\hline & (1) & (2) & $\begin{array}{c}(3) \\
(2)-(1)\end{array}$ & (4) & (5) & $\begin{array}{c}(6) \\
(5)-(4)\end{array}$ & $\begin{array}{c}(7) \\
(3)-(6)\end{array}$ \\
\hline $\begin{array}{l}\text { 0-1-year-olds } \\
\text { placebo index }\end{array}$ & -0.150 & 0.052 & 0.202 & 0.075 & 0.021 & -0.054 & 0.256 \\
\hline personality index & 0.059 & -0.308 & $-0.366^{* *}$ & 0.090 & 0.129 & 0.039 & $-0.405^{* *}$ \\
\hline dev. \& health index & -0.133 & -0.055 & 0.078 & -0.033 & 0.004 & 0.037 & 0.041 \\
\hline $\mathrm{N}$ & 100 & 87 & & 327 & 398 & & \\
\hline 2-3-year-olds & & & & & & & \\
\hline health index & -0.079 & -0.181 & -0.102 & 0.080 & -0.071 & $-0.151 * *$ & 0.049 \\
\hline behavior index & -0.133 & -0.196 & -0.064 & 0.163 & -0.009 & $-0.172 * *$ & 0.108 \\
\hline personality index & -0.184 & 0.036 & 0.220 & 0.051 & 0.028 & -0.023 & 0.242 \\
\hline language index & -0.336 & 0.248 & $0.584 * * *$ & -0.035 & 0.167 & $0.202 * * *$ & $0.382 * *$ \\
\hline motor ability index & -0.371 & 0.246 & $0.617 * * *$ & -0.142 & 0.210 & $0.352 * * *$ & 0.265 \\
\hline basic life skills index & -0.273 & 0.447 & $0.720 * * *$ & -0.182 & 0.264 & $0.446 * * *$ & $0.274 *$ \\
\hline social skills index & -0.313 & 0.177 & $0.489 * * *$ & -0.041 & 0.179 & 0.220 & 0.269 \\
\hline general well-being & -0.183 & -0.156 & 0.027 & 0.128 & -0.031 & $-0.159 * *$ & 0.186 \\
\hline skills index & -0.431 & 0.373 & $0.805 * * *$ & -0.134 & 0.273 & $0.407 * * *$ & $0.397 * *$ \\
\hline $\mathrm{N}$ & 92 & 91 & & 320 & 296 & & \\
\hline
\end{tabular}

Notes: The first two columns give averages for children born in the first half of the 2006/2007 cohort (i.e. between July and December 2006) and for children born in the second half (i.e. January-June 2007). Columns (4) and (5) show averages for the control years respectively. Column (3) is the difference between column (2) and column (1) and thus represents a simple RD-estimator. Column (6) represents the pure seasonal effects between children born in the first half of a cohort and those born in the second half. Column (7) is then the difference between the RD-estimator and the seasonal effects - thus, the Diff-in-Diff-estimator on the raw data without any controls and the full time frame. ${ }^{*}$ indicates significance at $10 \%,{ }^{* *}$ indicates significance at $5 \%,{ }^{* * *}$ indicates significance at $1 \%$ level. 
Table 5: Baseline Diff-in-Diff, 0-1-year-olds

\begin{tabular}{|c|c|c|c|c|c|c|}
\hline \multirow[t]{2}{*}{ time frame: } & \multicolumn{2}{|c|}{ July-June } & \multicolumn{2}{|c|}{ July-June } & \multicolumn{2}{|c|}{ October-March } \\
\hline & (1) & (2) & (3) & (4) & $(5)$ & (6) \\
\hline \multicolumn{7}{|l|}{ Panel A: personality index } \\
\hline \multirow[t]{2}{*}{ reform } & $-0.392 * *$ & $-0.392 * *$ & $-0.388 * *$ & $-0.383^{*}$ & $-0.549 * *$ & $-0.513^{*}$ \\
\hline & 0.174 & 0.193 & 0.189 & 0.208 & 0.255 & 0.277 \\
\hline $\mathrm{N}$ & 816 & 695 & 694 & 589 & 392 & 327 \\
\hline \multicolumn{7}{|l|}{ Panel B: development \& health } \\
\hline \multirow[t]{2}{*}{ reform } & 0.042 & 0.042 & 0.282 & 0.319 & -0.060 & -0.046 \\
\hline & 0.188 & 0.209 & 0.186 & 0.206 & 0.298 & 0.354 \\
\hline $\mathrm{N}$ & 806 & 686 & 685 & 581 & 387 & 323 \\
\hline \multicolumn{7}{|l|}{ Panel C : placebo index } \\
\hline \multirow[t]{2}{*}{ reform } & 0.262 & 0.221 & 0.264 & 0.219 & 0.206 & 0.064 \\
\hline & 0.177 & 0.192 & 0.204 & 0.220 & 0.219 & 0.225 \\
\hline $\mathrm{N}$ & 817 & 696 & 695 & 590 & 392 & 327 \\
\hline socio-demographic controls & & $\mathrm{x}$ & & $\mathrm{x}$ & & $\mathrm{x}$ \\
\hline birth months FE & $\mathrm{x}$ & $\mathrm{x}$ & $\mathrm{x}$ & $\mathrm{x}$ & $\mathrm{x}$ & $\mathrm{x}$ \\
\hline Dec. 2006 \& Jan. 2007 births & $\mathrm{x}$ & $\mathrm{x}$ & & & $\mathrm{x}$ & $\mathrm{x}$ \\
\hline
\end{tabular}

Notes: All regressions show estimates of equation (1). Standard errors are clustered at mothers' person number (ID) and are reported in italics. Socio-demographic controls include the child's age at survey, a dummy for the child's gender, a dummy for migration background of the parents, dummies for the mother's pre-birth education level, number of siblings, and a dummy for living in East or West Germany. The control group consists of birth cohorts 2004/2005, 2005/2006 and 2007/2008, i.e. children born between July 2004 and June 2006 and between July 2007 and June 2008 for columns (1)-(4) and children born between October 2004 and March 2006 and between October 2007 and March 2008 for columns (5) and (6). In columns (3) and (4), children born in December 2006 and in January 2007 are excluded from the sample.

${ }^{*}$ indicates significance at $10 \%,{ }^{* *}$ indicates significance at $5 \%,{ }^{* * *}$ indicates significance at $1 \%$ level. Source: GSOEP 2003-2010 
Table 6: Heterogeneous effects by direction of change, 0 -1-year-olds

\begin{tabular}{|c|c|c|c|c|c|c|}
\hline \multirow[t]{2}{*}{ time frame: } & \multicolumn{2}{|c|}{ July-June } & \multicolumn{2}{|c|}{ July-June } & \multicolumn{2}{|c|}{ October-March } \\
\hline & (1) & $(2)$ & (3) & (4) & $(5)$ & (6) \\
\hline \multicolumn{7}{|l|}{ Panel A: personality index } \\
\hline \multirow[t]{2}{*}{ reform } & -0.493 & $-0.610^{*}$ & $-0.572 *$ & $-0.760 * *$ & -0.750 & $-0.936^{*}$ \\
\hline & 0.318 & 0.341 & 0.338 & 0.366 & 0.517 & 0.510 \\
\hline \multirow[t]{2}{*}{ reform $\mathrm{x}$ gain } & 0.146 & 0.347 & 0.272 & 0.601 & 0.334 & 0.694 \\
\hline & 0.381 & 0.412 & 0.408 & 0.442 & 0.599 & 0.600 \\
\hline $\mathrm{N}$ & 810 & 690 & 688 & 584 & 387 & 322 \\
\hline \multicolumn{7}{|l|}{ Panel B: development \& health } \\
\hline \multirow[t]{2}{*}{ reform } & 0.244 & 0.288 & 0.280 & 0.376 & 0.317 & 0.286 \\
\hline & 0.241 & 0.306 & 0.274 & 0.341 & 0.271 & 0.409 \\
\hline \multirow[t]{2}{*}{ reform $\mathrm{x}$ gain } & -0.340 & -0.427 & -0.049 & -0.150 & -0.584 & -0.602 \\
\hline & 0.346 & 0.408 & 0.367 & 0.434 & 0.497 & 0.630 \\
\hline $\mathrm{N}$ & 800 & 681 & 679 & 576 & 382 & 318 \\
\hline \multicolumn{7}{|l|}{ Panel C : placebo index } \\
\hline \multirow[t]{2}{*}{ reform } & 0.156 & 0.227 & 0.065 & 0.129 & -0.416 & -0.367 \\
\hline & 0.305 & 0.355 & 0.345 & 0.399 & 0.391 & 0.399 \\
\hline \multirow[t]{2}{*}{ reform $\mathrm{x}$ gain } & -0.017 & -0.186 & 0.120 & -0.032 & 0.702 & 0.449 \\
\hline & 0.350 & 0.402 & 0.399 & 0.455 & 0.460 & 0.507 \\
\hline $\mathrm{N}$ & 811 & 691 & 689 & 585 & 387 & 322 \\
\hline socio-demographic controls & & $\mathrm{x}$ & & $\mathrm{x}$ & & $\mathrm{x}$ \\
\hline birth months FE & $\mathrm{x}$ & $\mathrm{x}$ & $\mathrm{x}$ & $\mathrm{x}$ & $\mathrm{x}$ & $\mathrm{x}$ \\
\hline Dec. 2006 \& Jan. 2007 births & $\mathrm{x}$ & $\mathrm{x}$ & & & $\mathrm{x}$ & $\mathrm{x}$ \\
\hline
\end{tabular}

Notes: All regressions show estimates of equation (2). Standard errors are clustered at mothers' person number (ID) and are reported in italics. Socio-demographic controls include the child's age at survey, a dummy for the child's gender, a dummy for migration background of the parents, dummies for the mother's pre-birth education level, number of siblings, and a dummy for living in East or West Germany. The control group consists of birth cohorts 2004/2005, 2005/2006 and 2007/2008, i.e. children born between July 2004 and June 2006 and between July 2007 and June 2008 for columns (1)-(4) and children born between October 2004 and March 2006 and between October 2007 and March 2008 for columns (5) and (6). In columns (3) and (4), children born in December 2006 and in January 2007 are excluded from the sample.

${ }^{*}$ indicates significance at $10 \%,{ }^{* *}$ indicates significance at $5 \%,{ }^{* * *}$ indicates significance at $1 \%$ level. Source: GSOEP 2003-2010 
Table 7: Predicted reform effects on 0-1-year-olds by amount of change in benefits

\section{personality index}

\begin{tabular}{cc}
\hline amount of change & \\
$-3,768$ EUR & -0.557 \\
$-2,000$ EUR & -0.518 \\
$-1,000$ EUR & -0.496 \\
0 EUR & -0.474 \\
1,000 EUR & -0.452 \\
2,000 EUR & -0.430 \\
2,850 EUR & -0.411 \\
5,000 EUR & -0.364 \\
10,000 EUR & -0.254 \\
21,857 EUR & 0.007 \\
23,760 EUR & 0.049 \\
\hline
\end{tabular}

Notes: This table shows the reform effect for different amounts of change in overall benefits as predicted from equation (3), i.e. $\left(\beta_{2} \times\right.$ amount of change $\left.+\beta_{1}\right)$. The predictions are based on values for $\beta_{1}$ and $\beta_{2}$ as estimated in table A4, column (2) i.e. time frame July-June and including both birth months fixed effects and socio-demographic controls. 
Table 8: Pseudo-reform effects, 0-1-year-olds

\begin{tabular}{lcc}
\hline \multicolumn{2}{c}{ Dependent Variables } \\
& personality index & development \& health index \\
\hline Panel A: equation (1) & & \\
reform & 0.164 & 0.164 \\
& 0.166 & 0.192 \\
$\mathrm{~N}$ & 580 & 572 \\
\hline Panel B: equation (2) & & \\
reform & 0.324 & 0.063 \\
& 0.300 & 0.329 \\
reform x gain & -0.263 & 0.101 \\
& 0.363 & 0.405 \\
$\mathrm{~N}$ & 576 & 568 \\
\hline Panel C: equation (3) & & \\
reform & 0.161 & 0.162 \\
& 0.201 & 0.221 \\
reform x change & 0.001 & -0.003 \\
& 0.027 & 0.023 \\
$\mathrm{~N}$ & 576 & 568 \\
\hline birth months FE & $\mathrm{x}$ & $\mathrm{x}$ \\
socio-demographic controls & $\mathrm{x}$ & $\mathrm{x}$ \\
\hline
\end{tabular}

Notes: Panel A shows estimates of equation (1), Panel B of equation (2), Panel C of equation (3). Standard errors are clustered at mothers' person number (ID) and are reported in italics. Socio-demographic controls include the child's age at survey, a dummy for the child's gender, a dummy for migration background of the parents, dummies for the mother's pre-birth education level, number of siblings, and a dummy for living in East or West Germany. The control group consists of children born between July 2003 and June 2005 i.e. birth cohorts $2003 / 2004$ and 2004/2005. The pseudo-reform is assumed to take place on January 1st, 2006 , i.e. the cohort 2005/2006 represents the pseudo-treatment group. ${ }^{*}$ indicates significance at $10 \%,{ }^{* *}$ indicates significance at $5 \%,{ }^{* * *}$ indicates significance at $1 \%$ level. Source: GSOEP 2003-2010 
Table 9: Baseline Diff-in-Diff, 2-3-year-olds

\begin{tabular}{|c|c|c|c|c|c|c|}
\hline \multirow[t]{2}{*}{ time frame: } & \multicolumn{2}{|c|}{ July-June } & \multicolumn{2}{|c|}{ July-June } & \multicolumn{2}{|c|}{ October-March } \\
\hline & (1) & (2) & (3) & (4) & (5) & (6) \\
\hline $\begin{array}{l}\text { Panel A: health index } \\
\text { reform }\end{array}$ & $\begin{array}{l}0.055 \\
0.219\end{array}$ & $\begin{array}{r}-0.097 \\
0.250\end{array}$ & $\begin{array}{l}0.076 \\
0.241\end{array}$ & $\begin{array}{r}-0.062 \\
0.278\end{array}$ & $\begin{array}{l}0.372 \\
0.352\end{array}$ & $\begin{array}{l}0.234 \\
0.412\end{array}$ \\
\hline $\mathrm{N}$ & 800 & 602 & 686 & 513 & 374 & 285 \\
\hline $\begin{array}{l}\text { Panel B: behavior index } \\
\text { reform }\end{array}$ & $\begin{array}{c}0.089 \\
0.177 \\
795\end{array}$ & $\begin{array}{c}0.105 \\
0.206 \\
599\end{array}$ & $\begin{array}{c}0.173 \\
0.193 \\
681\end{array}$ & $\begin{array}{c}0.119 \\
0.224 \\
510\end{array}$ & $\begin{array}{c}-0.195 \\
0.264 \\
374\end{array}$ & $\begin{array}{c}-0.073 \\
0.313 \\
285\end{array}$ \\
\hline $\begin{array}{l}\text { Panel C: personality index } \\
\text { reform }\end{array}$ & $\begin{array}{c}0.236 \\
0.177 \\
800\end{array}$ & $\begin{array}{c}0.186 \\
0.205 \\
602\end{array}$ & $\begin{array}{c}0.279 \\
0.196 \\
686\end{array}$ & $\begin{array}{c}0.209 \\
0.226 \\
513\end{array}$ & $\begin{array}{c}-0.060 \\
0.264 \\
374\end{array}$ & $\begin{array}{c}-0.096 \\
0.319 \\
285\end{array}$ \\
\hline $\begin{array}{l}\text { Panel D: general well-being } \\
\text { reform }\end{array}$ & $\begin{array}{c}0.180 \\
0.203 \\
800\end{array}$ & $\begin{array}{c}0.069 \\
0.235 \\
602\end{array}$ & $\begin{array}{c}0.243 \\
0.224 \\
686\end{array}$ & $\begin{array}{c}0.106 \\
0.258 \\
513\end{array}$ & $\begin{array}{c}0.129 \\
0.129 \\
374\end{array}$ & $\begin{array}{c}0.069 \\
0.392 \\
285\end{array}$ \\
\hline $\begin{array}{l}\text { Panel E: language skills } \\
\text { reform } \\
\mathrm{N}\end{array}$ & $\begin{array}{c}0.379 * * \\
0.175 \\
799\end{array}$ & $\begin{array}{c}0.348^{*} \\
0.202 \\
601\end{array}$ & $\begin{array}{c}0.482 * * \\
0.197 \\
685\end{array}$ & $\begin{array}{c}0.468 * * \\
0.224 \\
512\end{array}$ & $\begin{array}{c}0.090 \\
0.250 \\
374\end{array}$ & $\begin{array}{c}0.101 \\
0.309 \\
285\end{array}$ \\
\hline $\begin{array}{l}\text { Panel F: motor ability } \\
\text { reform }\end{array}$ & $\begin{array}{c}0.250 \\
0.184 \\
800\end{array}$ & $\begin{array}{c}0.213 \\
0.205 \\
602\end{array}$ & $\begin{array}{c}0.299 \\
0.199 \\
686\end{array}$ & $\begin{array}{c}0.299 \\
0.231 \\
513\end{array}$ & $\begin{array}{c}0.183 \\
0.278 \\
374\end{array}$ & $\begin{array}{c}0.201 \\
0.310 \\
285\end{array}$ \\
\hline $\begin{array}{l}\text { socio-demographic controls } \\
\text { birth months FE } \\
\text { Dec. } 2006 \text { \& Jan. } 2007 \text { births }\end{array}$ & $\begin{array}{l}\mathrm{X} \\
\mathrm{X}\end{array}$ & $\begin{array}{l}\mathrm{X} \\
\mathrm{X} \\
\mathrm{X}\end{array}$ & $\mathrm{X}$ & $\begin{array}{l}\mathrm{x} \\
\mathrm{x}\end{array}$ & $\begin{array}{l}\mathrm{X} \\
\mathrm{X}\end{array}$ & $\begin{array}{l}\mathrm{x} \\
\mathrm{x} \\
\mathrm{x}\end{array}$ \\
\hline
\end{tabular}


Table 9 continued from previous page

\begin{tabular}{lcccccc}
\hline time frame: & \multicolumn{2}{c}{ July-June } & \multicolumn{2}{c}{ July-June } & \multicolumn{2}{c}{ October-March } \\
& $(1)$ & $(2)$ & $(3)$ & $(4)$ & $(5)$ & $(6)$ \\
\hline Panel G: basic life skills & & & & & & \\
reform & $0.253^{*}$ & 0.250 & $0.328^{* *}$ & 0.260 & 0.078 & 0.295 \\
& 0.155 & 0.168 & 0.165 & 0.177 & 0.219 & 0.250 \\
$\mathrm{~N}$ & 799 & 601 & 685 & 512 & 374 & 285 \\
\hline Panel H: social skills & & & & & & \\
reform & 0.255 & 0.113 & $0.318^{*}$ & 0.174 & -0.003 & -0.098 \\
& 0.176 & 0.203 & 0.193 & 0.220 & 0.284 & 0.356 \\
$\mathrm{~N}$ & 799 & 601 & 685 & 512 & 374 & 285 \\
\hline Panel I: skills index & & & & & & \\
reform & $0.380^{* * *}$ & 0.312 & $0.476^{* *}$ & $0.405^{*}$ & 0.119 & 0.172 \\
& 0.179 & 0.205 & 0.199 & 0.228 & 0.273 & 0.327 \\
$\mathrm{~N}$ & 800 & 602 & 686 & 513 & 374 & 285 \\
\hline socio-demographic controls & & $\mathrm{x}$ & & $\mathrm{x}$ & & $\mathrm{x}$ \\
birth months FE & $\mathrm{x}$ & $\mathrm{x}$ & $\mathrm{x}$ & $\mathrm{x}$ & $\mathrm{x}$ & $\mathrm{x}$ \\
Dec. 2006 \& Jan. 2007 births & $\mathrm{x}$ & $\mathrm{x}$ & & & $\mathrm{x}$ & $\mathrm{x}$ \\
\hline
\end{tabular}

Notes: All regressions show estimates of equation (1). Standard errors are clustered at mothers' person number (ID) and are reported in italics. Socio-demographic controls include the child's age at survey, a dummy for the child's gender, a dummy for migration background of the parents, dummies for the mother's pre-birth education level, number of siblings, and a dummy for living in East or West Germany. The control group consists of birth cohorts 2004/2005, 2005/2006 and 2007/2008, i.e. children born between July 2004 and June 2006 and between July 2007 and June 2008 for columns (1)-(4) and children born between October 2004 and March 2006 and between October 2007 and March 2008 for columns (5) and (6). In columns (3) and (4), children born in December 2006 and in January 2007 are excluded from the sample.

${ }^{*}$ indicates significance at $10 \%,{ }^{* *}$ indicates significance at $5 \%,{ }^{* * *}$ indicates significance at $1 \%$ level. Source: GSOEP 2003-2010 
Table 10: Heterogeneous effects by direction of change, 2-3-year-olds

\begin{tabular}{|c|c|c|c|c|c|c|}
\hline \multirow[t]{2}{*}{ time frame: } & \multicolumn{2}{|c|}{ July-June } & \multicolumn{2}{|c|}{ July-June } & \multicolumn{2}{|c|}{ October-March } \\
\hline & (1) & (2) & (3) & (4) & (5) & (6) \\
\hline \multicolumn{7}{|l|}{ Panel A: health index } \\
\hline \multirow[t]{2}{*}{ reform } & -0.359 & -0.594 & -0.478 & -0.660 & 0.145 & -0.448 \\
\hline & 0.399 & 0.432 & 0.437 & 0.474 & 0.434 & 0.353 \\
\hline \multirow[t]{2}{*}{ reform $\mathrm{x}$ gain } & 0.609 & 0.786 & 0.822 & 0.992 & 0.380 & 0.997 \\
\hline & 0.510 & 0.563 & 0.567 & 0.635 & 0.667 & 0.751 \\
\hline $\mathrm{N}$ & 753 & 601 & 641 & 512 & 362 & 285 \\
\hline \multicolumn{7}{|l|}{ Panel B: behavior index } \\
\hline \multirow[t]{2}{*}{ reform } & -0.009 & -0.075 & 0.168 & 0.033 & $-0.739 * *$ & $-0.778^{*}$ \\
\hline & 0.270 & 0.303 & 0.288 & 0.317 & 0.374 & 0.418 \\
\hline \multirow[t]{2}{*}{ reform $x$ gain } & 0.222 & 0.344 & 0.087 & 0.204 & 0.860 & $1.049 *$ \\
\hline & 0.369 & 0.403 & 0.403 & 0.433 & 0.527 & 0.597 \\
\hline $\mathrm{N}$ & 750 & 598 & 638 & 509 & 362 & 285 \\
\hline \multicolumn{7}{|l|}{ Panel C: personality index } \\
\hline \multirow[t]{2}{*}{ reform } & 0.127 & 0.034 & 0.182 & 0.007 & -0.388 & -0.565 \\
\hline & 0.283 & 0.322 & 0.298 & 0.347 & 0.439 & 0.487 \\
\hline \multirow[t]{2}{*}{ reform $x$ gain } & 0.171 & 0.253 & 0.158 & 0.343 & 0.492 & 0.751 \\
\hline & 0.371 & 0.409 & 0.403 & 0.446 & 0.568 & 0.647 \\
\hline $\mathrm{N}$ & 753 & 601 & 641 & 512 & 362 & 285 \\
\hline \multicolumn{7}{|l|}{ Panel D: general well-being } \\
\hline \multirow[t]{2}{*}{ reform } & -0.156 & -0.366 & -0.142 & -0.384 & -0.353 & $-0.810 * *$ \\
\hline & 0.307 & 0.353 & 0.325 & 0.375 & 0.396 & 0.366 \\
\hline \multirow[t]{2}{*}{ reform $x$ gain } & 0.525 & 0.714 & 0.602 & 0.837 & 0.761 & $1.323 *$ \\
\hline & 0.431 & 0.483 & 0.474 & 0.533 & 0.629 & 0.714 \\
\hline $\mathrm{N}$ & 753 & 601 & 641 & 512 & 362 & 285 \\
\hline \multicolumn{7}{|l|}{ Panel E: language skills } \\
\hline \multirow[t]{2}{*}{ reform } & 0.191 & 0.019 & 0.214 & 0.003 & -0.461 & -0.628 \\
\hline & 0.276 & 0.321 & 0.303 & 0.345 & 0.311 & 0.383 \\
\hline \multirow[t]{2}{*}{ reform $x$ gain } & 0.316 & 0.524 & 0.454 & $0.746^{*}$ & $0.965 * *$ & $1.145^{*}$ \\
\hline & 0.356 & 0.408 & 0.398 & 0.444 & 0.468 & 0.585 \\
\hline $\mathrm{N}$ & 752 & 600 & 640 & 511 & 362 & 285 \\
\hline \multicolumn{7}{|l|}{ Panel F: motor ability } \\
\hline \multirow[t]{2}{*}{ reform } & 0.106 & 0.080 & 0.086 & 0.029 & 0.021 & 0.051 \\
\hline & 0.277 & 0.310 & 0.309 & 0.338 & 0.293 & 0.363 \\
\hline \multirow[t]{2}{*}{ reform $x$ gain } & 0.161 & 0.200 & 0.246 & 0.446 & 0.202 & 0.170 \\
\hline & 0.390 & 0.420 & 0.429 & 0.463 & 0.504 & 0.602 \\
\hline $\mathrm{N}$ & 753 & 601 & 641 & 512 & 362 & 285 \\
\hline socio-demographic controls & & $\mathrm{x}$ & & $\mathrm{x}$ & & $\mathrm{x}$ \\
\hline birth months FE & $\mathrm{x}$ & $\mathrm{x}$ & $\mathrm{x}$ & $\mathrm{x}$ & $\mathrm{x}$ & $\mathrm{x}$ \\
\hline Dec. 2006 \& Jan. 2007 births & $\mathrm{x}$ & $\mathrm{x}$ & & & $\mathrm{x}$ & $\mathrm{x}$ \\
\hline
\end{tabular}


Table 10 continued from previous page

\begin{tabular}{lcccccc}
\hline time frame: & \multicolumn{2}{c}{ July-June } & \multicolumn{2}{c}{ July-June } & \multicolumn{2}{c}{ October-March } \\
& $(1)$ & $(2)$ & $(3)$ & $(4)$ & $(5)$ & $(6)$ \\
\hline Panel G: basic life skills & & & & & & \\
reform & 0.390 & 0.193 & 0.298 & 0.213 & 0.076 & 0.182 \\
& 0.251 & 0.263 & 0.271 & 0.282 & 0.336 & 0.369 \\
reform x gain & -0.070 & 0.114 & 0.002 & 0.117 & -0.021 & 0.143 \\
& 0.332 & 0.336 & 0.359 & 0.359 & 0.449 & 0.481 \\
N & 752 & 600 & 640 & 511 & 362 & 285 \\
\hline Panel H: social skills & & & & & & \\
reform & -0.030 & -0.090 & -0.047 & -0.115 & $-0.584 *$ & $-0.787 * *$ \\
& 0.260 & 0.295 & 0.282 & 0.323 & 0.335 & 0.388 \\
reform x gain & 0.399 & 0.346 & 0.513 & 0.503 & $0.956^{*}$ & 1.085 \\
& 0.367 & 0.411 & 0.401 & 0.453 & 0.532 & 0.665 \\
N & 752 & 600 & 640 & 511 & 362 & 285 \\
\hline Panel I: skills index & & & & & & \\
reform & 0.182 & 0.073 & 0.189 & 0.050 & -0.305 & -0.379 \\
& 0.271 & 0.301 & 0.298 & 0.330 & 0.305 & 0.329 \\
reform x gain & 0.262 & 0.390 & 0.398 & 0.600 & 0.688 & 0.833 \\
& 0.376 & 0.414 & 0.419 & 0.458 & 0.502 & 0.606 \\
N & 753 & 601 & 641 & 512 & 362 & 285 \\
\hline socio-demographic controls & & $\mathrm{x}$ & & $\mathrm{x}$ & & $\mathrm{x}$ \\
birth months FE & $\mathrm{x}$ & $\mathrm{x}$ & $\mathrm{x}$ & $\mathrm{x}$ & $\mathrm{x}$ & $\mathrm{x}$ \\
Dec. 2006 \& Jan. 2007 births & $\mathrm{x}$ & $\mathrm{x}$ & & & $\mathrm{x}$ & $\mathrm{x}$ \\
\hline & & & & & &
\end{tabular}

Notes: All regressions show estimates of equation (2). Standard errors are clustered at mothers' person number (ID) and are reported in italics. Socio-demographic controls include the child's age at survey, a dummy for the child's gender, a dummy for migration background of the parents, dummies for the mother's pre-birth education level, number of siblings, and a dummy for living in East or West Germany. The control group consists of birth cohorts 2004/2005, 2005/2006 and 2007/2008, i.e. children born between July 2004 and June 2006 and between July 2007 and June 2008 for columns (1)-(4) and children born between October 2004 and March 2006 and between October 2007 and March 2008 for columns (5) and (6). In columns (3) and (4), children born in December 2006 and in January 2007 are excluded from the sample. ${ }^{*}$ indicates significance at $10 \%,{ }^{* *}$ indicates significance at $5 \%$, *** indicates significance at 1\% level. Source: GSOEP 2003-2010 
Table 11: Predicted reform effects on 2-3-year-olds by amount of change in benefits

language skills basic life skills

\begin{tabular}{ccc}
\hline amount of change & & \\
$-3,768$ & 0.143 & 0.244 \\
$-2,000$ & 0.194 & 0.244 \\
$-1,000$ & 0.223 & 0.244 \\
0 & 0.252 & 0.244 \\
1,000 & 0.281 & 0.244 \\
2,000 & 0.310 & 0.244 \\
2,850 & 0.335 & 0.244 \\
5,000 & 0.397 & 0.244 \\
10,000 & 0.542 & 0.244 \\
21,857 & 0.886 & 0.244 \\
23,760 & 0.941 & 0.244 \\
\hline
\end{tabular}

Notes: This table shows the reform effect for different amounts of change in overall benefits as predicted from equation (3), i.e. $\left(\beta_{2} \times\right.$ amount of change $\left.+\beta_{1}\right)$. The predictions are based on values for $\beta_{1}$ and $\beta_{2}$ as estimated in table A6, column (2) i.e. time frame July-June and including both birth months fixed effects and socio-demographic controls. 
Table 12: Pseudo-reform effects, 2-3-year-olds

Dependent variables

\begin{tabular}{|c|c|c|c|c|c|c|c|c|c|}
\hline & health & behavior & personality & gen. well-being & language skills & motor ability & basic life skills & social skills & skills index \\
\hline \multicolumn{10}{|l|}{ Panel A: equation (1) } \\
\hline \multirow[t]{2}{*}{ reform } & 0.010 & $-0.374 * *$ & 0.078 & -0.081 & -0.146 & 0.279 & -0.143 & -0.132 & -0.041 \\
\hline & 0.180 & 0.187 & 0.192 & 0.179 & 0.182 & 0.191 & 0.179 & 0.177 & 0.172 \\
\hline $\mathrm{N}$ & 506 & 504 & 506 & 506 & 505 & 506 & 505 & 505 & 506 \\
\hline \multicolumn{10}{|l|}{ Panel B: equation (2) } \\
\hline \multirow[t]{2}{*}{ reform } & -0.354 & $-0.884 * * *$ & -0.167 & $-0.592 * *$ & -0.373 & 0.019 & -0.474 & -0.135 & -0.318 \\
\hline & 0.257 & 0.318 & 0.333 & 0.284 & 0.316 & 0.274 & 0.315 & 0.312 & 0.291 \\
\hline \multirow[t]{2}{*}{ reform $x$ gain } & 0.570 & $0.786^{* *}$ & 0.370 & $0.789 * *$ & 0.332 & 0.424 & 0.508 & 0.000 & 0.428 \\
\hline & 0.348 & 0.391 & 0.385 & 0.347 & 0.362 & 0.361 & 0.382 & 0.361 & 0.343 \\
\hline $\mathrm{N}$ & 505 & 503 & 505 & 505 & 504 & 505 & 504 & 504 & 505 \\
\hline \multicolumn{10}{|l|}{ Panel C: equation (3) } \\
\hline \multirow[t]{2}{*}{ reform } & -0.257 & $-0.662 * * *$ & -0.070 & $-0.411^{* *}$ & -0.215 & 0.162 & -0.255 & -0.164 & -0.151 \\
\hline & 0.200 & 0.219 & 0.227 & 0.199 & 0.200 & 0.200 & 0.215 & 0.205 & 0.190 \\
\hline \multirow[t]{2}{*}{ reform $x$ change } & $0.067 * * *$ & $0.076 * * *$ & 0.042 & $0.087 * * *$ & 0.017 & 0.028 & 0.030 & 0.005 & 0.027 \\
\hline & 0.024 & 0.029 & 0.029 & 0.027 & 0.025 & 0.031 & 0.030 & 0.028 & 0.026 \\
\hline $\mathrm{N}$ & 505 & 503 & 505 & 505 & 504 & 505 & 504 & 504 & 505 \\
\hline \multirow{2}{*}{$\begin{array}{l}\text { birth months FE } \\
\text { socio-demogr. controls }\end{array}$} & $\mathrm{x}$ & $\mathrm{x}$ & $\mathrm{x}$ & $\mathrm{x}$ & $\mathrm{x}$ & $\mathrm{x}$ & $\mathrm{x}$ & $\mathrm{x}$ & $\mathrm{x}$ \\
\hline & $\mathrm{x}$ & $\mathrm{x}$ & $\mathrm{x}$ & $\mathrm{x}$ & $\mathrm{x}$ & $\mathrm{x}$ & $\mathrm{x}$ & $\mathrm{x}$ & $\mathrm{x}$ \\
\hline
\end{tabular}

Notes: Panel A shows estimates of equation (1), Panel B of equation (2), Panel C of equation (3). Standard errors are clustered at mothers' person number (ID) and are reported in italics. Socio-demographic controls include the child's age at survey, a dummy for the child's gender, a dummy for migration background of the parents, dummies for the mother's pre-birth education level, number of siblings, and a dummy for living in East or West Germany. The control group consists of children born between July 2003 and June 2005 i.e. birth cohorts $2003 / 2004$ and 2004/2005. The pseudo-reform is assumed to take place on January 1st, 2006, i.e. the cohort 2005/2006 represents the pseudo-treatment group.

${ }^{*}$ indicates significance at $10 \%,{ }^{* *}$ indicates significance at 5\%, ${ }^{* * *}$ indicates significance at $1 \%$ level. Source: GSOEP 2003-2010 


\section{A Appendix}

\section{A.1 Eligibility and calculation of the benefit amount under both regulations}

\section{Erziehungsgeld (up to 2007):}

Eligibility for Erziehungsgeld in the first year after a child's birth was determined by both parents' income in the calendar year before birth $^{63}$. If a mother was not employed while she received Erziehungsgeld, only her partner's pre-birth income was considered (see BMFSFJ, 2005). To calculate gross yearly income, I include income from wages, self-employment and second jobs. According to $\S 2$ Einkommensteuergesetz (personal income tax code), income from renting, interest or dividends would also be relevant for income calculation. In my sample however, 94\% of households do not have any income from renting at all, and if they have its contribution to Erziehungsgeld-relevant income is quite low (lower than $10 \%$ for $45 \%$ of the households). $89 \%$ of the households do not have any income from interest or dividends neither and if they have its contribution is below $10 \%$ for $75 \%$ of the households. For that reason and for simplicity, I concentrate only on labor income. To approximate net income, some standard deductions ${ }^{64}$ were taken into account. Income from part-time employment while receiving any benefits was also considered and reduced the probability to be eligible as well as the benefit amount.

Based on the pre-birth income of the partner and potential additional income from maternal part-time employment, eligibility for the first year can be determined. Parents were eligible if they had a yearly net income of no more than 30,000 EUR (or 23,000 EUR for singles). For every additional child living in the household, income was allowed to rise by 3,140 EUR. This rule applied for the first six months after a child's birth - afterwards, parents only received the full amount, if they did not earn more than 16,500 EUR (or 13,400 EUR for singles) plus the additional bonus per child. If income exceeded this amount, benefits were reduced by $5.2 \%$ of the income, that was higher than the threshold. Having information on the number of children living in the household, on the income relevant for benefit calculation and on each mother's

\footnotetext{
${ }^{63} \mathrm{~A}$ calendar year is by law defined as the time between January 1st and December 31 st of a given year. Thus, even if a child was born on December 30th 2006, the income from January to December 2005 was the income relevant for eligibility.

${ }^{64}$ As I do not have information on each individual's Werbungskosten (income-related expenses), I assume the minimum deductible amount of - at that time - 920 EUR; Moreover 24\% (or 19\% for civil servants) of gross income are deducted, as well as unemployment benefits.
} 
partner, I can determine whether the mother was eligible for the full amount of Erziehungsgeld, whether she received the full amount in the first six months and less thereafter or whether she was not eligible at all.

I repeat this procedure for eligibility in the second year, which was given by the partner's income in the calendar year of the child's birth and by the mother's income while receiving benefits. The respective eligibility status for Erziehungsgeld is then assigned to each observation in the sample, independent from the child's true birth date, because I want to investigate for which amount each family would qualify under both regulations. I thus calculate the benefit each family would get according to their income, number of children and marital status, considering that the benefit amount was possibly reduced after month 6 and that it was not possible to receive less than 10 EUR per month.

For the years preceding 2004, the calculation slightly differed, since standard deductions amounted to 1044 EUR and $27 \%$ (or $22 \%$ for civil servants) of gross income. Eligibility thresholds were also slightly higher than thereafter. As this change for the 2003/2004 cohort could also have induced some minor impact on children's well-being, I prefer to use control groups born after 2004 who should then all be subject to the same eligibility rules.

To check the quality of my calculations, I compare them with the variable „maternity allowance during maternity leave (Mutterschaftsgeld), parental allowance (Elterngeld), childraising allowance (Erziehungsgeld)“ which is provided in the GSOEP as a current monthly amount and as an average monthly amount for the year before the survey was conducted. Even though correlations are quite low, I still believe in the reliability of my calculations because the variable in the questionnaire covers several problems: first, if benefits are indicated as zero, I do not know whether the mother was actually not eligible or whether she just didn't apply for the benefits. Moreover, it remains obscure whether parents chose the regular amount of Erziehungsgeld or the Budget version and whether the amount indicated in the questionnaire is the benefit for one child or for several children. To avoid at least the first problem, I exclude all observations for which either the questionnaire's variable or my own calculations indicate zero benefits. Means are quite comparable afterwards (see table A11).

\section{[Table A11 about here]}

\section{Elterngeld (since 2007):}

Calculation of eligibility is easy for the new benefit system: parents are not eligible, if their gross yearly income in the calendar year before birth exceeds 500,000 EUR or 250,000 EUR 
for singles. In my sample, all parents are below this threshold and are thus eligible for some amount of Elterngeld.

The benefit amount is now dependent on the gross monthly income of the 12 months before a child's birth. In comparison to the old regulation, if a child is born on the 30th of December in 2006, income from December 2005 to November 2006 is considered. Since my data does not provide information on exact income for each month, but only on the average income per month of each year, I decide to take pre-birth average monthly income if the child is born between January and April, average monthly income of the year of birth if the child is born in the last third of the year and an average of pre-birth and year of birth income if it is born between May and August.

I use the Elterngeldrechner provided by the Federal Ministry for Family Affairs, Senior Citizens, Women and Youth (BMFSFJ) to calculate expected benefits for each family. The Elterngeldrechner uses detailed information on family composition, parents' background variables and gross income to calculate the expected amount of benefits a parent would receive. As I do not have all information and to simplify my calculations, I assume that there are no twins and that each child is born on the first day of the respective month ${ }^{65}$. Elterngeld increases by a sibling premium of at least 75 EUR (or $10 \%$ of the benefit amount) if there is a second child aged younger than three or two further children aged younger than six. I add this premium once for each family having two or more children. Moreover, because of missing information on compliance to the church tax, I assume all parents to pay this tax. Concerning the tax class, I follow Raute (2014) and assume that tax class IV without factor is chosen ${ }^{66}$.

I compute the expected benefit amount for each family and thus for each possible gross income in my data for a transfer duration of 12 months ${ }^{67}$.

Similar to Erziehungsgeld, I compare my calculations with the variable provided in the

\footnotetext{
${ }^{65}$ Actually, benefit calculation depends on the exact birth date. Since my data only provides my with the month of birth, I prefer to assume the same day of a respective month for every child.

${ }^{66}$ For singles, tax class IV yields the same results as being taxed under class I. Married couples normally choose to be taxed with class IV, if they have relatively equal incomes - otherwise the lower-income partner (mostly the woman) chooses tax class V, while the higher-earner is taxed with class III. In my sample, only about 20 $\%$ of married couples have relatively equal income - the problem is however, that a lower-earning pregnant women could have changed her tax class from V to III before birth to have lower deductions and thus to receive a higher amount of Elterngeld after birth. As I do not have any information on that, choosing tax class $\mathrm{V}$ for all married low-earning women would probably not improve over assuming tax class IV for all women.

${ }^{67} \mathrm{My}$ calculations with the Elterngeldrechner took place in 2014. Unfortunately, the calculation of the benefit amount was slightly changed in 2013, i.e. my calculations are based on the new calculation rule, even though the children were born before 2013. As these changes rather led to a small decrease in the benefit amount (see Süddeutsche Zeitung 2012; Kindergeld.info 2012), I will probably underestimate the expected amount for some families. This should not inflate my resulting effects, but rather understate them.
} 
GSOEP questionnaires. Correlations are quite high and means are of comparable size. Moreover, I compare my results with the Elterngeldstatistik 2010 provided by the Statistisches Bundesamt (Federal Statistical Office): The statistic shows a mean amount of Elterngeld of 721 EUR in the first month after birth, while I calculated a mean monthly benefit amount of approximately 699 EUR. Comparing the shares of families in the different benefit segments, only the shares in the lowest two groups differ: In my sample $8 \%$ receive the minimum amount of 300 EUR per month, while $27 \%$ do so in the official statistic. $36.5 \%$ of parents in my sample get 300-500 EUR, this share is only $19 \%$ in the official statistic. For the remaining segments, shares are nearly equal. Furthermore, the assumption that parental leave is taken for 12 months also seems to be justified: the Elterngeldstatistik indicates an average leave taking of 11.7 months for women.

In the end, I can then compare eligibility for each family under the old and the new regulation and additionally calculate the difference in expected overall benefits when receiving Elterngeld instead of Erziehungsgeld.

\section{A.2 Additional figures and tables}

Table A1: Overall amount of Erziehungsgeld and Elterngeld in EUR

\begin{tabular}{lcccc}
\hline & Mean & Minimum & Maximum & $\mathrm{N}$ \\
\hline Amount ErzG & $5,054.74$ & 0 & 7,368 & 2,100 \\
Amount ErzG(Budget) & $3,721.13$ & 0 & 5,520 & 2,100 \\
Amount EG & $7,826.15$ & 3,600 & 23,760 & 2,009 \\
Amount EG if pre-birth employed & $9,669.86$ & 3,600 & 23,760 & 1,323 \\
Change (EG-ErzG) & $2,850.87$ & $-3,768$ & 23,760 & 2,009 \\
Change (EG-Budget) & $4,171.08$ & $-1,920$ & 23,760 & 2,009 \\
\hline
\end{tabular}

Notes: This table provides summary statistics for the overall amounts of benefits after the entire transfer duration. Transfer duration is 12 months for Elterngeld (EG) and the Budget version of Erziehungsgeld and varies between 0 months and 24 months for Erziehungsgeld (ErzG). Benefits were calculated applying the procedure explained in Appendix A.1. The maximum amounts include the full overall amount plus one sibling premium. 
Table A2: Background characteristics (large time frame)

2006/2007 2004/05, 2005/06, 2007/08

July-Dec. Jan.-June RD July-Dec. Jan.-June seasonal effects DiD

(1) (2) (3) (4) (5) $\quad$ (5)
(2)-(1)
(5)-(4)
(3)-(6)

Mother's characteristics (pre-birth)

$\begin{array}{lccccccc}\text { maternity leave } & 0.034 & 0.034 & 0.001 & 0.065 & 0.060 & -0.006 & 0.007 \\ \text { child rearing } & 0.169 & 0.172 & 0.004 & 0.170 & 0.176 & 0.006 & -0.002 \\ \text { no leave } & 0.798 & 0.793 & -0.005 & 0.765 & 0.764 & -0.001 & -0.004 \\ \text { working hours } & 36.479 & 35.870 & -0.609 & 34.471 & 33.819 & -0.652 & 0.043 \\ \text { full-time } & 0.438 & 0.402 & -0.036 & 0.376 & 0.331 & -0.045 & 0.009 \\ \text { part-time } & 0.135 & 0.103 & -0.031 & 0.157 & 0.215 & 0.058^{*} & -0.089 \\ \text { not employed } & 0.348 & 0.379 & 0.031 & 0.340 & 0.370 & 0.030 & 0.001 \\ \text { other employment } & 0.079 & 0.115 & 0.036 & 0.127 & 0.085 & -0.043 * & 0.079 \\ & & & & & & & \\ \text { Partner's characteristics (pre-birth) } & & & & & \\ \text { working hours } & 43.631 & 45.632 & 2.000 & 44.585 & 44.118 & -0.468 & 2.468 \\ \text { full-time } & 0.841 & 0.818 & -0.022 & 0.850 & 0.864 & 0.014 & -0.036 \\ \text { part-time } & 0.029 & 0.015 & -0.014 & 0.027 & 0.027 & 0.000 & -0.014 \\ \text { not employed } & 0.072 & 0.136 & 0.064 & 0.100 & 0.082 & -0.018 & 0.082 \\ \text { other employment } & 0.058 & 0.030 & -0.028 & 0.023 & 0.027 & 0.005 & -0.032\end{array}$

Net household income (pre-birth)

\begin{tabular}{lccccccc} 
up to 500 & 0.000 & 0.012 & 0.012 & 0.010 & 0.008 & -0.003 & 0.015 \\
$500-1,000$ & 0.070 & 0.060 & -0.010 & 0.045 & 0.083 & $0.038^{*}$ & -0.048 \\
$1,000-1,500$ & 0.105 & 0.120 & 0.016 & 0.116 & 0.109 & -0.007 & 0.023 \\
$1,500-2,000$ & 0.186 & 0.108 & -0.078 & 0.164 & 0.098 & $-0.067 * *$ & -0.011 \\
$2,000-2,500$ & 0.209 & 0.229 & 0.020 & 0.205 & 0.218 & 0.013 & 0.007 \\
$2,500-3,000$ & 0.151 & 0.108 & -0.043 & 0.127 & 0.139 & 0.012 & -0.055 \\
$3,000-3,500$ & 0.093 & 0.145 & 0.052 & 0.113 & 0.154 & 0.041 & 0.010 \\
3,500-4,000 & 0.035 & 0.084 & 0.049 & 0.075 & 0.041 & $-0.034^{*}$ & $0.083^{* *}$ \\
more than 4,000 & 0.151 & 0.133 & -0.019 & 0.144 & 0.150 & 0.007 & -0.025 \\
\hline
\end{tabular}


Table A2 continued from previous page

2006/2007

July-Dec. Jan.-June
2004/05, 2005/06, 2007/08

RD July-Dec. Jan.-June seasonal effects

(6)

$(5)-(4)$

DiD

(3)

(2)-(1)
(4)

(5)
(7)

(3)-(6)

\section{Mother's characteristics (current)}

married

German born

age at birth

East German

no graduation

low education

medium education

high education

years of schooling
0.743

0.917

29.193

0.229

0.037

0.183

0.495

0.284

12.472
0.752

\subsection{2}

31.190

0.229

0.029

0.049

0.510

0.412

13.108
0.010

$-0.156^{* * *}$

$1.998 * * *$

$-0.001$

$-0.007$

$-0.134 * * *$

0.014

$0.127 *$

0.637
0.714

0.890

29.987

0.262

0.019

0.130

0.558

0.294

12.927
0.760

0.853

30.882

0.221

0.039

0.122

0.531

0.309

12.788
0.046

$-0.037$

$0.895^{*}$

$-0.041$

0.020

$-0.008$

$-0.027$

0.015

$-0.139$
$-0.036$

$0.119 * *$

1.103

0.040

$-0.027$

$-0.126^{* *}$

0.041

0.112

$0.776^{*}$

\section{Partner's characteristics (current)}

no graduation

low education

medium education

high education

years of schooling

\begin{abstract}
0.021
\end{abstract}
0.105

0.526

0.347

12.677
0.012

0.072

0.506

0.410

13.259

-0.009
-0.033
-0.020
0.062
0.582

0.026

0.113

0.468

0.394

12.927

0.010
0.076
0.535
0.378
13.074

$-0.015$

$-0.037$

0.067

$-0.015$

0.147
0.006

0.004

$-0.087$

0.077

0.435

\section{Child's characteristics}

\begin{tabular}{lccccccc} 
gender (girl=1) & 0.459 & 0.495 & 0.037 & 0.514 & 0.491 & -0.023 & 0.059 \\
first born child & 0.550 & 0.524 & -0.027 & 0.488 & 0.434 & -0.054 & 0.028 \\
age (0-1-y.) & 6.336 & 6.195 & -0.141 & 6.326 & 7.309 & $0.983^{* * *}$ & $-1.124^{*}$ \\
$\mathrm{n}^{\circ}$ siblings (0-1-y.) & 0.820 & 0.632 & -0.188 & 0.701 & 0.912 & $0.212^{* * *}$ & $-0.399^{* *}$ \\
premature birth & 0.260 & 0.140 & $-0.121^{* *}$ & 0.154 & 0.166 & 0.011 & $-0.132^{*}$ \\
low birth weight & 0.140 & 0.115 & -0.025 & 0.063 & 0.061 & -0.002 & -0.023 \\
age (2-3-y.) & 30.239 & 37.000 & $6.761^{* * *}$ & 30.399 & 36.010 & $5.611^{* * *}$ & $1.149 * *$ \\
weight (2-3-y.) & 13.202 & 14.833 & $1.631^{* * *}$ & 13.705 & 14.637 & 0.932 & $0.699^{* *}$ \\
height (2-3-y.) & 93.235 & 97.978 & $4.742^{* * *}$ & 92.000 & 96.136 & $4.136^{* * *}$ & 0.607 \\
$\mathrm{n}^{\circ}$ siblings (2-3-y.) & 0.769 & 0.568 & -0.201 & 0.636 & 0.814 & $0.178^{* *}$ & $-0.379^{* *}$ \\
\hline
\end{tabular}

Notes: The first two columns give averages for children born in the first half of the 2006/2007 cohort (July-December 2006) and for children born in the second half (JanuaryJune 2007). Columns (4) and (5) show averages for the control years respectively. Column (3) is the difference between column (2) and column (1) and thus represents a simple RDestimator. Column (6) represents the pure seasonal effects between children born in the first half of a cohort and those born in the second half. Column (7) is then the difference between the RD-estimator and the seasonal effects - thus, the Diff-in-Diff-estimator on the raw data without any controls and the full time frame.

${ }^{*}$ indicates significance at $10 \%,{ }^{* *}$ indicates significance at $5 \%,{ }^{* *}$ indicates significance at $1 \%$ level. Samples for both age groups were pooled expect for the following age-specific variables: indicators for premature birth and low birth weight are based on the newborn sample, indicators for weight and height on data of the 2-3-year-olds. Age indicators (in months) and the number of siblings at birth are estimated separately for each sample. 
Table A3: Background characteristics (small time frame)

2006/2007 2004/05, 2005/06, 2007/08

Oct.-Dec. Jan.-March RD Oct.-Dec. Jan.-March seasonal effects DiD
(1)
(2)
(3)
(4)
(5)
(6)

(2)-(1)

$(5)-(4)$

(3)-(6)

\begin{tabular}{|c|c|c|c|c|c|c|c|}
\hline \multicolumn{8}{|c|}{ Mother's characteristics (pre-birth) } \\
\hline maternity leave & 0.050 & 0.044 & -0.006 & 0.073 & 0.058 & -0.015 & 0.010 \\
\hline child rearing & 0.225 & 0.267 & 0.042 & 0.175 & 0.151 & -0.024 & 0.066 \\
\hline no leave & 0.725 & 0.689 & -0.036 & 0.752 & 0.791 & 0.040 & -0.076 \\
\hline working hours & 36.456 & 38.060 & 1.604 & 34.261 & 32.415 & -1.846 & 3.450 \\
\hline full time & 0.500 & 0.333 & -0.167 & 0.394 & 0.309 & -0.085 & -0.082 \\
\hline part time & 0.125 & 0.089 & -0.036 & 0.146 & 0.223 & $0.077^{*}$ & -0.113 \\
\hline not employed & 0.325 & 0.444 & 0.119 & 0.321 & 0.367 & 0.046 & 0.074 \\
\hline other employment & 0.050 & 0.133 & 0.083 & 0.139 & 0.101 & -0.038 & 0.121 \\
\hline \multicolumn{8}{|c|}{ Partner's characteristics (pre-birth) } \\
\hline working hours & 44.160 & 44.828 & 0.668 & 44.234 & 44.897 & 0.663 & 0.004 \\
\hline full time & 0.793 & 0.750 & -0.043 & 0.833 & 0.867 & 0.034 & -0.077 \\
\hline part time & 0.000 & 0.028 & 0.028 & 0.010 & 0.027 & 0.017 & 0.011 \\
\hline not employed & 0.103 & 0.194 & 0.091 & 0.127 & 0.088 & -0.039 & 0.130 \\
\hline other employment & 0.103 & 0.028 & -0.076 & 0.029 & 0.018 & -0.012 & -0.064 \\
\hline \multicolumn{8}{|c|}{ net household income (pre-birth) } \\
\hline up to 500 & 0.000 & 0.023 & 0.023 & 0.008 & 0.015 & 0.007 & 0.015 \\
\hline $500-1000$ & 0.000 & 0.091 & $0.091 *$ & 0.031 & 0.076 & 0.045 & 0.046 \\
\hline $1000-1500$ & 0.108 & 0.159 & 0.051 & 0.148 & 0.106 & -0.042 & 0.093 \\
\hline $1500-2000$ & 0.216 & 0.136 & -0.080 & 0.156 & 0.068 & $-0.088 * *$ & 0.008 \\
\hline $2000-2500$ & 0.135 & 0.205 & 0.069 & 0.195 & 0.250 & 0.055 & 0.015 \\
\hline $2500-3000$ & 0.135 & 0.136 & 0.001 & 0.109 & 0.114 & 0.004 & -0.003 \\
\hline $3000-3500$ & 0.108 & 0.136 & 0.028 & 0.125 & 0.167 & 0.042 & -0.013 \\
\hline $3500-4000$ & 0.081 & 0.045 & -0.036 & 0.078 & 0.030 & $-0.048 *$ & 0.012 \\
\hline more than 4000 & 0.216 & 0.068 & $-0.148 *$ & 0.148 & 0.174 & 0.026 & $-0.174^{*}$ \\
\hline
\end{tabular}

continued on next page 
Table A3 continued from previous page

2006/2007

Oct.-Dec. Jan.-March
2004/05, 2005/06, 2007/08

RD Oct.-Dec. Jan.-March seasonal effects

DiD

(3)

(4)

(5)

(6)

(5)-(4)

(3)-(6)

(2)-(1)

\section{Mother's characteristics (current)}

married

German born

age at birth

0.731

1.073

29.709

0.255

0.036

0.164

0.455

0.345

12.936

0.771

1.275

East Germany

no graduation

low education

medium education

high education

years of schooling
30.941

0.196

0.041

0.061

0.469

0.429

13.202
0.040

$0.202 * * *$

1.232

$-0.058$

0.004

$-0.102$

0.015

0.083

0.266
0.706

1.089

29.846

0.243

0.030

0.115

0.564

0.291

12.864
0.783

1.133

30.898

0.253

0.043

0.099

0.621

0.236

12.506
0.078

0.044

$1.051^{*}$

0.010

0.013

$-0.016$

0.057

$-0.055$

$-0.358$
$-0.038$

$0.158 * *$

0.181

$-0.069$

$-0.009$

$-0.087$

$-0.043$

0.138

0.624

\section{Partner's characteristics (current)}

no graduation

low education

medium edu

high education

years of edu

\begin{abstract}
0.021
\end{abstract}
0.085

0.532

0.362

12.933
0.025

0.100

0.425

0.450

13.038

\subsection{4}

0.015

$-0.107$

0.088

0.104
0.014

0.108

0.496

0.381

12.685

\subsection{7}

0.101

0.529

0.362

12.963
$-0.007$

$-0.006$

0.033

$-0.019$

0.278
0.011

0.021

$-0.139$

0.107

$-0.174$

\section{Child's characteristics}

\section{gender (girl=1)}

first born child

age (0-1-y.)

$\mathrm{n}^{\circ}$ siblings (0-1-y.)

premature birth

low birth weight

age (2-3-y.)

weight $(2-3-y$.

height (2-3-y.

$\mathrm{n}^{\circ}$ siblings (2-3-y.)
0.473

0.509

5.365

1.000

0.212

0.115

28.911

13.279

91.952

1.000

\subsection{9}

0.490

3.955

0.727

0.091

0.068

38.545

14.864

98.205

0.675

$\begin{array}{cc}0.076 & 0.550 \\ -0.019 & 0.491 \\ -1.41 * * & 5.000 \\ -0.273 * * & 0.707 \\ -0.121 & 0.173 \\ -0.047 & 0.040 \\ 9.634 * * * & 28.755 \\ 1.584 * * * & 13.309 \\ 6.252 * * * & 90.765 \\ -0.325 & 0.679\end{array}$

\subsection{2}

0.440

5.434

0.986

0.179

0.063

37.731

14.965

96.743

0.847

\section{$-0.038$}

$-0.051$

0.434

$0.279 * *$

0.005

0.024

$8.975^{* * *} *$

$1.655^{* * *}$

$5.978 * * *$

0.168
0.115

0.032

$-1.845^{* *}$

$-0.552 * *$

$-0.126$

$-0.071$

0.671

$-0.071$

0.274

$-0.493$

Notes: Interpretation is similar to table A2, except that the observations now only contain children born in the second quarter of a cohort (i.e. between October and December) and children born in the third quarter (i.e. January-March). Column (7) is then the difference between the RD-estimator and the seasonal effects - thus, the Diff-in-Diff-estimator on the raw data without any controls and the full time frame of 3 months before and after 01/2007. ${ }^{*}$ indicates significance at $10 \%,{ }^{* *}$ indicates significance at $5 \%,{ }^{* * *}$ indicates significance at $1 \%$ level. 
Figure A1: Comparison of residuals' means of dependent variables, 0-1-year-olds

Placebo index

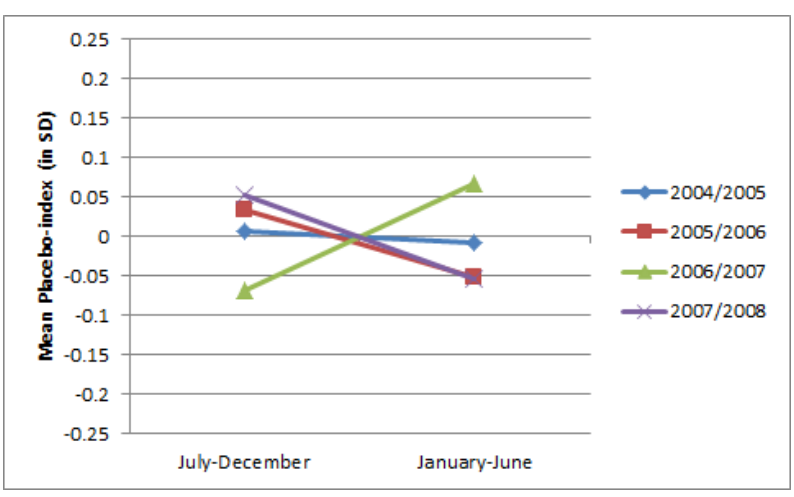

Personality index

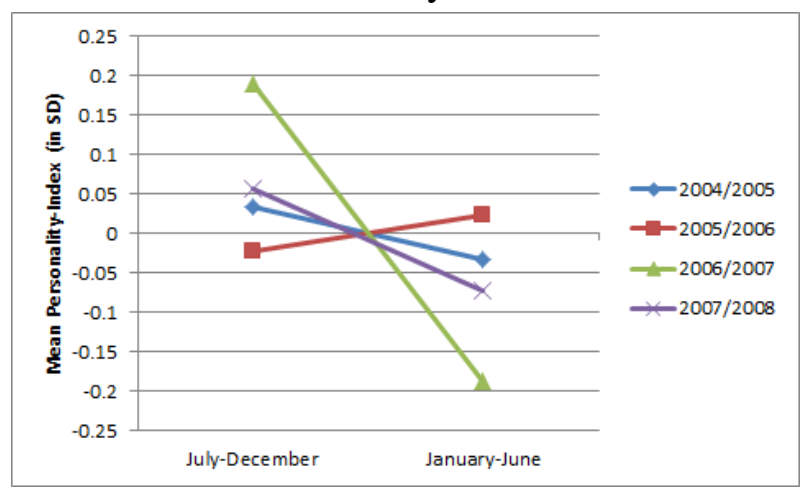

Health \& development index

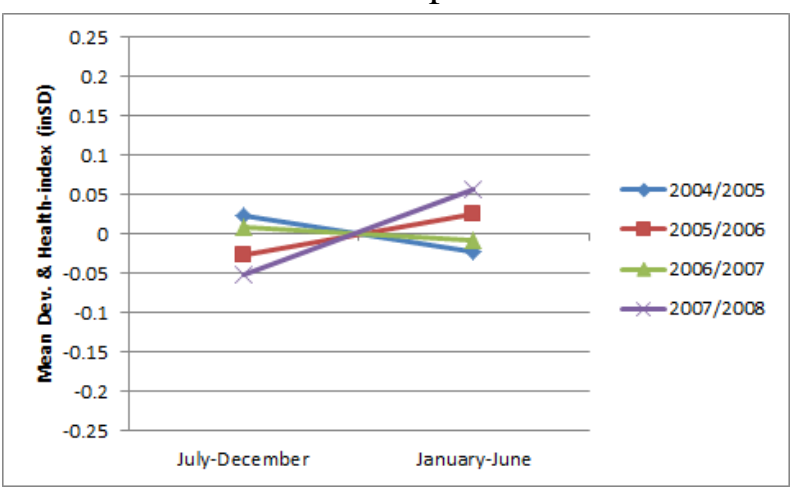

Notes: Depicted are the means of respective residuals (after controlling for the child's age and gender, migration background of the mother, education level of the mother, employment status of the mother, marital status of the mother, the mother's age at birth and the region of residence) for the first and the second half of a cohort. The lines just represent a connection between the two points. The dependent variables' residuals' means are measured in standard deviations. The green line depicts the means for the treatment cohort 2006/2007. The red, blue and purple lines represent the control cohorts. 
Figure A2: Comparison of residuals' means of dependent variables, 2-3-year-olds

Health index

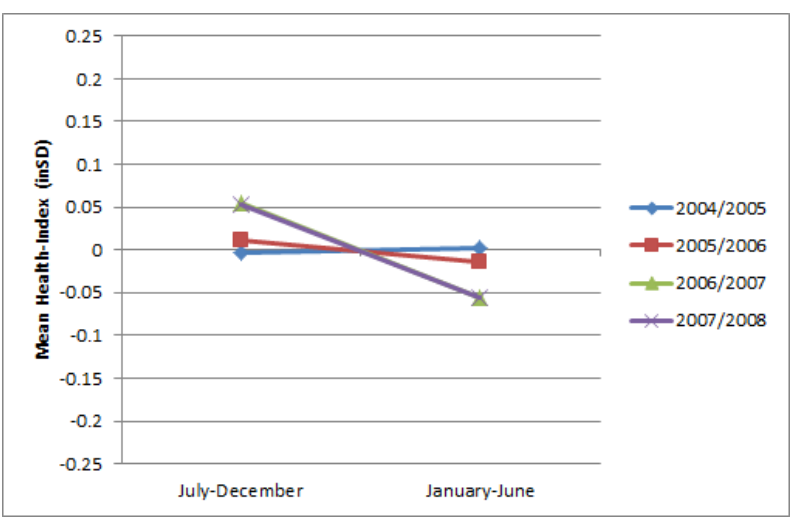

Personality index

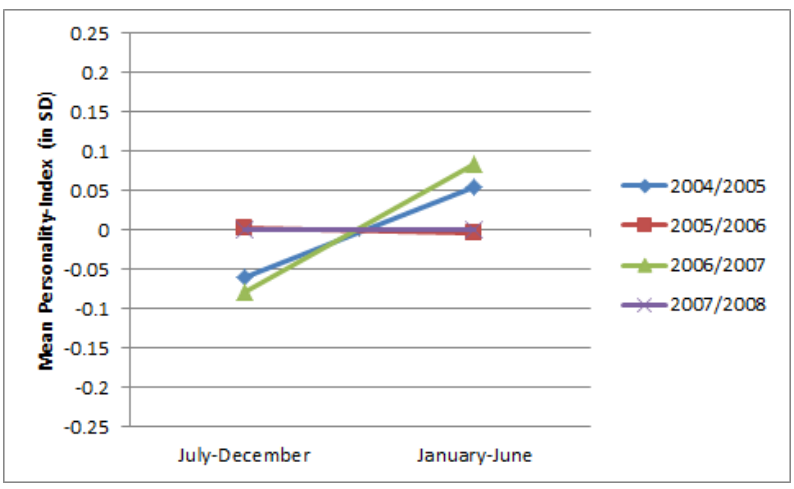

Motor ability index

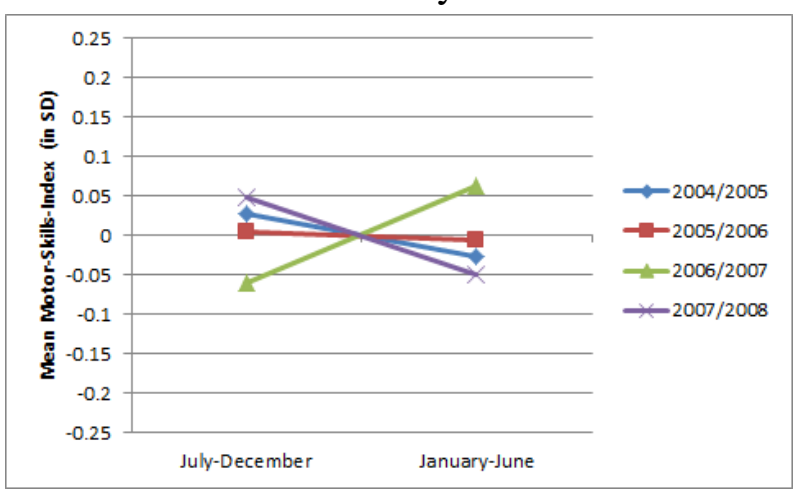

Behavior index

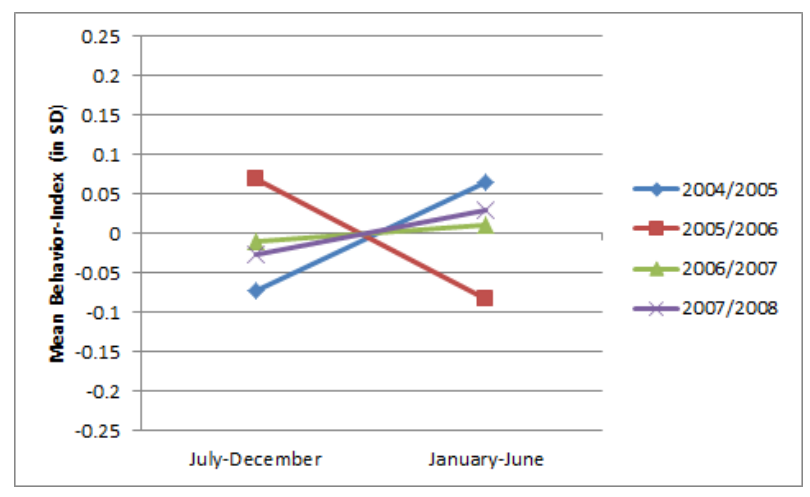

Language skills index

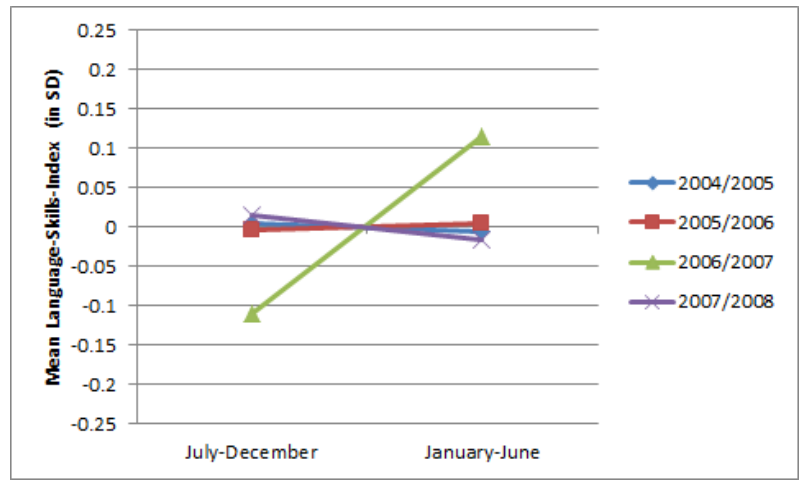

Basic life skills index

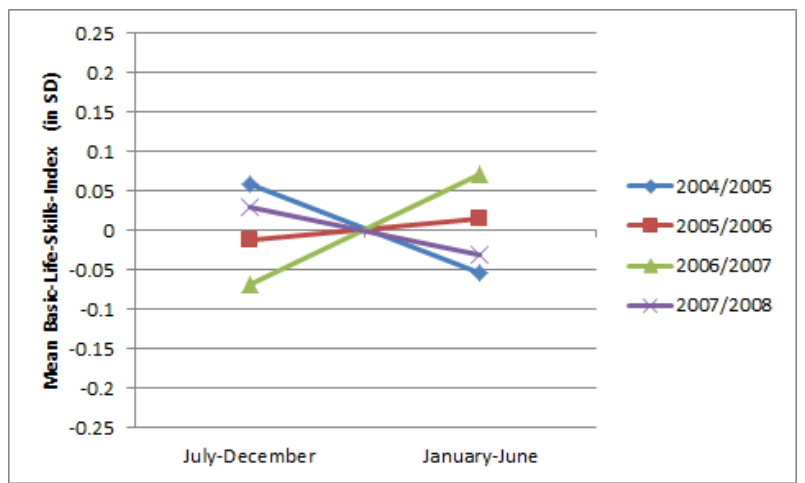

continued on next page 
Social skills index

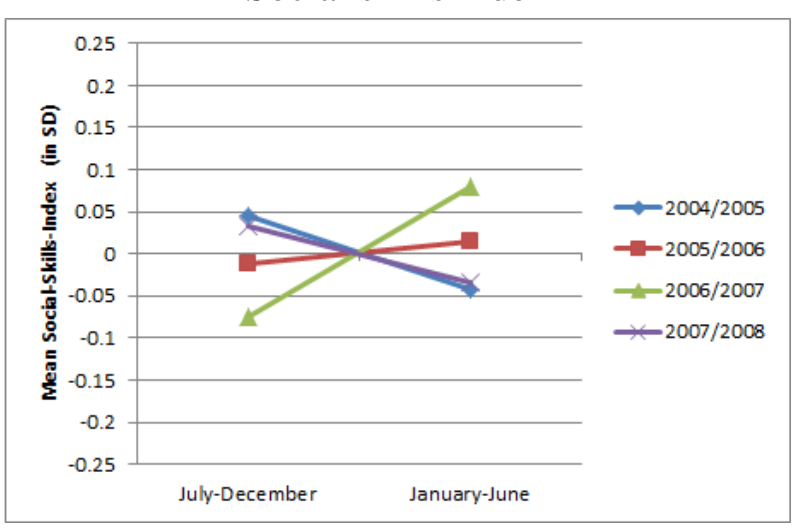

Skills index

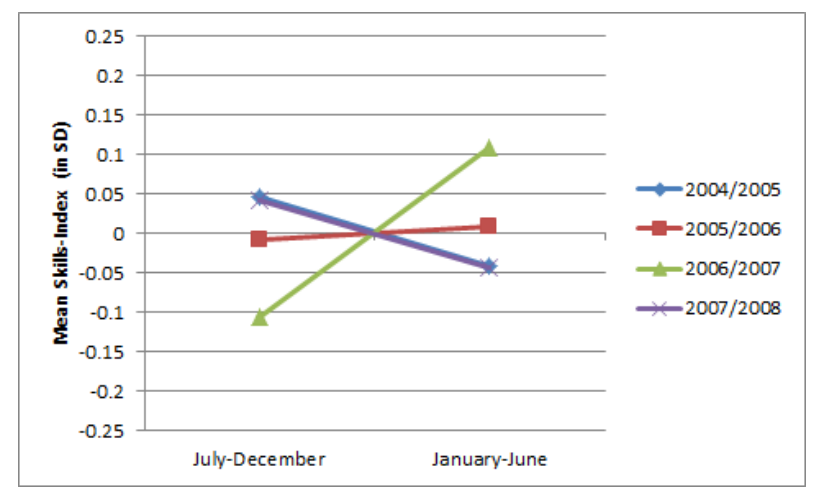

General well-being index

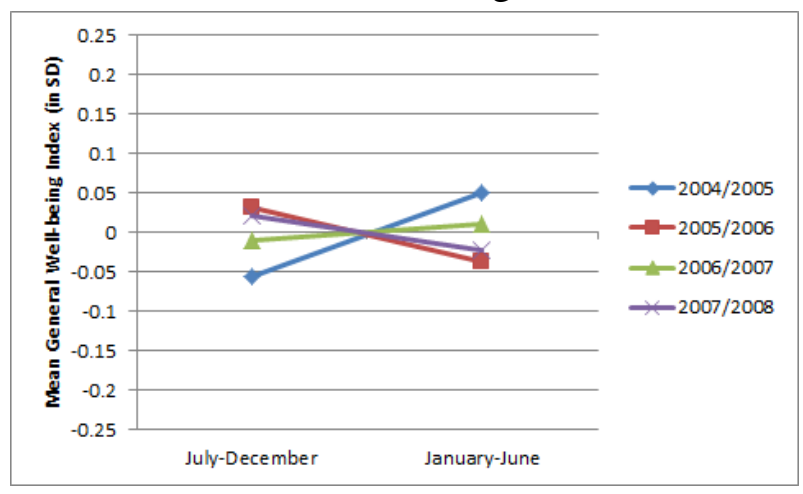

Notes: Depicted are the means of respective residuals (after controlling for the child's age and gender, migration background of the mother, education level of the mother, employment status of the mother, marital status of the mother, the mother's age at birth and the region of residence) for the first and the second half of a cohort. The lines just represent a connection between the two points. The dependent variables' residuals' means are measured in standard deviations. The green line depicts the means for the treatment cohort 2006/2007. The red, blue and purple lines represent the control cohorts. 
Table A4: Heterogeneous effects by exact amount of change, 0-1-year-olds

\begin{tabular}{|c|c|c|c|c|c|c|}
\hline \multirow[t]{2}{*}{ time frame: } & \multicolumn{2}{|c|}{ July-June } & \multicolumn{2}{|c|}{ July-June } & \multicolumn{2}{|c|}{ October-March } \\
\hline & (1) & (2) & (3) & (4) & (5) & (6) \\
\hline \multicolumn{7}{|l|}{ Panel A: personality index } \\
\hline \multirow[t]{2}{*}{ reform } & $-0.433 * *$ & $-0.474 * *$ & $-0.445^{*}$ & $-0.511 * *$ & $-0.589 *$ & $-0.622 *$ \\
\hline & 0.214 & 0.231 & 0.233 & 0.249 & 0.311 & 0.334 \\
\hline \multirow[t]{2}{*}{ reform $\mathrm{x}$ change } & 0.010 & 0.022 & 0.015 & 0.039 & 0.007 & 0.020 \\
\hline & 0.031 & 0.034 & 0.033 & 0.036 & 0.055 & 0.054 \\
\hline $\mathrm{N}$ & 810 & 690 & 688 & 584 & 387 & 322 \\
\hline \multicolumn{7}{|l|}{ Panel B: development \& health } \\
\hline \multirow[t]{2}{*}{ reform } & 0.075 & 0.126 & 0.281 & 0.380 & 0.000 & 0.061 \\
\hline & 0.203 & 0.240 & 0.210 & 0.245 & 0.301 & 0.396 \\
\hline \multirow[t]{2}{*}{ reform $\mathrm{x}$ change } & -0.021 & -0.035 & -0.014 & -0.030 & -0.038 & -0.058 \\
\hline & 0.022 & 0.023 & 0.021 & 0.022 & 0.040 & 0.044 \\
\hline $\mathrm{N}$ & 800 & 681 & 679 & 576 & 382 & 318 \\
\hline \multicolumn{7}{|l|}{ Panel C : placebo index } \\
\hline \multirow[t]{2}{*}{ reform } & 0.206 & 0.209 & 0.163 & 0.171 & 0.117 & 0.072 \\
\hline & 0.207 & 0.241 & 0.238 & 0.272 & 0.252 & 0.283 \\
\hline \multirow[t]{2}{*}{ reform $\mathrm{x}$ change } & -0.011 & -0.021 & -0.001 & -0.011 & -0.009 & -0.035 \\
\hline & 0.024 & 0.029 & 0.026 & 0.031 & 0.032 & 0.037 \\
\hline $\mathrm{N}$ & 811 & 691 & 869 & 585 & 387 & 322 \\
\hline socio-demographic controls & & $\mathrm{x}$ & & $\mathrm{x}$ & & $\mathrm{x}$ \\
\hline birth months FE & $\mathrm{x}$ & $\mathrm{x}$ & $\mathrm{x}$ & $\mathrm{x}$ & $\mathrm{x}$ & $\mathrm{x}$ \\
\hline Dec. 2006 \& Jan. 2007 birth & $\mathrm{x}$ & $\mathrm{x}$ & & & $\mathrm{x}$ & $\mathrm{x}$ \\
\hline
\end{tabular}

Notes: All regressions show estimates of equation (3). Standard errors are clustered at mothers' person number (ID) and are reported in italics. Socio-demographic controls include the child's age at survey, a dummy for the child's gender, a dummy for migration background of the parents, dummies for the mother's pre-birth education level, number of siblings, and a dummy for living in East or West Germany. The control group consists of birth cohorts 2004/2005, 2005/2006 and 2007/2008, i.e. children born between July 2004 and June 2006 and between July 2007 and June 2008 for columns (1)-(4) and children born between October 2004 and March 2006 and between October 2007 and March 2008 for columns (5) and (6). In columns (3) and (4), children born in December 2006 and in January 2007 are excluded from the sample.

${ }^{*}$ indicates significance at $10 \%,{ }^{* *}$ indicates significance at $5 \%,{ }^{* * *}$ indicates significance at $1 \%$ level. Source: GSOEP 2003-2010 
Table A5: Baseline Diff-in-Diff, 0-1-year-olds, by birth-order

\begin{tabular}{lcccccc}
\hline time frame: & \multicolumn{2}{c}{ July-June } & \multicolumn{2}{c}{ July-June } & \multicolumn{2}{c}{ October-March } \\
& $(1)$ & $(2)$ & $(3)$ & $(4)$ & $(5)$ & $(6)$ \\
\hline Firstborn children & & & & & & \\
& & & & & & \\
Panel A: personality index & & & & & & \\
reform & -0.255 & -0.240 & -0.227 & -0.175 & -0.182 & -0.039 \\
& 0.238 & 0.272 & 0.250 & 0.280 & 0.391 & 0.455 \\
$\mathrm{~N}$ & 385 & 306 & 334 & 266 & 183 & 141 \\
\hline Panel B: development \& health & & & & & & 0.642 \\
reform & 0.354 & 0.388 & $0.575 * *$ & $0.632 * *$ & 0.462 & 0.642 \\
& 0.271 & 0.316 & 0.278 & 0.317 & 0.483 & 0.595 \\
$\mathrm{~N}$ & 378 & 300 & 372 & 260 & 179 & 138 \\
\hline Panel C : placebo index & & & & & & \\
reform & 0.158 & 0.039 & 0.189 & 0.067 & 0.183 & 0.042 \\
& 0.209 & 0.235 & 0.240 & 0.268 & 0.308 & 0.337 \\
$\mathrm{~N}$ & 385 & 306 & 334 & 266 & 183 & 141 \\
\hline \hline
\end{tabular}

Non-firstborn children

Panel D: personality index

\begin{tabular}{lcccccc} 
reform & $-0.525^{* *}$ & $-0.530^{*}$ & $-0.568^{* *}$ & $-0.599^{*}$ & $-0.906^{* * *}$ & $-0.966^{* * *}$ \\
& 0.260 & 0.279 & 0.287 & 0.307 & 0.337 & 0.344 \\
$\mathrm{~N}$ & 431 & 391 & 360 & 324 & 209 & 188 \\
\hline Panel E: development \& health & & & & & & \\
reform & -0.191 & -0.158 & 0.066 & 0.123 & -0.474 & -0.504 \\
& 0.274 & 0.281 & 0.262 & 0.273 & 0.376 & 0.426 \\
$\mathrm{~N}$ & 428 & 388 & 358 & 322 & 208 & 187 \\
\hline Panel F : placebo index & & & & & & \\
reform & 0.379 & $0.584^{*}$ & 0.292 & 0.516 & 0.222 & 0.418 \\
& 0.296 & 0.319 & 0.343 & 0.365 & 0.299 & 0.320 \\
$\mathrm{~N}$ & 432 & 392 & 361 & 325 & 209 & 188 \\
\hline socio-demographic controls & & $\mathrm{x}$ & & $\mathrm{x}$ & & $\mathrm{x}$ \\
birth months FE & $\mathrm{x}$ & $\mathrm{x}$ & $\mathrm{x}$ & $\mathrm{x}$ & $\mathrm{x}$ & $\mathrm{x}$ \\
Dec. 2006 \& Jan. 2007 births & $\mathrm{x}$ & $\mathrm{x}$ & & & $\mathrm{x}$ & $\mathrm{x}$ \\
\hline
\end{tabular}

Notes: Estimates are similar to estimates in table 5 except that they do not control for the number of siblings. Panel A-C show results for a sample only containing firstborn children, Panel D-F only includes children from higher birth-orders.

${ }^{*}$ indicates significance at $10 \%,{ }^{* *}$ indicates significance at $5 \%,{ }^{* * *}$ indicates significance at $1 \%$ level. Source: GSOEP 2003-2010 
Table A6: Heterogeneous effects by exact amount of change, 2-3-year-olds

\begin{tabular}{|c|c|c|c|c|c|c|}
\hline \multirow[t]{2}{*}{ time frame: } & \multicolumn{2}{|c|}{ July-June } & \multicolumn{2}{|c|}{ July-June } & \multicolumn{2}{|c|}{ October-March } \\
\hline & (1) & (2) & (3) & (4) & (5) & (6) \\
\hline \multicolumn{7}{|l|}{ Panel A: health index } \\
\hline \multirow[t]{2}{*}{ reform } & -0.014 & -0.157 & -0.054 & -0.167 & 0.444 & 0.205 \\
\hline & 0.285 & 0.305 & 0.318 & 0.336 & 0.421 & 0.495 \\
\hline \multirow[t]{2}{*}{ reform $\mathrm{x}$ change } & 0.006 & 0.018 & 0.013 & 0.027 & -0.021 & 0.022 \\
\hline & 0.034 & 0.036 & 0.036 & 0.038 & 0.044 & 0.043 \\
\hline $\mathrm{N}$ & 753 & 601 & 641 & 512 & 362 & 285 \\
\hline \multicolumn{7}{|l|}{ Panel B: behavior index } \\
\hline \multirow[t]{2}{*}{ reform } & 0.129 & 0.110 & 0.242 & 0.130 & -0.138 & -0.026 \\
\hline & 0.202 & 0.224 & 0.222 & 0.240 & 0.286 & 0.335 \\
\hline \multirow[t]{2}{*}{ reform $x$ change } & -0.007 & 0.002 & -0.016 & -0.001 & -0.025 & -0.024 \\
\hline & 0.039 & 0.041 & 0.041 & 0.043 & 0.069 & 0.074 \\
\hline $\mathrm{N}$ & 750 & 598 & 638 & 509 & 362 & 285 \\
\hline \multicolumn{7}{|l|}{ Panel C: personality index } \\
\hline \multirow[t]{2}{*}{ reform } & 0.227 & 0.103 & 0.282 & 0.128 & 0.063 & -0.004 \\
\hline & 0.203 & 0.230 & 0.220 & 0.249 & 0.311 & 0.373 \\
\hline \multirow[t]{2}{*}{ reform $x$ change } & 0.008 & 0.025 & 0.002 & 0.025 & -0.053 & -0.051 \\
\hline & 0.037 & 0.040 & 0.039 & 0.043 & 0.057 & 0.057 \\
\hline $\mathrm{N}$ & 753 & 601 & 641 & 512 & 362 & 285 \\
\hline \multicolumn{7}{|l|}{ Panel D: general well-being } \\
\hline \multirow[t]{2}{*}{ reform } & 0.146 & -0.007 & 0.188 & 0.006 & 0.251 & 0.113 \\
\hline & 0.240 & 0.269 & 0.264 & 0.288 & 0.388 & 0.468 \\
\hline \multirow[t]{2}{*}{ reform $x$ change } & 0.005 & 0.024 & 0.003 & 0.028 & -0.047 & -0.020 \\
\hline & 0.037 & 0.040 & 0.039 & 0.043 & 0.055 & 0.057 \\
\hline $\mathrm{N}$ & 753 & 601 & 641 & 512 & 362 & 285 \\
\hline \multicolumn{7}{|l|}{ Panel E: language skills } \\
\hline \multirow[t]{2}{*}{ reform } & $0.359 *$ & 0.252 & $0.450 * *$ & 0.319 & 0.127 & 0.069 \\
\hline & 0.195 & 0.226 & 0.218 & 0.246 & 0.282 & 0.372 \\
\hline \multirow[t]{2}{*}{ reform $x$ change } & 0.008 & 0.029 & 0.015 & 0.045 & -0.006 & 0.007 \\
\hline & 0.034 & 0.039 & 0.037 & 0.041 & 0.035 & 0.040 \\
\hline $\mathrm{N}$ & 752 & 600 & 640 & 511 & 362 & 285 \\
\hline \multicolumn{7}{|l|}{ Panel F: motor ability } \\
\hline \multirow[t]{2}{*}{ reform } & 0.122 & 0.121 & 0.113 & 0.144 & 0.175 & 0.275 \\
\hline & 0.204 & 0.221 & 0.227 & 0.245 & 0.294 & 0.363 \\
\hline \multirow[t]{2}{*}{ reform $x$ change } & 0.026 & 0.027 & 0.037 & 0.047 & -0.011 & -0.025 \\
\hline & 0.038 & 0.043 & 0.041 & 0.046 & 0.037 & 0.040 \\
\hline $\mathrm{N}$ & 752 & 601 & 641 & 512 & 362 & 285 \\
\hline socio-demographic controls & & $\mathrm{x}$ & & $\mathrm{x}$ & & $\mathrm{x}$ \\
\hline birth months FE & $\mathrm{x}$ & $\mathrm{x}$ & $\mathrm{x}$ & $\mathrm{x}$ & $\mathrm{x}$ & $\mathrm{x}$ \\
\hline Dec. 2006 \& Jan. 2007 births & $\mathrm{x}$ & $\mathrm{x}$ & & & $\mathrm{x}$ & $\mathrm{x}$ \\
\hline
\end{tabular}


Table A6 continued from previous page

\begin{tabular}{|c|c|c|c|c|c|c|}
\hline \multirow[t]{2}{*}{ time frame: } & \multicolumn{2}{|c|}{ July-June } & \multicolumn{2}{|c|}{ July-June } & \multicolumn{2}{|c|}{ October-March } \\
\hline & (1) & (2) & (3) & (4) & $(5)$ & (6) \\
\hline \multicolumn{7}{|l|}{ Panel G: basic life skills } \\
\hline \multirow[t]{2}{*}{ reform } & 0.237 & 0.244 & $0.339 *$ & 0.298 & 0.173 & 0.380 \\
\hline & 0.173 & 0.186 & 0.187 & 0.198 & 0.240 & 0.276 \\
\hline \multirow[t]{2}{*}{ reform $x$ change } & -0.007 & 0.000 & -0.014 & -0.008 & -0.053 & -0.053 \\
\hline & 0.031 & 0.032 & 0.033 & 0.034 & 0.037 & 0.042 \\
\hline $\mathrm{N}$ & 752 & 600 & 640 & 511 & 362 & 285 \\
\hline \multicolumn{7}{|l|}{ Panel H: social skills } \\
\hline \multirow[t]{2}{*}{ reform } & 0.179 & 0.103 & 0.216 & 0.111 & 0.053 & -0.010 \\
\hline & 0.206 & 0.230 & 0.228 & 0.250 & 0.322 & 0.413 \\
\hline \multirow[t]{2}{*}{ reform $x$ change } & 0.009 & 0.008 & 0.010 & 0.019 & -0.019 & -0.023 \\
\hline & 0.029 & 0.033 & 0.031 & 0.034 & 0.040 & 0.046 \\
\hline $\mathrm{N}$ & 752 & 600 & 640 & 511 & 362 & 285 \\
\hline \multicolumn{7}{|l|}{ Panel I: skills index } \\
\hline \multirow[t]{2}{*}{ reform } & 0.037 & 0.242 & $0.373 *$ & 0.294 & 0.178 & 0.243 \\
\hline & 0.201 & 0.224 & 0.225 & 0.245 & 0.305 & 0.388 \\
\hline \multirow[t]{2}{*}{ reform $x$ change } & 0.012 & 0.021 & 0.016 & 0.035 & -0.029 & -0.031 \\
\hline & 0.037 & 0.041 & 0.016 & 0.044 & 0.039 & 0.043 \\
\hline $\mathrm{N}$ & 753 & 601 & 641 & 512 & 362 & 285 \\
\hline socio-demographic controls & & $\mathrm{x}$ & & $\mathrm{x}$ & & $\mathrm{x}$ \\
\hline birth months FE & $\mathrm{x}$ & $\mathrm{x}$ & $\mathrm{x}$ & $\mathrm{x}$ & $\mathrm{x}$ & $\mathrm{x}$ \\
\hline Dec. 2006 \& Jan. 2007 births & $\mathrm{x}$ & $\mathrm{x}$ & & & $\mathrm{x}$ & $\mathrm{x}$ \\
\hline
\end{tabular}

Notes: All regressions show estimates of equation (3). Standard errors are clustered at mothers' person number (ID) and are reported in italics. Socio-demographic controls include the child's age at survey, a dummy for the child's gender, a dummy for migration background of the parents, dummies for the mother's pre-birth education level, number of siblings, and a dummy for living in East or West Germany. The control group consists of birth cohorts 2004/2005, 2005/2006 and 2007/2008, i.e. children born between July 2004 and June 2006 and between July 2007 and June 2008 for columns (1)-(4) and children born between October 2004 and March 2006 and between October 2007 and March 2008 for columns (5) and (6). In columns (3) and (4), children born in December 2006 and in January 2007 are excluded from the sample.

${ }^{*}$ indicates significance at $10 \%,{ }^{* *}$ indicates significance at $5 \%,{ }^{* * *}$ indicates significance at $1 \%$ level. Source: GSOEP 2003-2010 
Table A7: Baseline Diff-in-Diff, 2-3-year-olds, firstborn children

\begin{tabular}{|c|c|c|c|c|c|c|}
\hline \multirow[t]{2}{*}{ time frame: } & \multicolumn{2}{|c|}{ July-June } & \multicolumn{2}{|c|}{ July-June } & \multicolumn{2}{|c|}{ October-March } \\
\hline & (1) & (2) & (3) & (4) & (5) & (6) \\
\hline $\begin{array}{l}\text { Panel A: health index } \\
\text { reform }\end{array}$ & $\begin{array}{l}0.186 \\
0.375\end{array}$ & $\begin{array}{l}0.132 \\
0.422\end{array}$ & $\begin{array}{l}0.162 \\
0.415\end{array}$ & $\begin{array}{l}0.166 \\
0.468\end{array}$ & $\begin{array}{l}0.921 \\
0.669\end{array}$ & $\begin{array}{l}0.930 \\
0.802\end{array}$ \\
\hline $\mathrm{N}$ & 378 & 277 & 330 & 244 & 173 & 127 \\
\hline $\begin{array}{l}\text { Panel B: behavior index } \\
\text { reform } \\
\mathrm{N}\end{array}$ & $\begin{array}{c}0.289 \\
0.263 \\
377\end{array}$ & $\begin{array}{c}0.158 \\
0.319 \\
276\end{array}$ & $\begin{array}{l}0.439 \\
0.279 \\
329\end{array}$ & $\begin{array}{c}0.141 \\
0.340 \\
243\end{array}$ & $\begin{array}{c}0.319 \\
0.447 \\
173\end{array}$ & $\begin{array}{c}0.356 \\
0.541 \\
127\end{array}$ \\
\hline $\begin{array}{l}\text { Panel C: personality index } \\
\text { reform }\end{array}$ & $\begin{array}{c}0.470 * \\
0.245 \\
378\end{array}$ & $\begin{array}{c}0.369 \\
0.294 \\
277\end{array}$ & $\begin{array}{c}0.560 * * \\
0.268 \\
330\end{array}$ & $\begin{array}{c}0.414 \\
0.321 \\
244\end{array}$ & $\begin{array}{c}0.165 \\
0.428 \\
173\end{array}$ & $\begin{array}{c}0.066 \\
0.521 \\
127\end{array}$ \\
\hline $\begin{array}{l}\text { Panel D: overall well-being } \\
\text { reform }\end{array}$ & $\begin{array}{c}0.441 \\
0.325 \\
378\end{array}$ & $\begin{array}{c}0.314 \\
0.378 \\
277\end{array}$ & $\begin{array}{c}0.521 \\
0.361 \\
330\end{array}$ & $\begin{array}{c}0.352 \\
0.419 \\
244\end{array}$ & $\begin{array}{c}0.742 \\
0.611 \\
173\end{array}$ & $\begin{array}{c}0.711 \\
0.741 \\
127\end{array}$ \\
\hline $\begin{array}{l}\text { Panel E: language skills } \\
\text { reform }\end{array}$ & $\begin{array}{c}0.597 * * \\
0.256 \\
377\end{array}$ & $\begin{array}{c}0.572 * \\
0.310 \\
276\end{array}$ & $\begin{array}{c}0.756 * * * \\
0.283 \\
329\end{array}$ & $\begin{array}{c}0.670 * * \\
0.340 \\
243\end{array}$ & $\begin{array}{c}0.456 \\
0.452 \\
173\end{array}$ & $\begin{array}{c}0.629 \\
0.551 \\
127\end{array}$ \\
\hline $\begin{array}{l}\text { Panel F: motor ability } \\
\text { reform }\end{array}$ & $\begin{array}{c}0.629 * * \\
0.285\end{array}$ & $\begin{array}{c}0.617^{*} \\
0.321\end{array}$ & $\begin{array}{c}0.788 * * * \\
0.304\end{array}$ & $\begin{array}{c}0.767 * * \\
0.348\end{array}$ & $\begin{array}{l}0.760 \\
0.484\end{array}$ & $\begin{array}{c}0.962 * \\
0.558\end{array}$ \\
\hline $\mathrm{N}$ & 378 & 277 & 330 & 244 & 173 & 127 \\
\hline $\begin{array}{l}\text { socio-demographic controls } \\
\text { birth months FE } \\
\text { Dec. } 2006 \text { \& Jan. } 2007 \text { births }\end{array}$ & $\begin{array}{l}\mathrm{x} \\
\mathrm{x}\end{array}$ & $\begin{array}{l}\mathrm{x} \\
\mathrm{x} \\
\mathrm{x}\end{array}$ & $\mathrm{X}$ & $\begin{array}{l}\mathrm{x} \\
\mathrm{x}\end{array}$ & $\begin{array}{l}\mathrm{x} \\
\mathrm{x}\end{array}$ & $\begin{array}{l}\mathrm{x} \\
\mathrm{x} \\
\mathrm{x}\end{array}$ \\
\hline
\end{tabular}


Table A7 continued from previous page

\begin{tabular}{|c|c|c|c|c|c|c|}
\hline \multirow[t]{2}{*}{ time frame: } & \multicolumn{2}{|c|}{ July-June } & \multicolumn{2}{|c|}{ July-June } & \multicolumn{2}{|c|}{ October-March } \\
\hline & (1) & (2) & (3) & (4) & (5) & (6) \\
\hline \multicolumn{7}{|l|}{ Panel G: basic life skills } \\
\hline & 0.212 & 0.233 & 0.222 & 0.243 & 0.325 & 0.390 \\
\hline $\mathrm{N}$ & 377 & 276 & 329 & 243 & 173 & 127 \\
\hline \multicolumn{7}{|l|}{ Panel H: social skills } \\
\hline \multirow[t]{2}{*}{ reform } & 0.364 & 0.320 & 0.468 & 0.394 & 0.354 & 0.318 \\
\hline & 0.275 & 0.328 & 0.301 & 0.354 & 0.516 & 0.661 \\
\hline $\mathrm{N}$ & 377 & 276 & 329 & 243 & 173 & 127 \\
\hline \multicolumn{7}{|l|}{ Panel I: skills index } \\
\hline \multirow[t]{2}{*}{ reform } & $0.661 * *$ & $0.603^{*}$ & $0.842 * * *$ & $0.706 * *$ & 0.622 & 0.767 \\
\hline & 0.273 & 0.324 & 0.299 & 0.356 & 0.502 & 0.623 \\
\hline $\mathrm{N}$ & 378 & 277 & 330 & 244 & 173 & 127 \\
\hline socio-demographic controls & & $\mathrm{x}$ & & $\mathrm{x}$ & & $\mathrm{x}$ \\
\hline birth months FE & $\mathrm{X}$ & $\mathrm{x}$ & $\mathrm{x}$ & $\mathrm{x}$ & $\mathrm{X}$ & $\mathrm{X}$ \\
\hline Dec. 2006 \& Jan. 2007 births & $\mathrm{x}$ & $\mathrm{x}$ & & & $\mathrm{x}$ & $\mathrm{x}$ \\
\hline
\end{tabular}

Notes: Estimates are similar to estimates in table 9 except that they do not control for the number of siblings; The sample is restricted to firstborn children.

${ }^{*}$ indicates significance at $10 \%,{ }^{* *}$ indicates significance at $5 \%,{ }^{* * *}$ indicates significance at $1 \%$ level. Source: GSOEP 2003-2010 
Table A8: Baseline Diff-in-Diff, 2-3-year-olds, non-firstborn children

\begin{tabular}{|c|c|c|c|c|c|c|}
\hline \multirow[t]{2}{*}{ time frame: } & \multicolumn{2}{|c|}{ July-June } & \multicolumn{2}{|c|}{ July-June } & \multicolumn{2}{|c|}{ October-March } \\
\hline & (1) & (2) & (3) & (4) & (5) & (6) \\
\hline \multicolumn{7}{|l|}{ Panel A: health index } \\
\hline reform & -0.089 & -0.218 & 0.000 & -0.116 & -0.187 & -0.405 \\
\hline & 0.237 & 0.255 & 0.259 & 0.296 & 0.345 & 0.327 \\
\hline $\mathrm{N}$ & 422 & 343 & 356 & 284 & 201 & 169 \\
\hline \multicolumn{7}{|l|}{ Panel B: behavior index } \\
\hline \multirow[t]{2}{*}{ reform } & -0.142 & 0.084 & -0.128 & 0.135 & $-0.635 * *$ & -0.369 \\
\hline & 0.244 & 0.288 & 0.264 & 0.320 & 0.302 & 0.343 \\
\hline $\mathrm{N}$ & 418 & 341 & 352 & 282 & 201 & 169 \\
\hline \multicolumn{7}{|l|}{ Panel C: personality index } \\
\hline \multirow[t]{2}{*}{ reform } & 0.013 & -0.010 & -0.014 & 0.021 & -0.240 & -0.291 \\
\hline & 0.252 & 0.292 & 0.276 & 0.321 & 0.326 & 0.400 \\
\hline $\mathrm{N}$ & 422 & 343 & 356 & 284 & 201 & 169 \\
\hline \multicolumn{7}{|l|}{ Panel D: overall well-being } \\
\hline \multirow[t]{2}{*}{ reform } & -0.092 & -0.109 & -0.045 & -0.016 & -0.445 & -0.511 \\
\hline & 0.244 & 0.282 & 0.264 & 0.311 & 0.340 & 0.368 \\
\hline $\mathrm{N}$ & 422 & 343 & 356 & 284 & 201 & 169 \\
\hline \multicolumn{7}{|l|}{ Panel E: language skills } \\
\hline \multirow[t]{2}{*}{ reform } & 0.081 & 0.185 & 0.105 & 0.274 & -0.328 & -0.104 \\
\hline & 0.255 & 0.264 & 0.294 & 0.301 & 0.301 & 0.311 \\
\hline $\mathrm{N}$ & 422 & 343 & 356 & 284 & 201 & 169 \\
\hline \multicolumn{7}{|l|}{ Panel F: motor ability } \\
\hline \multirow[t]{2}{*}{ reform } & -0.128 & -0.175 & -0.185 & -0.189 & -0.324 & -0.360 \\
\hline & 0.224 & 0.255 & 0.254 & 0.305 & 0.278 & 0.296 \\
\hline $\mathrm{N}$ & 422 & 343 & 356 & 284 & 201 & 169 \\
\hline \multirow{3}{*}{$\begin{array}{l}\text { socio-demographic controls } \\
\text { birth months FE } \\
\text { Dec } 2006 \text { \& Jan } 2007 \text { hirths }\end{array}$} & & $\mathrm{x}$ & & $\mathrm{x}$ & & $\mathrm{x}$ \\
\hline & $\mathrm{x}$ & $\mathrm{x}$ & $\mathrm{x}$ & $\mathrm{x}$ & $\mathrm{x}$ & $\mathrm{x}$ \\
\hline & $\mathrm{x}$ & $\mathrm{x}$ & & & $\mathrm{x}$ & $\mathrm{x}$ \\
\hline
\end{tabular}


Table A8 continued from previous page

\begin{tabular}{lcccccc}
\hline time frame: & \multicolumn{2}{c}{ July-June } & \multicolumn{2}{c}{ July-June } & \multicolumn{2}{c}{ October-March } \\
& $(1)$ & $(2)$ & $(3)$ & $(4)$ & $(5)$ & $(6)$ \\
\hline Panel G: basic life skills & & & & & & \\
reform & 0.105 & 0.230 & 0.131 & 0.251 & -0.126 & 0.068 \\
& 0.219 & 0.244 & 0.233 & 0.258 & 0.302 & 0.362 \\
$\mathrm{~N}$ & 422 & 343 & 356 & 284 & 201 & 169 \\
\hline Panel H: social skills & & & & & & \\
reform & 0.097 & -0.063 & 0.129 & 0.007 & -0.379 & -0.468 \\
& 0.229 & 0.237 & 0.256 & 0.270 & 0.315 & 0.338 \\
N & 422 & 343 & 356 & 284 & 201 & 169 \\
\hline Panel I: skills index & & & & & & \\
reform & 0.048 & 0.060 & 0.055 & 0.114 & -0.383 & -0.282 \\
& 0.235 & 0.255 & 0.268 & 0.297 & 0.293 & 0.304 \\
N & 422 & 343 & 356 & 284 & 201 & 169 \\
\hline socio-demographic controls & & $\mathrm{x}$ & & $\mathrm{x}$ & & $\mathrm{x}$ \\
birth months FE & $\mathrm{X}$ & $\mathrm{X}$ & $\mathrm{x}$ & $\mathrm{x}$ & $\mathrm{x}$ & $\mathrm{X}$ \\
Dec. 2006 \& Jan. 2007 births & $\mathrm{x}$ & $\mathrm{x}$ & & & $\mathrm{x}$ & $\mathrm{x}$ \\
\hline
\end{tabular}

Notes: Estimates are similar to estimates in table 9 except that they do not control for the number of siblings; sample is restricted to non-firstborn children.

${ }^{*}$ indicates significance at $10 \%,{ }^{* *}$ indicates significance at $5 \%,{ }^{* * *}$ indicates significance at $1 \%$ level. Source: GSOEP 2003-2010 
Table A9: Potential channel: change in net monthly household income

\begin{tabular}{|c|c|c|c|c|c|c|c|c|c|c|}
\hline & \multicolumn{2}{|c|}{$2006 / 2007$} & \multicolumn{4}{|c|}{$2004 / 2005,2005 / 06,2007 / 08$} & \multirow[b]{2}{*}{$\begin{array}{c}\text { DiD } \\
(7) \\
(3)-(6)\end{array}$} & \multirow[b]{2}{*}{$\mathrm{N}$} & \multirow[b]{2}{*}{$\begin{array}{c}\text { DiD } \\
\text { (with controls) }\end{array}$} & \multirow[b]{2}{*}{$\mathrm{N}$} \\
\hline & $\begin{array}{c}\text { July-Dec. } \\
\text { (1) }\end{array}$ & $\begin{array}{c}\text { Jan.-June } \\
\text { (2) }\end{array}$ & $\begin{array}{c}\mathrm{RD} \\
(3) \\
(2)-(1)\end{array}$ & $\begin{array}{c}\text { July-Dec. } \\
\text { (4) }\end{array}$ & $\begin{array}{c}\text { Jan.-June } \\
\text { (5) }\end{array}$ & $\begin{array}{c}\text { seasonal effects } \\
(6) \\
(5)-(4)\end{array}$ & & & & \\
\hline $\begin{array}{l}\Delta \text { hh income } \\
\text { average effect }\end{array}$ & 114.44 & 219.35 & 104.91 & -69.21 & 17.20 & 86.40 & 18.50 & 579 & 96.86 & 552 \\
\hline loser - families & 253.70 & 107.68 & -146.02 & 111.21 & 343.43 & $232.22 *$ & $-378.24^{*}$ & 204 & $-447.14 * *$ & 189 \\
\hline winner - families & -9.76 & 271.62 & 281.37 & -171.57 & -132.87 & 38.70 & 242.67 & 375 & 347.61 & 363 \\
\hline
\end{tabular}

Notes: $\Delta$ hh income is the change in net monthly household income in the year after childbirth compared to the net monthly household income in the year before the child was born.

The first two columns give averages for children born in the first half of the 2006/2007 cohort (i.e. between July and December 2006) and for children born in the second half (i.e. January-June 2007). Columns (4) and (5) show averages for the control years respectively. Column (3) is the difference between column (2) and column (1) and thus represents a simple RD-estimator. Column (6) represents the pure seasonal effects between children born in the first half of a cohort and those born in the second half. Column (7) is then the difference between the RD-estimator and the seasonal effects - thus, the Diff-in-Diff-estimator on the raw data without any controls and the full time frame. Sample is based on mothers of 2-3-years old children. Robust standard errors are used.

${ }^{*}$ indicates significance at $10 \%,{ }^{* *}$ indicates significance at 5\%, ${ }^{* * *}$ indicates significance at $1 \%$ level. Source: GSOEP $2003-2010$ 
Table A10: Potential channel: childcare situation, 2-3-year-olds

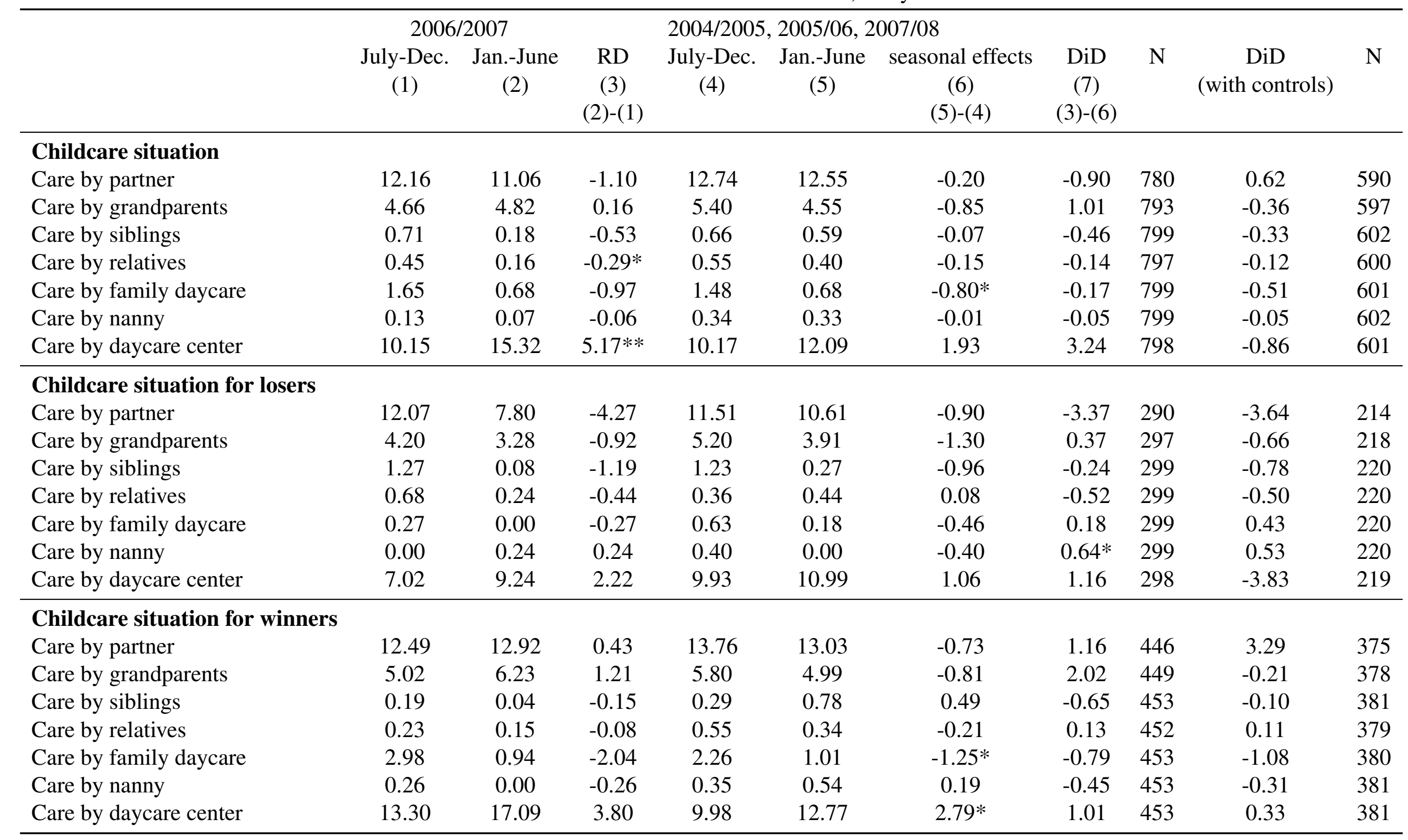

Notes: Interpretation analogous to table A9. Sample is based on mothers of 2-3-years old children.

${ }^{*}$ indicates significance at $10 \%,{ }^{* *}$ indicates significance at 5\%, ${ }^{* * *}$ indicates significance at $1 \%$ level. Source: GSOEP 2003-2010 
Table A11: Comparison GSOEP and own calculations

\begin{tabular}{lcc}
\hline & GSOEP-variable & own calculations \\
\hline ErzG months 1-6 & 280.30 & 303.14 \\
ErzG months 7-12 & 261.57 & 275.47 \\
ErzG months 13-24 & 288.58 & 260.35 \\
EG & 624.10 & 697.54 \\
\hline
\end{tabular}

Notes: This table compares mean benefits per month for Erziehungsgeld and Elterngeld as indicated in the GSOEP-questionnaires and as calculated according to the benefit calculation rules explained in appendix A.1. All zero benefits are excluded from the means. 